\title{
From Theoretical Reaction Dynamics to Chemical Modeling of Combustion
}

\author{
Stephen J. Klippenstein
}

Chemical Sciences and Engineering Division, Argonne National Laboratory, Argonne, IL, 60439, USA

Corresponding Author: Stephen J. Klippenstein

9700 S. Cass Ave.

Chemical Sciences and Engineering Division

Argonne National Laboratory

Argonne, IL, 60439, USA

Phone: +1-630-252-3596

E-mail: sjk@anl.gov

Colloquium Topic Area: $\quad$ Invited Plenary

Keywords: Theoretical Chemical Kinetics; Ab Initio Electronic Structure Theory; Transition State Theory; Master Equation; Combustion Chemistry 


\section{Abstract}

The chemical modeling of combustion treats the chemical conversion of hundreds of species through thousands of reactions. Recent advances in theoretical methodologies and computational capabilities have transformed theoretical chemical kinetics from a largely empirical to a highly predictive science. As a result, theoretical chemistry is playing an increasingly significant role in the combustion modeling enterprise. The accurate prediction of the temperature and pressure dependence of gas phase reactions requires state-of-the-art implementations of a variety of theoretical methods: ab initio electronic structure theory, transition state theory, classical trajectory simulations, and the master equation. In this work, we illustrate the current state-of-the-art in predicting the kinetics of gas-phase reactions through sample calculations for some prototypical reactions central to combustion chemistry. These studies are used to highlight the success of theory, as well as its remaining challenges, through comparisons with experiments ranging from elementary reaction kinetics studies through to global observations such as flame speed measurements. The illustrations progress from the treatment of relatively simple abstraction and addition reactions, which proceed over a single transition state, through to the complexity of multiwell multichannel reactions that commonly occur in studies of the growth of polycyclic aromatic hydrocarbons. In addition to providing high quality rate prescriptions for combustion modelers, theory will be seen to indicate various shortcomings in the foundations of chemical modeling. Future progress in the fidelity of the chemical modeling of combustion will benefit from more widespread applications of theoretical chemical kinetics and from increasingly intimate couplings of theory, experiment, and modeling. 


\section{Introduction}

Recent years have seen an explosion in the number of studies using kinetic models to explore the chemistry of combustion. A survey of the 2015 volume of Combustion and Flame finds studies implementing kinetics models for biofuels (methanol, ethanol, n-butanol, isobutanol, 2-methylbutanol, n-pentanol, 2- and 3-pentanol, dimethyl ether, tetrahydrofuran, 2,5-dimethylfuran, tetrahydropyran, diethylcarbonate, and tripropyleneglycol mono-methyl ether), gasoline, diesel, and jet fuel surrogates and blends (primary reference fuel, toluene reference fuel, gasoline surrogate, gasoline and ethanol, Real Fuel 2, n-heptane/toluene/methyl-pentanoate, diesel surrogate, and JP-10), large alkanes (pentane, n-hexane, n-heptane,7-dimethyloctane, n-dodecane, hexadecane, and exo-tricyclodecane), aromatics (benzene, toluene, and styrene), naphthenes (methlycyclohexane and ethylcyclohexane), foundational fuels (hydrogen, carbon monoxide, syngas, methane, natural gas, propane, $n$-butane, ethylene, acetylene, propene, and C3-C5 aldehydes), pollutants (ammonia, methylnitrate, $\mathrm{NO}_{2}$ and $\mathrm{N}_{2} \mathrm{O}$ in methane, $\mathrm{NOx}$ in alcohols, carbon sulfides, sour gas, $\mathrm{HCl}$ and $\mathrm{Cl}_{2}$, and $\left.\mathrm{O}_{3}\right)$, energetic materials ( $\mathrm{HMX}$ ), and fire inhibitors $\left(\mathrm{C}_{3} \mathrm{H}_{2} \mathrm{~F}_{3} \mathrm{Br}, \mathrm{C}_{2} \mathrm{~F}_{5} \mathrm{H}, \mathrm{CCl}_{4}\right.$, and $\left.\mathrm{CF}_{3} \mathrm{H}\right)$. These modeling studies explore a variety of chemical problems including the development of new mechanisms for novel fuels, an improved understanding of ignition, low-temperature/cool-flame chemistry, the chemistry of surrogates and other fuel mixtures, the effect of additives and dopants on the chemistry, improvement of mechanisms for core fuels, the dependence of pollutant formation (soot, NOx, SOx, etc.) on fuel and on combustion conditions, the coupling of chemistry and fluid dynamics, and the role of ions in combustion.

This increased focus on chemical modeling arises from a variety of societal drivers, coupled with the ever-improving fidelity and thus utility of modeling efforts, and the continuing expansion in computational capabilities. Computational simulations of internal combustion engines require the coupling of chemical models for the conversion of the fuel into combustion products with numerical treatments of the fluid dynamics of reacting flows. Many recent efforts to meet the demands of improved fuel economy and reduced emissions focus on low temperature combustion schemes $[1,2]$ 
where the chemical aspects of the simulations are particularly important. Similarly, the push to consider alternative fuels as a means for reducing net $\mathrm{CO}_{2}$ emissions and improving our energy security requires detailed understanding of the connection between engine performance and fuel structure, with fuel chemistry being an integral part of this connection [3]. Chemical models for combustion are also of continuing importance for stationary combustors with oxy fuel [4] and MILD [5] combustion schemes continuing to be developed, and ever higher pressures being considered [6,7], again in response to efficiency and pollutant formation concerns.

Historically, engine simulations have by necessity employed very limited representations of either the chemistry or the fluid dynamics. Continuing advances in computational algorithms and hardware allow for simulations that employ more physically realistic treatments of both aspects of the problem [8,9]. As a result, such simulations are beginning to be used as engine design tools $[10,11]$. Continued improvements in the predictive accuracy of such simulations should greatly enhance their utility in efforts to reduce the number of expensive and time-consuming prototypes that need to be built.

Chemical models for combustion are used to describe not only the conversion of the fuel into oxidation products, but also the formation of various pollutants such as NOx, soot, and unburned hydrocarbons. Thus, comprehensive chemical models nowadays consist of thermochemical and transport properties for hundreds to thousands of species, together with rate coefficients for the thousands to tens of thousands of reactions that connect these species within the combustion environment. For example, as illustrated in Fig. S1, a survey of the 2015 volume of Combustion and Flame finds mechanisms with the number of species ranging from 10 to 3000 and the number of reactions ranging from 20 to more than 20,000. The largest mechanisms tend to focus on the low temperature chemistry of surrogate fuels, while the smaller mechanisms tend to be either reduced versions of these large mechanisms for utility in complex fluid dynamics simulations, or mechanisms that focus on the chemistry of small foundational fuels such as hydrogen, methane, syngas, and natural gas. 
The fidelity of the full simulations naturally depends on the accuracy of the parameters that make up the chemical model. Theoretical chemical reaction dynamics has long been a key player in the development of quantitative models for the underlying elementary reaction rate coefficients [12-14]. Historically, theory has focused on interpreting and extrapolating data from experimentally accessible conditions to those of relevance to combustion. However, recent years have seen a dramatic improvement in the accuracy of a priori theoretical predictions due to improved algorithms and increased computational power. Indeed, the accuracy of high-level theoretical studies now often rivals that of experiment. As a result, theoretical predictions are now routinely incorporated in combustion mechanisms. Recently, theoretical analyses have even been integrated into the mechanism generation and development effort [15-23]. In this review, we illustrate the extent of this transformation of theoretical chemical kinetics from an empirical to a predictive science through sample applications to a range of elementary reactions of importance to combustion chemistry.

The overarching goal of the combustion chemical modeling enterprise is to provide a model that faithfully reproduces the chemical transformations that occur during the conversion of the fuel into products and pollutants for all relevant conditions of temperature, pressure, stoichiometry, and dilution. This goal is generally expressed via the production of a comprehensive model that accurately reproduces all available experimental observations of quantities such as the ignition delay, flame speed, and species profiles - or at least to the extent possible with current chemical understanding [24]. From a fundamental science perspective, the incorporation of an improved (i.e., with lower uncertainty) representation of a specific elementary reaction process (as obtained from high level theoretical analyses for example) yields an improved model. However, such model revisions will often lead to increased discrepancies with the global observations, due to the presence of other shortcomings in the model. A repeated process of model refinement in response to such fundamental improvements should yield a chemical model that not only reproduces the available data, but also extrapolates more accurately to initial conditions that are not accessible experimentally. With this perspective, the significance of rate 
constant revisions is judged by the extent of their effect on global observables, rather than by whether or not they improvement agreement between model and experiment. Notably, uncertainty analyses for the chemical modeling of experimentally inaccessible initial conditions can be used to further drive such fundamental mechanism improvement efforts. Of course, theoretical methods for accurately predicting the kinetics of elementary reaction processes are an exceptionally useful tool for such efforts. The long term development of models for NOx chemistry [18,25-27] provides a useful illustration of this iterative refinement procedure, with theory having played a significant role in many of these refinements.

We begin this review by summarizing the basic physical model that underlies theoretical predictions for the temperature and pressure dependence of chemical reaction rate coefficients. Our initial application considers the first a priori predictions of the pressure dependent rate coefficient for the single well $\mathrm{H}+\mathrm{O}_{2}(+\mathrm{M}) \rightarrow \mathrm{HO}_{2}(+\mathrm{M})$ reaction, which is perhaps the most important pressure dependent reaction in combustion. We then discuss the treatment of addition kinetics for barrierless reactions, which are ubiquitous in combustion. For these reactions, particularly accurate rate predictions have been obtained through coupling of multi-reference electronic structure methods with advanced transition state theory (TST) methods. Next, the spectacular progress in theoretical thermochemistry is reviewed, followed by a brief discussion of abstraction reactions, which are perhaps the most common reaction in combustion. The next section notes the value of predictive theory for reactions that are difficult to study experimentally, such as $\mathrm{HO}_{2}+$ fuel reactions. The role of theory in developing a detailed molecular level description of low-temperature radical oxidation is then summarized through a review of our long-term studies of ethyl and propyl radical oxidations. A semiquantitative understanding of the uncertainties in theoretical predictions can be of great value in modeling, as demonstrated by Burke in his multiscale modeling approach [28]. These studies ultimately led us to the realization that at combustion temperatures the foundational assumption of thermalization prior to reaction is not always valid, and further that its breakdown significantly affects key combustion properties. These effects are illustrated here through calculations for the prompt dissociation of HCO. The important role of theory in the 
development of mechanisms for nitrogen chemistry is illustrated through new calculations for the reaction of $\mathrm{NH}_{2}$ with $\mathrm{NO}$. We illustrate the progress in theoretical treatments of nonadiabatic dynamics through a review of predictions for the $\mathrm{CH}+\mathrm{N}_{2}, \mathrm{O}+\mathrm{CO}$, and $\mathrm{O}+\mathrm{C}_{2} \mathrm{H}_{4}$ reactions. A discussion of polycyclic aromatic hydrocarbon (PAH) growth and decay illustrates the degree of overlap of chemical and internal energy relaxation timescales and the feasibility and importance of predicting the pressure dependence of the kinetics for such reactions. Finally, recent progress in predicting transport properties is reviewed, and some concluding remarks are made.

The illustrations presented here are drawn from high quality studies of small molecule reactions in part because that has been the emphasis of our own work. Chemical mechanisms for combustion are hierarchical in nature, with the mechanisms for larger fuels consisting of submechanisms for smaller fuels [24]. Thus, the mechanism for $\mathrm{H}_{2} / \mathrm{O}_{2}$ provides the foundation for all combustion mechanisms. Similarly, mechanisms for the $\mathrm{Cl}$ hydrocarbons $\mathrm{CO}, \mathrm{CH}_{4}, \mathrm{CH}_{2} \mathrm{O}$, and $\mathrm{CH}_{3} \mathrm{OH}$ are important components of mechanisms for almost all fuels. Including all fuels containing up to 3 or $4 \mathrm{C} / \mathrm{O}$ atoms (e.g., $\mathrm{C}_{2} \mathrm{H}_{6}, \mathrm{C}_{2} \mathrm{H}_{4}, \mathrm{C}_{2} \mathrm{H}_{2}, \mathrm{C}_{3} \mathrm{H}_{8}, \mathrm{C}_{3} \mathrm{H}_{6}, \mathrm{C}_{3} \mathrm{H}_{4}, \mathrm{C}_{2} \mathrm{H}_{5} \mathrm{OH}, \mathrm{CH}_{3} \mathrm{CHO}$, etc.) provides a core mechanism [2932] that is of utility in modeling more complex fuels such as standard reference fuels. Increasing the accuracy of the core mechanism improves the fidelity of chemical modeling for all fuels. Of course, there is also a huge body of valuable theoretical studies focusing on much larger species than reviewed here. Continuing to improve the accuracy of such large molecule studies, while also expanding the number of systems studied, is an important frontier for theoretical combustion kinetics. Studies of small molecule prototypes, such as those summarized here, are also of utility in validating the more approximate theoretical schemes that are applicable to the analysis of larger molecules.

\section{Chemical Reactions, Phenomenological Rate Coefficients, A Priori Rate Predictions, and}

\section{Uncertainty Estimation}

\subsection{Chemical Reactions and Phenomenological Rate Coefficients}


Chemical mechanisms generally consist of simple representations of the rate coefficients and rate laws describing the chemical transformations of a given set of species, and of the thermodynamics and transport properties of the constituent species. It is important to understand the connection between basic physical processes and the phenomenological rate laws that enter into chemical mechanisms [33]. With this understanding we can then implement physical models to predict the rate coefficients and to explore when rate descriptions are or are not appropriate. To start, consider the unimolecular dissociation of some chemical species (e.g., $\mathrm{CH}_{4}$ ) in a bath of molecules $\mathrm{M}$ (e.g., He). As illustrated schematically in Fig. 1, collisions with $\mathrm{He}$ atoms induce transitions up and down in energy for the $\mathrm{CH}_{4}$ molecules. Occasionally, one of the $\mathrm{CH}_{4}$ molecules will be excited to an internal energy state that exceeds the dissocation threshold. At this point, the decomposition of this $\mathrm{CH}_{4}$ molecule into $\mathrm{CH}_{3}$ and $\mathrm{H}$ radicals occurs in competition with further collisions with the bath gas, which may further excite or deexcite the molecule, perhaps even back below the dissociation threshold.

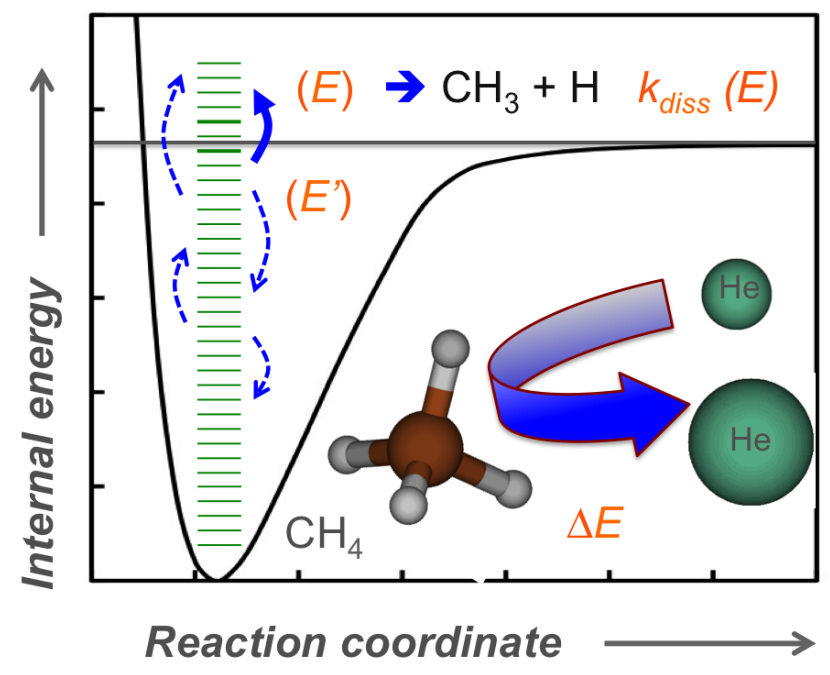

Figure 1: Schematic diagram of the dissociation of methane induced by collisions with He.

This competition between dissociation and collisional excitation/deexcitation ultimately determines the pressure dependence for the rate coefficient. In the low-pressure limit, every molecule that gets excited above the dissociation threshold ultimately dissociates, and the rate of dissociation is determined by the rate of exciting molecules to above the dissociation threshold. This rate is linearly 
dependent on the number of collisions and thus the pressure. It is also roughly proportional to the thermal probability of a molecule having an internal energy equal to the dissociation threshold, which is proportional to the density of states at the dissociation threshold, $\rho\left(D_{e}\right)$, times a Bolzmann factor in the dissociation energy, $\exp \left(-D_{e} / k_{B} T\right)$. In the high-pressure limit, the molecules continue to undergo numerous collisions even after they are excited above the dissociation threshold. The distribution of excited molecules then maintains the form of a Boltzmann distribution even at energies above the dissociation threshold and the rate coefficient, which is now independent of pressure, reduces to a Boltzmann average of the microcanonical dissociation rates.

At intermediate pressures, the rate is a complicated function of the competition between dissociation and collisional energy transfer. The master equation, Eq. (1), represents the time dependent variations in the energy resolved populations of $\mathrm{CH}_{4}, n(E, t)$, in terms of (i) a collisional energy transfer rate, $k_{c}\left(E, E^{\prime}\right)$, that describes the rate of transitions from initial energy state $E^{\prime}$ to final energy state $E$, and (ii) a microcanonical dissociation rate constant, $k_{d}(E)$, that describes the rate of dissociation of $\mathrm{CH}_{4}$ at a given $E$ :

$$
d n(E) / d t=\sum_{E^{\prime}} \mathrm{k}_{c}\left(\mathrm{E}, \mathrm{E}^{\prime}\right) n\left(E^{\prime}\right)-k_{d}(E) n(E)
$$

A temperature and pressure dependent thermal dissociation rate constant, $k_{\text {diss }}(T, P)$, for such an irreversible one-well system [34], may be directly obtained from the least negative eigenvalue of the transition matrix, $G$, representing the time variation of the species populations, as well as from a variety of other approaches [35,36].

This representation of the multistep dissociation process in terms of a single phenomenological rate law:

$$
d\left[\mathrm{CH}_{4}\right] / d t=k_{\text {diss }}(T, P)\left[\mathrm{CH}_{4}\right]
$$

requires a separation of timescales between the least negative eigenvalue of $G$, representing the overall dissociation process, and the remaining eigenvalues representing the internal energy relaxation process. When these eigenvalues are not well separated, as tends to happen at high temperatures for low barrier 
processes such as the dissociation of a weakly-bound radical $R[37,38]$, the dissociation and energy relaxation occur in unison and the chemical conversion cannot be represented with a simple rate law. Fortunately, for a simple unimolecular dissocation such complications are seldom problematic as there are generally no secondary chemical processes that are competitive with a dissociation that is fast enough to compete with internal energy relaxation. Thus, the kinetics of the overall system is typically insensitive to the presumed rate for fast dissociations as long as it large enough and the correct branching between different dissociation channels is maintained. A separate, but related difficulty occurs when the initial energy distribution of $\mathrm{R}$ (which will generally be formed from some other chemical reaction) includes some states that are so high in energy that they dissociate prior to thermalization [39]. In this case, some fraction of $\mathrm{R}$ will dissociate according to the usual rate law, while the other highly excited fraction is best considered as having dissociated already as part of the reaction that formed $\mathrm{R}$ [40]. In some instances, it is important to properly model these two fractions, because the dissociation of the low energy fraction may be occuring in competition with other chemical reactions. A more concrete discussion of this phemonenon in provided in Sec. 10, below.

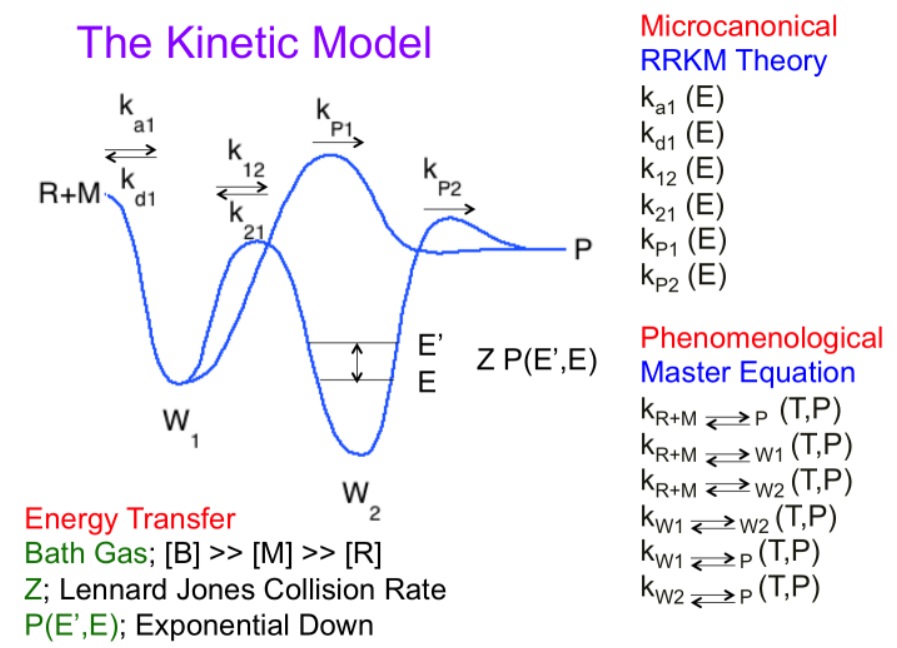

Figure 2: Schematic diagram of the physical model involved in master equation calculations. Microcanonical isomerization and dissociation rate constants (modelled with RRKM theory) and simple energy transfer models (employing for example, a combination of Lennard-Jone collision rates and the 
exponential down energy transfer kernel) define the transition matrix for a master equation whose solution yields the desired phenomenological rate constants.

Now consider a more general chemical reaction that passes through multiple chemical complexes (or wells, $\mathrm{W}_{\mathrm{i}}$ ) and may produce multiple bimolecular species (products, $\mathrm{P}$, and/or "reactants", which are denoted as $\mathrm{R}+\mathrm{M}$, to represent a radical, $\mathrm{R}$, and a molecule, $\mathrm{M}$, for a classic radical-molecule reaction), such as that illustrated in Fig. 2. The chemical dynamics involves isomerizations between each pair of wells and dissociations from each of the wells. These chemical processes are again activated and deactivated through collisions with a bath gas. For chemical modeling purposes, there is again a strong desire/need to represent the chemical transformations between these wells and products in terms of simple phenomenological rate laws describing the rate of transformation from any one species to any other species. It it important to recognize that these rate laws are not restricted to representing processes that are directly connected dynamically. Thus, for instance, the rate constant $\mathrm{k}_{\mathrm{R}+\mathrm{M} \rightarrow \mathrm{W} 2}$ for the formation of well 2 from the reactants $\mathrm{R}+\mathrm{M}$ is well defined and necessary for a proper rate law description of the thermal kinetics, even though it describes a process that must proceed dynamically through W1.

The master equation, which now describes the time dependence of the energy resolved populations in each of the wells, again provides a direct connection between the microscopic dynamics and the phenomenological rate coefficients required for modeling [41-43]. This connection again requires a separation in timescale between the eigenvalues of the transition matrix that describe chemical transformations (the chemically significant eigenvalues, CSEs) and those that describe collision-induced internal energy relaxation (the IEREs). With this separation there is a simple one-to-one correspondence between the time dependence in the reduced space consisting of the chemically significant eigenstates and the phenomenological rate laws. This correspondence readily allows for the direct evaluation of the phenomenological rate coefficients from the eigensolutions. By construction this solution is exact once the internal energy relaxation is complete, which by definition occurs on a timescale faster than the chemistry. This relation sometimes causes confusion as was discussed at length in a recent comment 
At low temperatures there is generally a dramatic separation of timescales and the connection is simple. However, at combustion temperatures, this separation is often blurred, and two or more of the "apparent" chemical species may equilibrate with one another on a timescale that is comparable to or shorter than the internal energy relaxation timescales. In this instance, the two equilibrating species are no longer distinct, and in reality it is not appropriate to consider them as distinguishable chemical species with their own separate kinetics. Consider, for example, a low barrier isomerizaton between cis and trans isomers of a given species. At very low temperatures, one might think of these as two distinct species, each with their own distinct chemistry. However, at higher temperatures, they start to isomerize very rapidly and one thinks of the two isomers as one joint species. The eigenvalue that corresponds to the isomerizaton process has become very large and has effectively entered the quasicontinuum of IEREs. Importantly, a simple reduction in the number of species, with a merging of the two isomers, yields a reduced master equation whose solution again directly provides the desired phenomenological rate coefficients [44]. Reactions of PAH radicals, with complex multiple-well multiple-product potential energy surfaces (PESs) having a wide variety of chemical timescales and corresponding CSE/IERE merging temperatures, provide a good illustration of these complexities (cf. Sec. 13).

The equilibration between $\mathrm{RO}_{2}$ and $\mathrm{QOOH}$ species, which is of key importance to low temperature oxidation, provides an especially relevant example of this merging phenomenon for combustion kinetics. These two species commonly merge at precisely the range of temperature of interest to low temperature combustion schemes $[45,46]$. Note that the merging of the two species does not imply that QOOH $+\mathrm{O}_{2}$ reactions are no longer effective, instead they will simply occur with a rate constant given by that for the ordinary $\mathrm{QOOH}+\mathrm{O}_{2}$ rate constant multiplied by the Boltzmann probability for $\mathrm{QOOH}$ in the $\mathrm{QOOH}: \mathrm{RO}_{2}$ equilbrium. This merging process creates some difficulty for accurate comprehensive modeling and it is an open question how best to deal with this phenomenon.

One approach is to extrapolate the rate coefficients for the individual species beyond their range 
of existence. Valid extrapolations should take care to reproduce the total rate constant for the merged species (which is still well defined) and to relate the relative rate coefficients to equilibrium branching ratios. We employed this approach in our work on propyl oxidation $[45,46]$ and our recent analysis of the HACA (Hydrogen Abstraction- $\mathrm{C}_{2} \mathrm{H}_{2}$-Addition) mechanism for PAH growth [47]. However, for complex multiwell potentials with multiple products, this merging, reduction, and extrapolation becomes fairly complicated and the extrapolations may yield unintended consequences. A more fundamental approach would involve a change in the number of species with conditions (e.g., temperature and pressure), but such a treatment is not currently feasible with standard chemical modeling codes. Furthermore, incorporating such a change would require dramatic changes in the mechanism input with thermochemical species and reaction rate definitions changing with temperature, etc. Another fundamentally correct alternative would implement energy resolved (rather than thermal) rate constants. This approach would again require substantial changes to the modeling codes and would significantly increase the computational effort if done for many species, but it would also allow for the study of some key questions regarding the effects of non-thermal distributions on the kinetics of combustion.

For simplicity, the above discussion of the CSE based master equation analysis focused on dissociation and isomerization processes. This analysis is readily extended to the treatment of bimolecular reactions [41-43]. For example, by also keeping track of the bimolecular species populations, the bimolecuar rate coefficients are also directly obtained from the connection between the CSEs and the rate laws $[41,42]$.

\subsection{A Priori Rate Predictions}

The a priori implementation of the master equation approach requires some model for the microcanonical dissociation and isomerization rates, and collisional energy transfer rates. RRKM theory, which assumes that intramolecular energy transfer is so rapid that microcanonical equilibrium is maintained throughout the course of the reaction and evaluates the flux through approximate physical 
dividing surfaces separating reactants from products, provides a useful procedure for predicting the microcanonical rates. Within RRKM theory, the microcanonical rate constant is expressed as

$$
k(E)=\frac{N(E)}{h \rho(E)}
$$

where $N(E)$ is the number of states for motion on the transition state (TS) dividing surface with an internal (rovibrational) energy less than $E, \rho(E)$ is the density of reactant states at energy $E$, and h is Planck's constant. The quantity $N(E) / h$ may be interpreted more generally as the flux per unit energy per unit time through the TS, with tunneling yielding non-zero flux even at energies below the TS threshold. Typically, the statistical assumptions are valid as long as the rates being modeled are not too large (i.e., less than about $10^{12} \mathrm{~s}^{-1}$ ). For reactions with a large barrier, realistic TS dividing surfaces are readily obtained from rigid-rotor harmonic-oscillator (RRHO) representations at the saddle point on the PES. However, higher fidelity predictions require the implementation of accurate state counting routines incorporating anharmonic corrections, treating variational and tunneling effects, and possibly considering complex TS dividing surfaces [48].

A priori implementations of RRKM theory employ ab initio electronic structure methods to determine the barrier height as well as the rovibrational properties of the reactants and the TS. The best methods to employ vary from system to system [49]. For many problems, coupled cluster theory in the $\operatorname{CCSD}(\mathrm{T})$ form [50] (with iterative treatment of single and double electron excitations and perturbative treatment of triple excitations), provides suitable high accuracy predictions of these properties. Predictions with further reduced uncertainty can be obtained through the consideration of various correction terms accounting for higher levels of electronic excitation and more extensive electronic interactions. Density functional theory (DFT) [51] provides a much less expensive commonly employed approach. For stable species, it generally provides structures and vibrational frequencies that are accurate enough for kinetics purposes. For TSs the accuracy is more variable, and classic DFT methods such as B3LYP can yield order of magnitude errors in the partition function. Although some of the 
newer density functionals (e.g., M06-2X [52], and B2PLYP-D3 [53,54]) are more reliable, some caution is still warranted. For simple bond fissions leading to the production of two radicals, accurate descriptions of the TS region require multi-reference methods, which are much less black box in nature [49]. Bond fissions also require more advanced TS counting methods and more general representations of the TS dividing surface [55]. Somewhat more detailed descriptions of the system dependent variations are provided below as we proceed through the various illustrations.

In contrast with these high accuracy a priori RRKM treatments, most theoretical studies have employed simple empirical treatments of energy transfer $[35,56,57]$. In particular, the collisional rates are generally expressed as a product of Lennard-Jones collision rates, $Z_{L J}$, with exponential down energy transfer probabilities

$$
k_{c}\left(E, E^{\prime}\right) \propto Z_{L J} \exp \left(-\frac{\Delta E}{\alpha}\right) ; \text { for } E<E^{\prime}
$$

where $\Delta E=E^{\prime}-E$. In. Eq. (4), $\alpha$ is effectively the average energy transferred per downward collision and microscopic reversibility is used to generate the collision rates for $E>E^{\prime}$. Simple power law representations of $\alpha$

$$
\alpha=\alpha_{300}(T / 300)^{n}
$$

allow for a reasonable reproduction of experimental data across a wide range of temperature and pressure. Fits to experiment [57-59], as well as trajectory simulations [60,61], commonly suggest $n$ values near 0.8. Empirically, room temperature $\alpha$ values are found to range from about $50 \mathrm{~cm}^{-1}$ to about $500 \mathrm{~cm}^{-1}$, with larger species generally having larger values.

\subsection{Uncertainty Estimation}

Ideally, uncertainties in theoretical predictions are obtained from the statistics of the deviations between predicted and true values for a large number of representative studies. Of course, the true values are generally unknown, and so one often resorts to the use of expermental values as a surrogate for them. 
As discussed in Sec. 5, for the heat of formation of stable species comparisons between Active Thermochemical Tables (ATcT) values of Ruscic [62] (taken as the surrogate for the true values) and theoretically predicted values have contributed immensely to progress in computational thermochemistry. However, even in this case the uncertainty in the ATcT values is a significant fraction of the apparent errors in the best theoretical predictions.

While there are a growing number of comparisons between theory and experiment for rate constants, it is rarely feasible to use such comparisons to quantitatively estimate the uncertainties in the theoretical predictions due to limitations in the number of systems that have been studied with equivalent theoretical methods. Furthermore, while experimental values have historically been taken as the surrogate for the true values, the uncertainty in such values is often rather limited. Indeed, it is our experience that the accuracy of our best theoretical predictions is often comparable to, or even exceeds, that of the available experimental data (cf. the comparisons presented below). Instead, comparisons of low and high-levels of theories for small molecules can be useful in estimating the uncertainties in applications of the low-levels of theory to larger molecules.

Even a qualitative understanding of the uncertainties in theoretical predictions would be a great boon for chemical modeling, and an expert practitioner can develop a crude sense of the uncertainties from experience. Importantly, the factors and corresponding uncertainties that enter into the calculation of a simple abstraction rate constant are quite different from those that enter into the calculation of the rate constant for a multiwell system with partial stabilization of intermediates. Thus, these qualitative uncertainty estimates should be strongly dependent on the particular type of reaction being studied, the theoretical methodologies that are employed, and the conditions of interest. Furthermore, the temptation to severely understate these uncertainties should be avoided, as this can then mask the true reasons for discrepancies in more global observations.

A useful, but underappreciated, qualitative procedure for estimating rate prediction uncertainties involves estimates for the uncertainties in each component of the calculation followed by the 
consideration of how those uncertainties couple together [63-65]. For example, in the calculation of an abstraction rate constant one might separately estimate the uncertainty in the barrier height, the partition functions, and the tunneling factor (cf. Sec. 9). Or in the calculation of pressure dependent phenomenological rate constants one might separately estimate the uncertainty in the microcanonical rate constants and in the collisional energy transfer rates. This reduction to components allows the expert to separately build experience for each of the components. This sort of component uncertainty analysis is at least conceptually an integral part of our efforts to reduce the uncertainty in our rate predictions via the consideration of which aspects of the calculation yield the greatest uncertainty and thus require further methodological improvements. Our own, admittedly limited, experience with the overall uncertainties estimated in this way is that they are fairly effective; i.e., the final rate predictions tend to agree with experiment to within the component theory based expectations. Such a component theory based procedure is most effective with first principles based rate predictions. However, in principle, uncertainties in empirical parameters can also be built in.

\section{3. $\mathrm{H}+\mathrm{O}_{2}(+\mathrm{M}) \rightarrow \mathrm{HO}_{2}(+\mathrm{M})$ : A Priori Pressure Dependence}

The competition between chain branching to $\mathrm{O}+\mathrm{OH}(\mathrm{R} 1)$ and collisional stabilization to $\mathrm{HO}_{2}$ (R2) in the reaction of $\mathrm{H}$ with $\mathrm{O}_{2}$ is of central importance to combustion, with these reactions showing up prominently in sensitivity plots for all fuels.

$$
\begin{aligned}
& \mathrm{H}+\mathrm{O}_{2} \rightarrow \mathrm{O}+\mathrm{OH} \\
& \mathrm{H}+\mathrm{O}_{2}(+\mathrm{M}) \rightarrow \mathrm{HO}_{2}(+\mathrm{M})
\end{aligned}
$$

The sensitivity plots presented in Fig. 3 illustrate the dominant role of these reactions for $\mathrm{H}_{2} / \mathrm{O}_{2}$ burning velocities [66], ignition delay [67], and fuel consumption in a flow reactor [68]. Theory has repeatedly been employed as a means to elucidate this competition as discussed in previous plenary lectures [1214]. Here we continue this theme with a review of our ongoing investigation of (R2) that focuses on predicting the effect of the collider on the pressure dependence. This collider dependence is generally 
important, but especially in modeling exhaust gas recirculation (EGR) [69,70], MILD combustion [5], and oxy fuel [4] schemes, for example, where the mole fractions of various colliders other than $\mathrm{N}_{2}$ are enhanced.

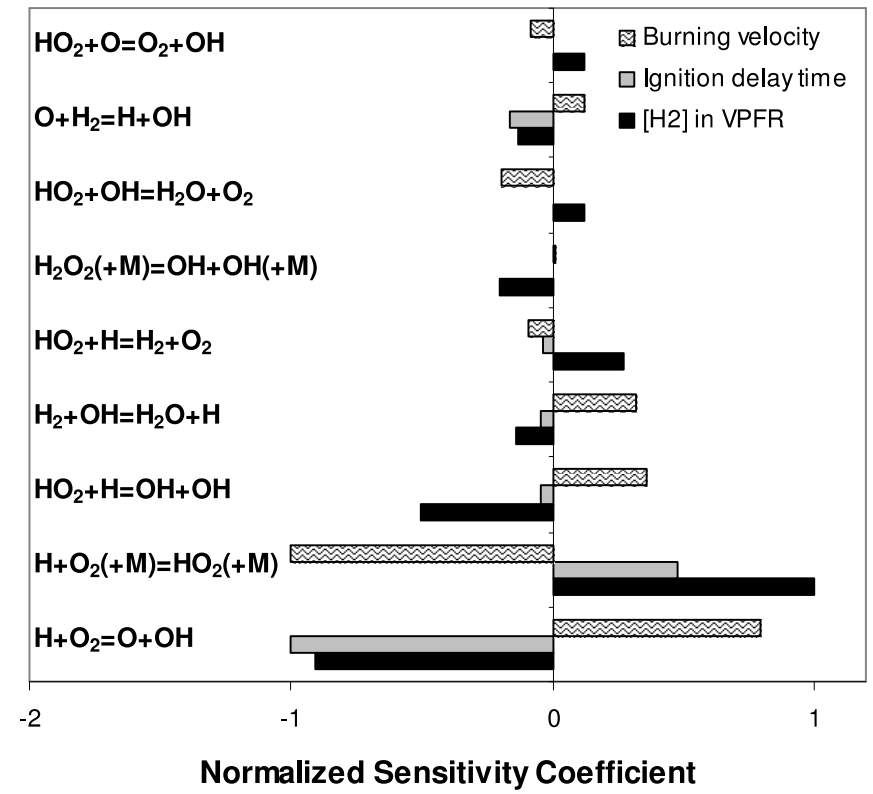

Figure 3: Normalized sensitivity coefficients to A-factors of reaction rate constants for $\mathrm{H}_{2} / \mathrm{O}_{2}$ combustion. Reproduced with permission from [71].

In a recent study, we explored the effectiveness of replacing the standard empirical model for energy transfer with an a priori model that employs parameters obtained from classical trajectory simulations [72]. In a preliminary study of methane dissociation by Jasper and Miller, trajectory simulations were used to evaluate the average energy transferred per collision [73]. However, this analysis led to predicted low-pressure rates that were too large by about a factor of two once vibrational anharmonicity effects were accounted for. This shortcoming is related to the inadequate treatment of collisional angular-momentum transfer in prior master equation analyses.

In reality, the total angular momentum, $J$, of a molecule is conserved between collisions with the bath gas, just as $E$ is. Thus, a proper 'two-dimensional' master equation (2DME) should treat the timedependent collision-induced variations in the $J$-distribution, just as is done for the $E$-distribution. Prior treatments effectively consider each collision to produce statistical distributions of $J$ (either canonical or 
microcanonical [58]). Properly including more limited $J$-transfer yields further bottlenecks to reaction, and thus lower predicted rate coefficients for a given energy transfer rate. To simplify the connection with trajectory simulations we defined an approximate representation for the collisional energy and angular momentum transfer probability

$$
P\left(E, J ; E^{\prime}, J^{\prime}\right) \propto \exp \left[-(\Delta \bar{E} / \alpha)^{\chi_{\alpha}}\right] \exp \left[-(\Delta \bar{J} / \gamma)^{\chi_{\gamma}}\right]
$$

where $\Delta \bar{E}$ and $\Delta \bar{J}$ are related to $\Delta E$ and $\Delta J$ via a rotation matrix:

$$
\begin{aligned}
& \Delta \bar{E}=|\Delta E \cos \theta-\Delta J \sin \theta| \\
& \Delta \bar{J}=|\Delta E \sin \theta+\Delta J \cos \theta|
\end{aligned}
$$

The parameters in this representation (e.g., $\alpha, \gamma, \theta, \chi_{\alpha}, \chi_{\nu}$ and $Z_{L J}$ ) may then be adjusted to reproduce the low order moments of $\mathrm{P}$ as evaluated from trajectory simulations.

Our first application of this 2DME approach predicted the pressure dependence for $\mathrm{CH}_{3}+\mathrm{H}=$ $\mathrm{CH}_{4}$ association, and for the low-temperature addition and high-temperature dissociation in the $\mathrm{C}_{2} \mathrm{H}_{2}+$ $\mathrm{H}=\mathrm{C}_{2} \mathrm{H}_{3}$ system [72] to within about $20 \%$ over the experimentally observed two to three order of magnitude variations in pressure. These two reactions are important in flame speeds due to their role in removing and producing $\mathrm{H}$ atoms. The PESs employed in the trajectory simulations were based on wellvalidated methods from earlier studies of just the energy transfer [61,73]. Meanwhile, the RRKM calculations coupled high accuracy electronic structure methods with variational TST using methods that had previously been shown to accurately predict the high-pressure limit $[59,74]$.

In a related analysis for the $\mathrm{H}+\mathrm{O}_{2}$ stabilization reaction (R2), we are now exploring the effect of different colliders (Ar, $\mathrm{N}_{2}$, and $\mathrm{He}$ ) on the predicted pressure dependence [75]. This analysis employs dynamically corrected variable reaction coordinate TST [55] based on a high accuracy well-validated multi-reference configuration-interaction PES [76]. Anharmonic corrections were obtained from detailed 
analyses of Troe and Ushakov [77,78]. The energy transfer parameters were obtained from trajectory calculations employing analytic potentials based on fits to high level ab initio data.

Our predictions for the pressure dependence of the $\mathrm{H}+\mathrm{O}_{2}(+\mathrm{Ar})$ recombination reaction at room temperature are compared in Fig. 4 with the available experimental data [79-84], with an empirical model based on a 2DME with a rotational microcanonical strong collider assumption [85], and with an analytic fit to some of the data [84]. Remarkably, these fully a priori predictions are essentially within the error bars of the experimental determinations across four orders of magnitude in pressure.

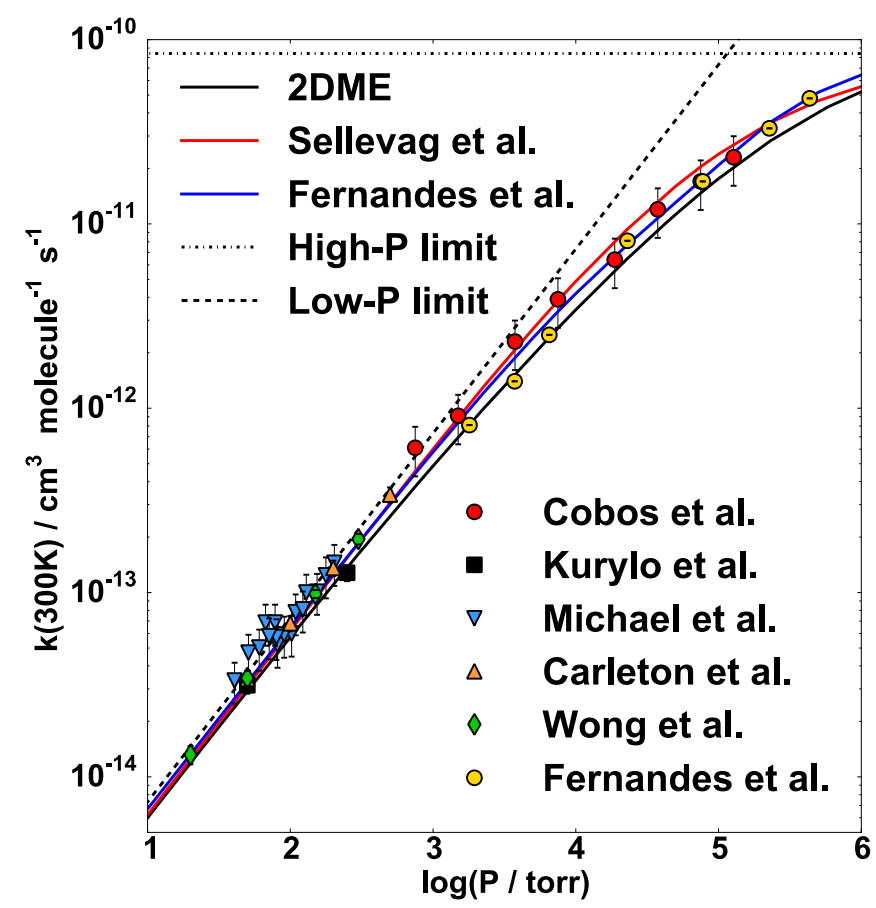

Figure 4: Pressure dependence of predicted and observed room temperature rate constants for $\mathrm{H}+\mathrm{O}_{2}$ $(+\mathrm{Ar}) \rightarrow \mathrm{HO}_{2}$ (+Ar). The points represent various experimental measurements [79-84]. The solid black line denotes the present a priori energy transfer based 2DME predictions, while the solid red and blue lines denote the fitted master equation results of Sellevag et al. [85] and the analytic fit of Fernandes et al. [84], respectively. The dashed and dashed-dotted lines denote the present low- and high-pressure limits, respectively.

The data presented in Fig. 5 illustrates that the good agreement between prediction and experiment [86-89] persists to the higher temperatures of relevance to combustion. Related results for $\mathrm{N}_{2}$ 
and He colliders show similar levels of agreement with the somewhat more limited experimental data. We are in the process of extending this analysis to consider $\mathrm{H}_{2} \mathrm{O}$ as a collider, which is of great practical interest since the high concentrations of $\mathrm{H}_{2} \mathrm{O}$ in some combustion environments, coupled with its enhanced efficiency, makes it a key contributor to the stabilization of $\mathrm{HO}_{2}$. Such an analysis is also of fundamental interest due to the presence of signifcant dipolar and H-bonding interactions. Preliminary results suggest that $\mathrm{H}_{2} \mathrm{O}$ has a substantially enhanced collision efficiency, but apparently not as enhanced as is commonly assumed. Further work should also consider the collision efficiency of $\mathrm{CO}_{2}$.

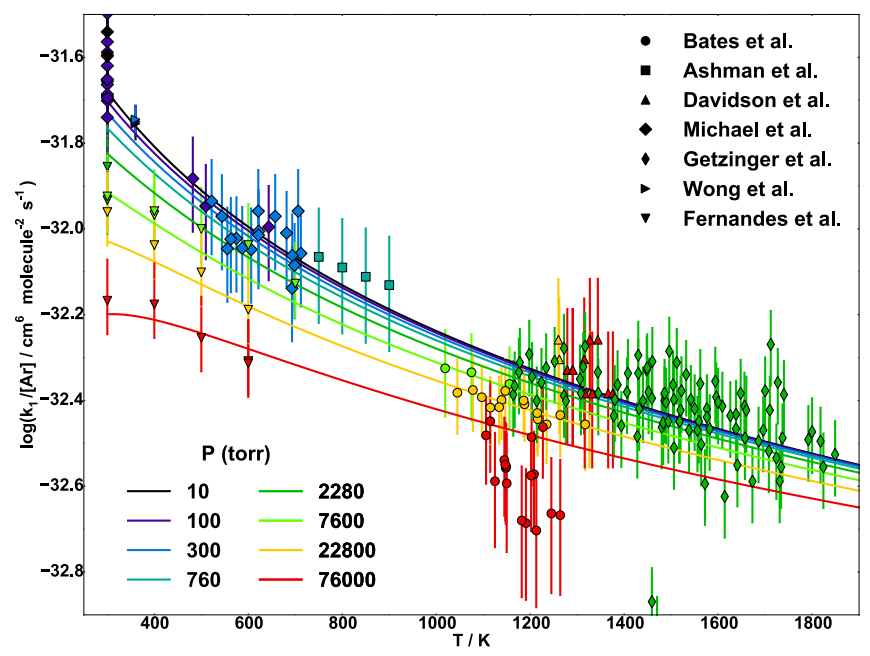

Figure 5: Temperature and pressure dependence of predicted and observed rate constants for $\mathrm{H}+\mathrm{O}_{2}$ $(+\mathrm{Ar}) \rightarrow \mathrm{HO}_{2}(+\mathrm{Ar})$. The different colored lines represent the a priori trajectory energy transfer based 2DME predictions for the pressures denoted in the label. The experimental data points $[80,83,84,86-89]$ are color coded according to the closest corresponding pressure from the theoretical analysis.

Attempts to utilize the data that arises from such high accuracy theoretical predictions of the pressure dependence emphasize a variety of shortcomings in current chemical modeling codes such as CHEMKIN [90]. The Troe parameterizations from these data are not the same for different colliders. While CHEMKIN allows for the inclusion of different parameterizations for each collider, doing so results in the high pressure limit being incorrectly increased to a multiple of the proper value, where that multiple is simply the number of explicit collider expressions. Furthermore, the standard Troe parameterization has limited fitting accuracy, with deviations between fit and data of 10-20\% common 
[91,92]. The PLOG format, which employs logarithmic interpolations of tabulated data [93], could circumvent the limitations in the Troe format, but the current CHEMKIN implementation does not allow for the specification of any collider specific information in the PLOG format. A recent study of Burke and Song indicates that we also need to pay more attention to how we convert the falloff data for single colliders to rate coefficients for a mixture of colliders [94]. This conversion is usually performed through linear mixture rules, which may introduce errors as large as $70 \%$. In our opinon, improved procedures for representing pressure dependent rate coefficients in modeling codes are sorely needed. Current limitations will severely hamper efforts to properly explore the kinetics of EGR, MILD, and oxy fuel combustion.

\section{Barrierless Reactions}

Barrierless radical-radical recombinations and their related reverse dissociations are important in many aspects of combustion chemistry. For example, as indicated by sensitivity studies from 2015 Combustion and Flame articles, they are important for understanding radical oxidation $\left(R+\mathrm{O}_{2}, \mathrm{R}+\right.$ $\left.\mathrm{HO}_{2}, \mathrm{CH}_{3}+\mathrm{O}\right)$ hydrocarbon growth $\left(\mathrm{C}_{3} \mathrm{H}_{3}+\mathrm{H}, \mathrm{C}_{3} \mathrm{H}_{3}+\mathrm{C}_{3} \mathrm{H}_{3}, \mathrm{CH}_{3}+\mathrm{C}_{3} \mathrm{H}_{5}, \mathrm{C}_{3} \mathrm{H}_{5}+\mathrm{C}_{3} \mathrm{H}_{5}, \mathrm{C}_{5} \mathrm{H}_{5}+\mathrm{H}\right.$, $\mathrm{C}_{5} \mathrm{H}_{5}+\mathrm{C}_{5} \mathrm{H}_{5}, \mathrm{C}_{6} \mathrm{H}_{5}+\mathrm{H}, \mathrm{C}_{6} \mathrm{H}_{5}+\mathrm{C}_{2} \mathrm{H}, \mathrm{C}_{7} \mathrm{H}_{5}+\mathrm{C}_{3} \mathrm{H}_{3}, \mathrm{C}_{7} \mathrm{H}_{7}+\mathrm{CH}, \mathrm{C}_{9} \mathrm{H}_{7}+\mathrm{H}$, and $\left.\mathrm{C}_{9} \mathrm{H}_{7}+\mathrm{C}_{3} \mathrm{H}_{3}\right)$, decomposition of fuel molecules at high temperatures (dimethylether, ethylcyclohexane, n-pentanol, alcohols and glycols, dimethylfuran, toluene), decomposition or formation of core molecules $\left(\mathrm{H}_{2} \mathrm{O}\right.$, $\mathrm{H}_{2} \mathrm{O}_{2}, \mathrm{CH}_{3} \mathrm{OH}, \mathrm{CH}_{4}, \mathrm{CH}_{3}+\mathrm{CH}_{3}, \mathrm{C}_{3} \mathrm{H}_{6}, \mathrm{C}_{3} \mathrm{H}_{8}, \mathrm{C}_{2} \mathrm{H}_{5} \mathrm{CHO}$, and $\mathrm{C}_{3} \mathrm{H}_{7} \mathrm{CHO}$ ), nitrogen chemistry, and sulfur chemistry. A recent study highlighted the important role of fuel radical recombinations with standard combustion radicals such as $\mathrm{H}, \mathrm{CH}_{3}, \mathrm{OH}$, and/or $\mathrm{HO}_{2}$ [95] under low-pressure flame conditions. Experimental determinations of the kinetics for such reactions are plagued by the difficulties of producing two radicals, quantitatively observing their populations, and isolating the observed kinetics to the reaction of interest. 
These reactions also present certain difficulties for theoretical studies. The TS lies at large separations ( 2-4 $\AA$ between the two reacting fragments) where standard single reference electronic structure methods [e.g., $\operatorname{CCSD}(\mathrm{T})]$ are generally inaccurate. The long-range nature of the TS creates further difficulties in that the intermolecular bending motions are not well treated as either harmonic oscillators or free rotors and the nature of the reaction coordinate is changing. To treat the latter problem we employ a variable reaction coordinate (VRC) defined in terms of fixed separations between arbitrarily located pivot points for the two reacting fragments. The variational principle of TST then allows for optimization of the pivot point locations to obtain the lowest and thus best rate. Numerical integration of classical phase space representations of the partition function provides an accurate treatment of the mode-coupling/anharmonicity issues for the intermolecular bends, but commonly requires on the order of $10^{3}$ potential energy surface evaluations in order to obtain convergence to 510\%. Direct CASPT2 [96] calculations with a small active space [e.g., 2 electrons in 2 orbitals (2e,2o) for a radical-radical reaction] often provide a suitably accurate treatment of the interactions in the TS region, and require only modest computational effort. Comparisons of VRC-TST predictions with classical trajectory simulations indicate the need for reductions in the predicted rate coefficients by 10 to $15 \%$ due to dynamical recrossings of the TS $[97,98]$, which are now included as a matter of course.

Early applications of the direct CASPT2 VRC-TST based approach, which examined a series of alkyl radical, $\mathrm{R}$, additions to $\mathrm{H}$ [99] and other alkyl radicals R' [97], demonstrated exceptional agreement with the limited experimental data. One of the useful outcomes of these studies was a strong numerical validation of the geometric mean rule, which relates the rate constant, $k_{A B}$, for the cross-radical reaction to those for the self-recombination rate constants, $k_{A A}$ and $k_{B B}$ :

$$
k_{A B}=2\left(k_{A A} k_{B B}\right)^{1 / 2}
$$

Subsequent generalizations of the approach allowed for the consideration of O [100] and N [101] centered radicals, resonantly stabilized radicals [102], halogen atoms [103], and singlet carbenes [104]. Overall, these studies suggest that our dynamically corrected direct CASPT2 VRC-TST predictions 
generally have uncertainties of about $20 \%$, although it is difficult to be sure due to the paucity of high accuracy experimental data for the high pressure limit, especially for high temperatures. Consideration of the underlying uncertainties in the theoretical methodologies validates this perspective.

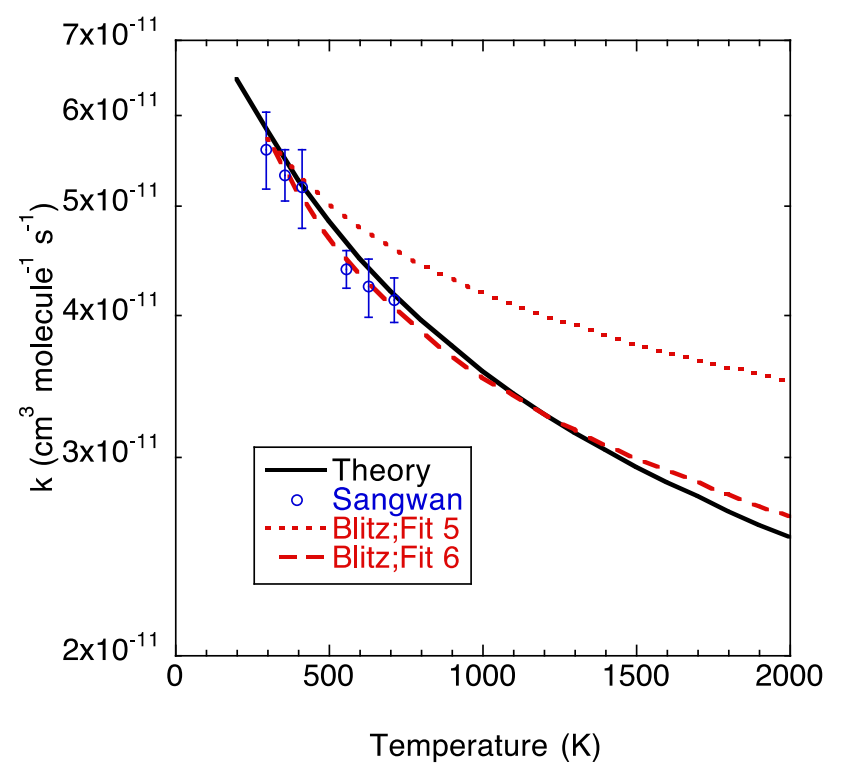

Figure 6: Plot of $\mathrm{CH}_{3}+\mathrm{CH}_{3}$ high-pressure recombination rate constants. The solid line denotes dynamically corrected direct CASPT2 results from [97]. The blue symbols denote the pulsed photolysis data of Sangwan et al. [105], the red dotted and dashed lines denote the two best fits in the recent master equation based extrapolation of experimental data to the high pressure limit by Blitz et al. [106].

The $\mathrm{CH}_{3}+\mathrm{CH}_{3}$ recombination is among the most well studied radical-radical reactions. As illustrated in Fig. 6, for this reaction the dynamically corrected direct CASPT2 VRC-TST predictions [97] are within the error bars of the recent pulsed photolysis data of Sangwan et al. [105] between 292 and $714 \mathrm{~K}$ and also agree quantitatively with one of the two best fits in a reanalysis of experiments that incorporates master equation fitting to extrapolate to the high pressure limit at temperatures up to 2000 K [106]. We now routinely employ the direct CASPT2 VRC-TST method in predicting the recombination kinetics for experimentally unstudied reactions $[18,95,104,107-110]$. 
Understanding the high accuracy of these theoretical predictions for barrierless recombination reactions has important ramifications for combustion chemical modeling. For example, the high pressure limit for $\mathrm{CH}_{3}+\mathrm{H}$ in GRI-Mech 2.11, which is currently being used in many established combustion mechanisms (e.g., AramcoMech 1.3 [29] and USCMech II [32]), is a factor of two to three lower than our predictions (which have an estimated uncertainty of only 20\%). Such lower values are apparently adopted to improve the predictions for methane/air flame speeds at higher pressures $(5-10 \mathrm{~atm})$. The need for such unphysical rate constant choices suggests other shortcomings in the mechanisms.

The addition of $\mathrm{O}_{2}$ to radicals is a central component of low temperature oxidation. Until recently, we had difficulties in obtaining high quality VRC-TST based predictions for this class of reaction. Typically, CASPT2, multi-reference configuration-interaction (MRCI), and Davidson corrected MRCI (MRCI+Q) [111,112] calculations yield very similar minimum energy path (MEP) potential energy profiles for radical-radical recombinations. However, for radical $+\mathrm{O}_{2}$ reactions, these profiles show significant discrepancies (cf. solid lines in Fig. 7), with these discordant MEPs leading to significantly different rate estimates. Furthermore, it is not clear which of these profiles is more accurate.

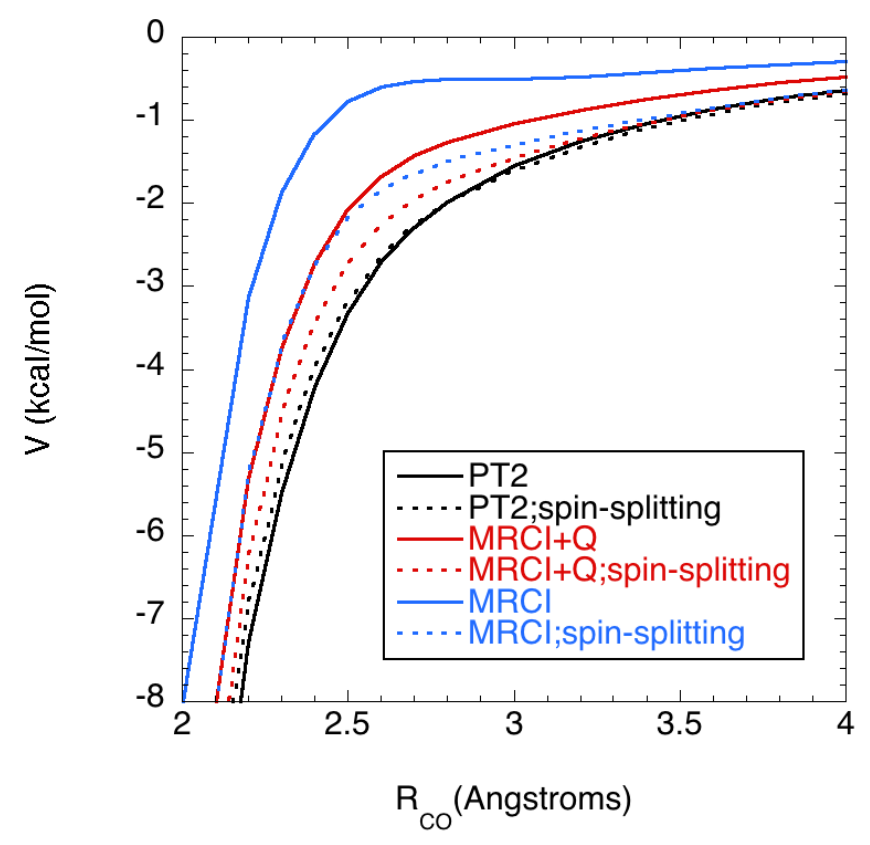

Figure 7: Plot of the $\mathrm{C}_{2} \mathrm{H}_{5}+\mathrm{O}_{2}$ interaction energy along the $\mathrm{R}_{\mathrm{CO}}$ distinguished coordinate minimum energy path. The black, red, and blue lines correspond to CASPT2, MRCI+Q, and MRCI calculations, 
respectively. The solid lines denote direct calculations of the interaction energy, while dashed lines denote calculations of the doublet-quartet splitting combined with $\operatorname{CCSD}(\mathrm{T})$ calculations of the quartet interaction energy.

Our recent resolution of this problem makes use of the fact that high level single reference methods can be used to evaluate the energy of the quartet state along the MEP. Then, multireference methods need only estimate the splitting between the doublet and quartet states along the MEP, which is less sensitive to the method employed [113]. An illustration of the effectiveness of this approach for the addition of $\mathrm{O}_{2}$ to ethyl radical is provided in Fig. 7. For the CASPT2 and MRCI+Q results, the maximum discrepancy between the two interaction energies is only $17 \%$ for the spin-splitting based approach (dotted lines), whereas it is $35 \%$ for the direct evaluation (solid lines).

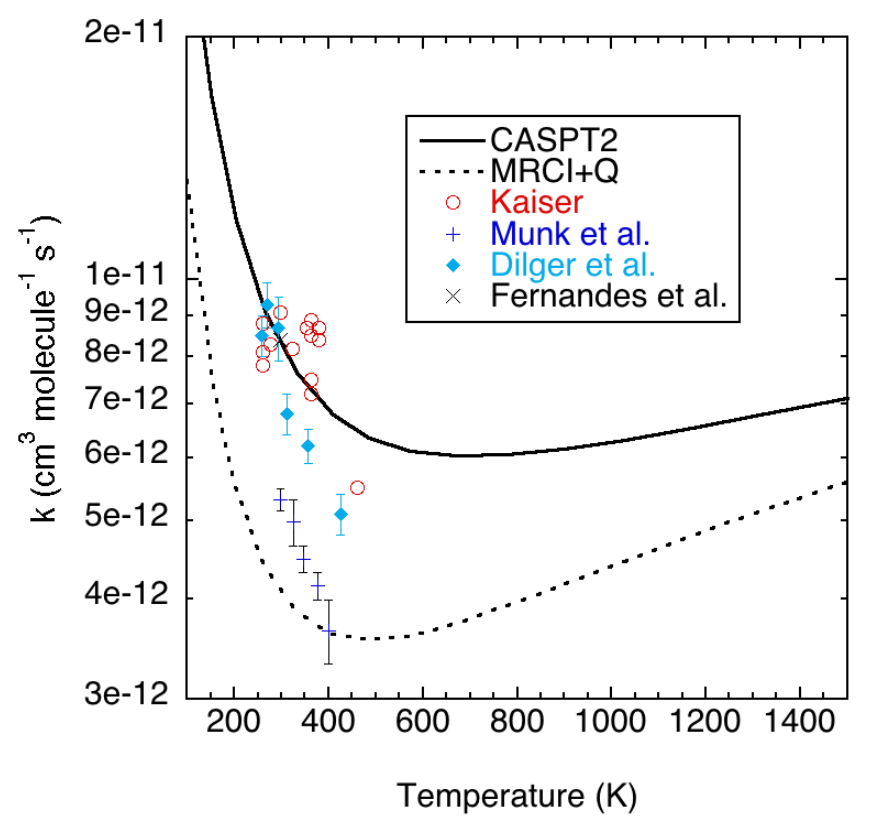

Figure 8: Plot of the temperature dependence of the recombination rate constant for $\mathrm{C}_{2} \mathrm{H}_{5}+\mathrm{O}_{2}$. The theoretical results are for the high-pressure limit, while the experimental data are for pressures of $\sim 1 \mathrm{~atm}$ of $\mathrm{H}_{2}$ (Munk et al. [114]), He (Kaiser [115]), and $\mathrm{N}_{2}$ (Dilger et al. [116]), or 100 bar of Ar (Fernandes et al. [117]). 
Our first application of this spin-splitting based method to the $\mathrm{C}_{2} \mathrm{H}_{3}+\mathrm{O}_{2}$ recombination led to a reduction in the range of the predicted rate constants by about a factor of two, with rate predictions based on a CASPT2 MEP reproducing the higher end of the experimental data, while rate predictions based on an MRCI+Q MEP roughly capture the lower end of the experimental data [113]. The two predictions deviate from their average by at most $30 \%$, with this deviation decreasing with increasing temperature. Applying this spin-splitting based methodology to the $\mathrm{C}_{2} \mathrm{H}_{5}+\mathrm{O}_{2}$ recombination yields similar quality rate predictions, as illustrated in Fig. 8. There is some ambiguity in the role of falloff at the higher temperatures, with master equation simulations (see below) suggesting the deviation from the high-pressure limit at $\sim 1$ atm should be $\sim 5,15$, and $30 \%$ for temperatures of 300, 400, and $500 \mathrm{~K}$. Nevertheless, it appears clear that the CASPT2 predictions are accurate to $30 \%$ or better, while the MRCI+Q predictions are too low. Notably, while theory and experiment agree quantitatively in the predicted decrease with temperature near room temperature, simple extrapolation of the experimental data would fail to capture the predicted rise at higher temperature. This rise is the result of the gradually decreassing transition state separation coupled with the transition from a fairly flat MEP to a sharply increasing MEP at about 2.6 ̊.

\section{Thermochemistry}

Thermochemistry is an underappreciated aspect of chemical modeling. Many quantities such as heat release rates, adiabatic flame temperature, the role of QOOH radicals in low-temperature chemistry [118], and the feasibility of growth pathways in soot formation [119] show strong sensitivity to thermochemical properties. It is not uncommon for the overall uncertainties in a model to be dominated by uncertainties in the thermochemical properties.

A concerted effort from the 1990 s to the early 2000 s yielded a variety of computational schemes for predicting room temperature heats of formation to 'chemical accuracy', which was defined as 1 $\mathrm{kcal} / \mathrm{mol}$ for the mean absolute deviation (MAD) from experiment. The CBS-QB3 approach of 
Petersson and coworkers [120] has become popular in combustion chemistry [19-22]. The G4 scheme of Raghavachari and coworkers shows somewhat better accuracy (i.e., lower MADs), but is also more computationally demanding [121]. Notably, Mebel and coworkers have found great utility for their G2M scheme, which is a modification of the earlier GAUSSIAN-2 scheme, in their exploration of PAH chemistry [122].

As Ruscic has noted, the $2 \sigma$ uncertainty, which is a better measure of accuracy than the commonly used MAD, is typically a factor of 2.5 to 3.5 times as large as that measure [123]. Boltzmann factors for an energy of $3 \mathrm{kcal} / \mathrm{mol}$ are $0.15,0.28$, and 0.39 at 800,1200 , and $1600 \mathrm{~K}$, respectively, with these temperatures being roughly representative of low, intermediate, and high temperature combustion regimes. Furthermore, the uncertainties in the TS energies tend to be larger than those for stable species, due to a generally greater role for multireference effects and more difficulty in predicting the stationary point geometry [124]. Thus, although schemes that are of chemical accuracy for the energies are of great utility, further improvement is required to reduce the uncertainty in kinetics predictions to the factor-oftwo or better levels that are typical of many experiments.

Each of these standard thermochemistry methods attempts to approximate the $\operatorname{CCSD}(\mathrm{T})$ complete basis set (CBS) limit in terms of a sum of smaller, more cost effective calculations. We have generally implemented approaches that employ fewer additivity assumptions in the attempt to approach the CCSD(T)/CBS limits (or the closely related QCISD(T)/CBS limit), with the particular basis sets we employ motivated by the limits of what is feasible for the particular system of interest. These $\operatorname{CCSD}(\mathrm{T}) / \mathrm{CBS}$ studies are largely motivated by the desire to accurately predict the energies of TSs (in order to also make kinetics predictions) where we find that common additivity assumptions are less successful. Feller and coworkers provided a useful illustration of the difficulty in accurately achieving the CCSD(T)/CBS limit for atomization energies [125]; extrapolations employing basis sets as large as aug-cc-pVQZ still yield $2 \sigma$ errors of $\sim 0.9 \mathrm{kcal} / \mathrm{mol}$. The recently developed explicitly correlated 
versions of $\operatorname{CCSD}(\mathrm{T})$ greatly facilitate this approach to the CBS limit [126], but do introduce some biases [127].

A few years ago, Goldsmith et al. explored the accuracy of a QCISD(T)/CBS(T,Q)//B3LYP approach in predicting the heats of formation for a set of $219 \mathrm{C} / \mathrm{O} / \mathrm{H}$ species of relevance to combustion [128]. The accuracy of the raw results was somewhat disappointing, with many deviations in the 1-2 $\mathrm{kcal} / \mathrm{mol}$ range. However, the inclusion of a bond additivity correction (BAC), to account for shortcomings in the treatment of multiple bonds, for example, yielded predictions with $2 \sigma$ uncertainties of just $0.58 \mathrm{kcal} / \mathrm{mol}$. Such BAC schemes found great utility in the early BAC-MP4 [129] combustion thermochemistry work of Melius. Unfortunately, BAC schemes are less useful for kinetics work due to the ambiguity of bond specifications at the TS.

Typical chemical accuracy schemes employ B3LYP [130] density functional theory to map out the rovibrational properties of the stationary points. More accurate density functional theory schemes are now available, with the M06-2X [52] and B2PLYP-D3 [53,54] being two of our current favorites. We have found that the latter accurately reproduces $\operatorname{CCSD}(\mathrm{T}) / \mathrm{cc}-\mathrm{pVTZ}$ geometries and frequencies even for most TSs, especially for radical oxidation reactions. However, as a double hybrid method that includes an MP2 component, it requires significantly more CPU than B3LYP or M06-2X. Nevertheless, we believe that it will provide an important piece towards improving the accuracy of predictions for larger molecules. Meanwhile, the M06-2X method provides improved (relative to B3LYP) treatments of torsional potentials and low-barrier TSs, for example, and has been used in a recently proposed composite scheme [131].

The last 10 years has seen spectacular progress in the accuracy of high level ab initio thermochemistry predictions, with a number of schemes, such as the W4 [132], HEAT [133], focal point [134], and Peterson-Feller-Dixon [135] methods, now yielding $2 \sigma$ uncertainties of about $0.2 \mathrm{kcal} / \mathrm{mol}$. Of course, this remarkable improvement in the overall accuracy comes at the expense of dramatically increased CPU cost. Nevertheless, such schemes are now readily applied to species with about 34 or 
fewer electrons, which allows for their application to many prototypical combustion reactions. The various high level schemes share many elements in common: they generally consist of geometry optimizations and harmonic vibrational analyses at the CCSD(T) level, complete basis set extrapolations employing Dunning's correlation consistent basis sets [136], and corrections accounting for the effects of higher order electron excitations, vibrational anharmonicity, core-valence interactions, relativity, and electron-nuclear coupling. After the accurate approach to the CCSD(T)/CBS limit, the CCSDT(Q) correction, which treats up to quadruple electron excitations, is the most important correction, but it is also the most costly to obtain. For kinetics purposes the improved accuracy of CCSD(T) frequencies is also very important. The use of B3LYP or MP2 frequencies can yield an order magnitude error in the rate prediction.

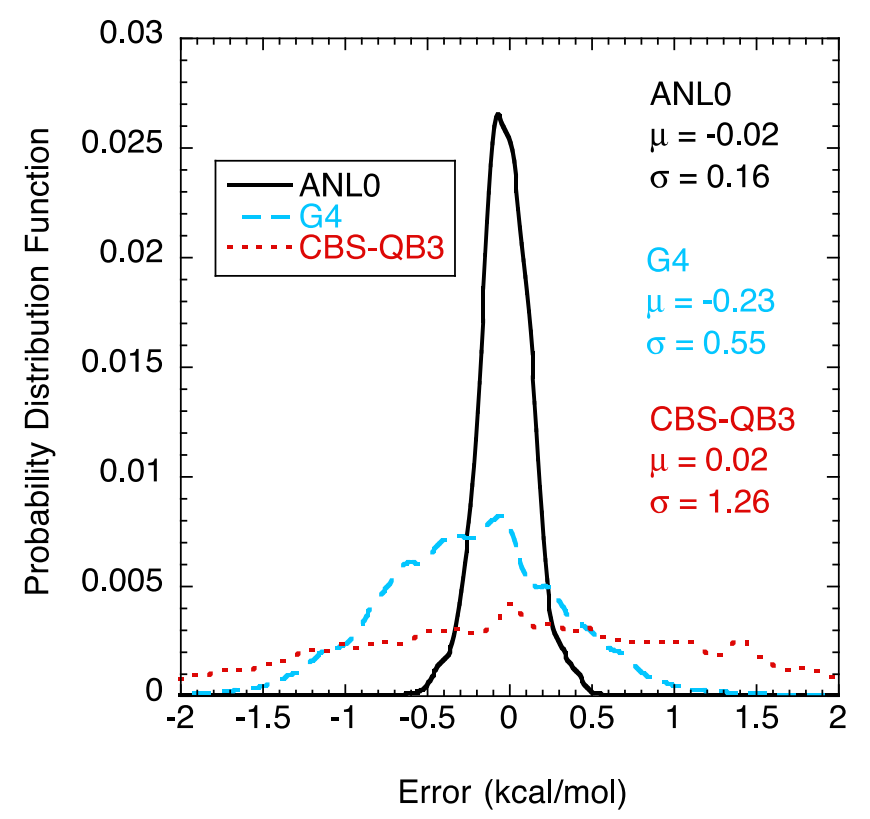

Figure 9: Probability distribution function of errors relative to ATcT for ANL0, G4, and CBS-QB3 calculated $0 \mathrm{~K}$ heats of formation for $138 \mathrm{C} / \mathrm{N} / \mathrm{O} / \mathrm{H}$ species.

We have recently applied our own version of high-level thermochemistry (ANL0) to a set of 371 molecules consisting of essentially all combustion relevant C/N/O/H molecules with fewer than 34 electrons [ 137 ]. The ATcT approach provides exceptionally accurate values through careful consideration of the network of connections and uncertainties for all available thermochemical 
measurements and theoretical predictions [62]. As part of this study, we compared our predictions with a set of 157 ATcT values. The probability distribution function (PDF) for the errors in the ANL0 predictions (relative to the ATcT benchmark values) is plotted in Fig. 9 for a subset of 138 species, where the few outliers with apparent errors $>0.5 \mathrm{kcal} / \mathrm{mol}$ have been removed prior to making this PDF. These outliers correspond to species for which either the ANLO approach is expected to be inaccurate [e.g., open shell singlets such as $\mathrm{O}\left({ }^{1} \mathrm{D}\right)$, which are inherently multi-reference problems] or the ATcT predictions have large uncertainties (e.g., NCNH and CHNN). For comparison purposes, we have also plotted the PDFs for CBS-QB3 and G4 calculations of the same set of 138 species.

The ANL0 predictions for this set have a $2 \sigma$ uncertainty of just $0.32 \mathrm{kcal} / \mathrm{mol}$. The corresponding Boltzmann factors at 800, 1200, and $1600 \mathrm{~K}$ are 0.81, 0.88, and 0.91, respectively. Notably, the set of 138 ATcT values considered in this analysis have an average $2 \sigma$ uncertainty of 0.11 $\mathrm{kcal} / \mathrm{mol}$. Unfortunately, it is difficult to disentangle the contribution of the ATcT uncertainties to the apparent ANL0 error, with the majority (72\%) of the predictions falling within a factor of two of the error bars in the ATcT values.

The ANL0 method, and other related high-level schemes, should be similarly useful in predicting barrier heights for chemical reactions. However, the greater role of multireference effects may lead to uncertainties that are somewhat larger. For now it seems reasonable to presume that such predictions will have $2 \sigma$ uncertainties of $\sim 0.5 \mathrm{kcal} / \mathrm{mol}$ or less, at least as long as the CCSDT(Q) correction (which provides some measure of multireference effects) is about $0.4 \mathrm{kcal} / \mathrm{mol}$ or lower. Limited applications to date suggest that the uncertainty may actually be less than this.

We are currently exploring extensions of the ANL0 approach to allow for the treatment of considerably larger systems. Preliminary results for a scheme that couples B2PLYP-D3/cc-pVTZ rovibrational analyses with $\operatorname{CCSD}(\mathrm{T})-\mathrm{F} 12 / \mathrm{CBS}\{\mathrm{T}, \mathrm{Q}\}$ energies, CCSDT(Q)/cc-pVDZ(d/s) higher order excitation corrections, cc-pcVTZ core-valence corrections, and empirical anharmonicity corrections have a $2 \sigma$ uncertainty of just $0.56 \mathrm{kcal} / \mathrm{mol}$ for a reference set of 138 molecules. This scheme may prove 
to be a reasonably optimal scheme for treating up to 6 heavy atoms. Replacing the $\operatorname{CCSD}(\mathrm{T})$ F12/CBS(T,Q) energy with a CCSD(T)-F12/cc-pVTZ-F12 + MP2-F12/cc-pVQZ-F12 - MP2-F12/ccpVTZ-F12 energy and the CCSDT(Q)/cc-pVDZ(d/s) higher order excitation correction with the $\operatorname{CCSDT}(\mathrm{Q}) / \mathrm{cc}-\mathrm{pVDZ}(\mathrm{p} / \mathrm{s})$ one may provide a high accuracy scheme that is appropriate for up to 9 heavy atoms. Notably, that system size correlates with the size of many of the fuel molecules being considered in the spark igntion component of DOEs Co-Optima program for co-optimization of fuels and engines $[138]$.

Molecular and TS entropies are another key aspect of thermochemistry that strongly affects combustion modeling. The progress in electronic structure methodologies allows for predictions of rotational constants and harmonic vibrational frequencies at a high level of accuracy. However, RRHObased entropy estimates, which provide the basis for much of the thermochemical data in combustion mechanisms, are not particularly accurate at the temperatures of relevance to combustion. Thus, the effect of entropic uncertainties on global combustion properties likely exceeds that of the uncertainties in the heat of formation, at least when the latter have been determined at a high level of theory.

A recent study of methane flame speeds by Sivaramakrishnan and coworkers illustrates the effect of improved thermodynamic representations that better account for anharmonicity and non-rigidity [139]. Replacing the $\mathrm{CH}_{\mathrm{x}}$ and $\mathrm{OH}_{\mathrm{x}}$ thermochemical properties in USC-Mech [32] with improved representations yields an increase in the flame speeds on the rich side by $9 \%$ at $\phi=1.4$, but by only $3 \%$ at $\phi=1.05$. It is unclear how large the corrections would be for larger less well studied species, but they could well be dramatically more significant.

Improved treatments of entropies incorporating corrections for anharmonicities and nonrigidities, are at the forefront of advanced TST methodologies, as discussed in other parts of this review. Unfortunately, such methodologies have not been routinely applied to the prediction of molecular entropies. The systematic application of theory to the prediction of entropies at a high level of accuracy 
for a large set of combustion relevant species at combustion relevant temperatures appears feasible and would be a great boon.

\section{Abstraction}

Abstraction reactions are ubiquitous in combustion, with ignition delays showing high sensitivities to abstractions from the fuel by $\mathrm{OH}, \mathrm{HO}_{2}, \mathrm{O}_{2}, \mathrm{RO}_{2}$, and/or $\mathrm{H}$ in global sensitivity studies [140-143]. Remarkably, abstraction reactions comprise $86 \%$ of the reactions in a recent mechanism for

the pyrolysis of ethane [144]. Abstraction reactions are particularly simple reactions to treat theoretically, and a priori rate predictions are routinely performed in conjunction with combustion modeling efforts [19-23]. However, for biofuels, the presence of hydrogen bonding interactions between the fuel and the abstractor, coupled with the low, or even submerged (below the bimolecular asymptote), barriers leads to various complexities in the analysis $[145,146]$.

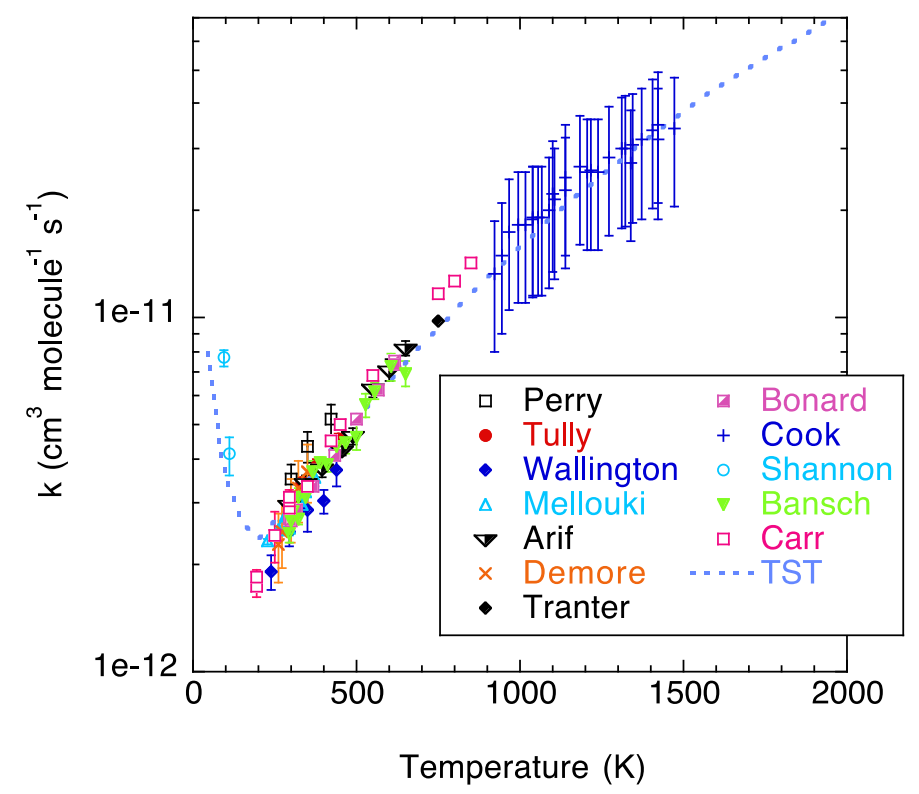

Figure 10: Plot of the rate constant $\mathrm{k}_{3}$ for $\mathrm{CH}_{3} \mathrm{OCH}_{3}+\mathrm{OH} \rightarrow \mathrm{CH}_{3} \mathrm{OCH}_{2}+\mathrm{H}_{2} \mathrm{O}$. The symbols denote various experimental results [156-165], while the line denotes the present AI-TST predictions.

Dimethyl ether is a prototypical small biofuel, whose kinetics is of considerable current interest [147-155]. The abstraction of an $\mathrm{H}$-atom from dimethyl ether by $\mathrm{OH}$ 


$$
\mathrm{CH}_{3} \mathrm{OCH}_{3}+\mathrm{OH} \rightarrow \mathrm{CH}_{3} \mathrm{OCH}_{2}+\mathrm{H}_{2} \mathrm{O}
$$

is particularly well studied experimentally and so provides a useful test for theoretical methodologies. Here we illustrate the ability of ab initio (AI)-TST to predict this rate constant. The theoretical analysis employs a CCSD(T)-F12b/cc-pVDZ-F12 rovibrational analyses, ANL0 style energies, M06-2X/ccpVTZ based evaluations of variational and 2-dimensional hindered rotor effects, and asymmetric Eckart tunneling corrections. More details are provided in the Supplementary Material. As illustrated in Fig. 10, our AI-TST predictions for $\mathrm{k}_{3}$ are in quantitative agreement with the available experimental data [156166] from 300 to $1400 \mathrm{~K}$, and provides a useful extrapolation to higher temperatures. A related AI-TST study of the kinetics of the $\mathrm{OH}+\mathrm{CH}_{3} \mathrm{OH}$ reaction finds a similar level of agreement [145].

While the agreement illustrated in Fig. 10 is impressive, it is of little direct value to combustion modeling; the experimental record has already provided definitive rate expressions for this reaction. Instead, such studies are of greatest value in validiating more approximate theoretical methodologies, which are more readily implemented for larger fuel molecules. As illustrated in Fig. 11, the TS geometry and barrier height show strong sensitivity to the electronic structure method (with the CCSD(T)-F12 values expected to be the most accurate). The imaginary frequency is even more sensitive, with predicted values ranging from 308 to $1482 \mathrm{~cm}^{-1}$. The plot also shows a strong correlaton between predicted TS location and barrier height, which results in similar correlations between imaginary frequency and barrier height. Studies of rate uncertainties [167] should account for these correlations. 


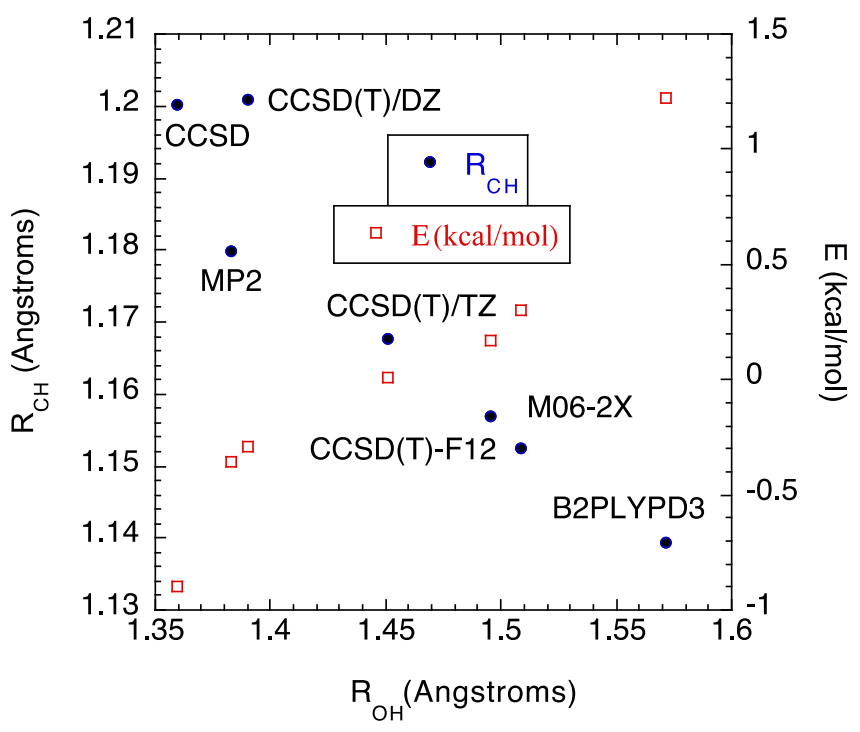

Figure 11: Plot of the correlation between $\mathrm{OH}$ separation, $\mathrm{R}_{\mathrm{OH}}$, and $\mathrm{CH}$ separation, $\mathrm{R}_{\mathrm{CH}}$, at the saddle point or saddle point energy, E. Note that the energies are each for ANL0 calculations at the geometries determined by the specified method.

These sensitivities map into significant variances in the predicted rates at low temperature, but at higher temperatures these variances are greatly reduced [165,168]. For example, calculations employing MP2/6-311G(d,p), M06-2X/cc-pVTZ, B2PLYP-D3/cc-pVTZ, CCSD/6-311G(d,p), CCSD(T)/cc-pVTZ, and $\operatorname{CCSD}(\mathrm{T})-\mathrm{F} 12 / \mathrm{cc}-\mathrm{pVDZ}-\mathrm{F} 12$ rovibrational analyses together with consistent ANL0 style energies show a factor of 6 variation at room temperature but agree to within a factor of 1.6 at $1500 \mathrm{~K}$. This decreased sensitivity is noteworthy as it implies that lower level rovibrational analyses, which are more readily applicable to larger biofuels, may yield rate predictions that are of useful accuracy for combustion modeling even when they poorly reproduce room temperature experimental data. However, accurate predictions for very large fuel molecules, such as typical bioesters, may still require careful consideration of their torsional complexity. For intermediate sized molecules, the multi-structural [169] and multi-path [170] variational TST approaches of Truhlar are finding great utility.

\section{7. $\mathrm{HO}_{2}+$ Fuel Reactions}


One of the greatest utilities of theory is in predicting rate constants for reactions that are likely significant but difficult to study experimentally. Although reactions of $\mathrm{HO}_{2}$ with closed shell molecules generally have large barriers, they show up with high sensitivity in global uncertainty analyses [141]. It is difficult to directly examine the elementary kinetics of such reactions experimentally for two reasons: their rates are low due to the high barrier, and simply increasing the temperature to increase the rates leads to decomposition of $\mathrm{HO}_{2}$. A recent study of the uncertainty in syngas mechanisms lists the oxidation reaction

$$
\mathrm{CO}+\mathrm{HO}_{2} \rightarrow \mathrm{CO}_{2}+\mathrm{OH}
$$

as the reaction with the greatest uncertainty, with a temperature independent uncertainty factor of 0.7 [171]. Furthemore, modeling studies of $\mathrm{H}_{2} / \mathrm{CO}$ ignition delays at high pressures noted a strong sensitivity to (R4) [172,173]. Attempts to examine (R4) experimentally have yielded only upper limits for the rate constant.

This sensitivity motivated our earlier theoretical study of (R4) [174], with the predicted rate coefficients yielding markedly improved agreement with measured ignition delays at high CO fractions. At the time, we estimated the uncertainty in our theoretical predictions to range from a factor of 2 to 1.7 for $\mathrm{T}$ in the range from 1000 to $2000 \mathrm{~K}$. This uncertainty largely arose from an estimated uncertainty of $1 \mathrm{kcal} / \mathrm{mol}$ in some of the predicted barrier heights due to modest multireference effects. The 2.5 to 3 times larger uncertainty assumed by Nagy et al. [171] is illustrative of the common reluctance to accept theoretical predictions at face value.

The inclusion of a CCSDT(Q) correction, as within the ANL0 approach, should provide a very effective treatment of possible multireference effects at the saddle point. Thus, we have reanlayzed the kinetics of (R4), incorporating ANL0 barriers, a two-dimensional hindered rotor treatment, and consideration of variational effects for the key TSs. Further details of this calculation are provided in the Supplemenatary Material. The ANL0 predicted barrier heights of 17.27, 9.93, 17.96, and 15.44 kcal/mol for TS1, TS2, TS3, and TS4, respectively are similar to, but somewhat lower than (e.g., $0.7 \mathrm{kcal} / \mathrm{mol}$ for 
the rate limiting barrier, TS1), the "best" estimated values from [174]. Notably, the CCSDT(Q) correction for TS1 is $-0.49 \mathrm{kcal} / \mathrm{mol}$, again suggesting modest multireference effects. Thus, the $2 \sigma$ uncertainty in this barrier height is perhaps $0.5 \mathrm{kcal} / \mathrm{mol}$. Our revised rate prediction, $\mathrm{k}_{4}=8.55 \times 10^{3} \mathrm{~T}^{2.52}$ $\exp (-15560 / \mathrm{RT}) \mathrm{cm}^{3}$ mole $^{-1} \mathrm{~s}^{-1}$ for temperatures ranging from 300 to $2500 \mathrm{~K}$, is greater than our earlier estimate [174] by a factor that varies from 2 to 1.5 to 1.2 as the temperatures varies from 1000 to 1500 to $2000 \mathrm{~K}$, which is within the previously estimated error bounds. The $2 \sigma$ uncertainty in this rate prediction is estimated to be a factor of 1.4 for the 1000 to $2000 \mathrm{~K}$ temperature range.

\section{Radical Oxidation; Ethyl and Propyl as Prototypes}

\subsection{Background}

Our current detailed understanding of chain branching in low temperature oxidation [175] has benefitted immensely from quantitative theoretical analyses [45, 176-186]. Many proposed schemes for improving efficiency and reducing pollutants in internal combustion engines rely on high fidelity descriptions of this low temperature chemistry [1,2]. Such high fidelity descriptions require a quantitative understanding of the kinetic role of various pathways on the four PESs describing (i) the initial abstractions to produce a particular radical $\mathrm{R}$; (ii) the addition of $\mathrm{O}_{2}$ to $\mathrm{R}$, isomerizations of the $\mathrm{RO}_{2}$ adduct via internal $\mathrm{H}$ abstractions to various $\mathrm{QOOH}$ species, and the decompositions of $\mathrm{RO}_{2}$ and the QOOH's to produce $\mathrm{HO}_{2}$ or $\mathrm{OH}$ and their coproducts; (iii) the addition of a second $\mathrm{O}_{2}$ to the QOOH, and the thermal dissociation of that $\mathrm{OOQOOH}$ to $\mathrm{OQ}^{\prime} \mathrm{OOH}+\mathrm{OH}$; and (iv) $\mathrm{OO}$ bond fission in $\mathrm{OQ}^{\prime} \mathrm{OOH}$ to yield a second $\mathrm{OH}$ and its coproduct, and other alternative dissociations.

\subsection{Ethyl Radical Oxidation}

Ethyl is the smallest alkyl radical for which the $\mathrm{R}+\mathrm{O}_{2}$ potential energy surface exhibits the main features of larger alkyl radicals. Thus, its reaction with $\mathrm{O}_{2}$ has served as a protopye, with a detailed and quantitative picture of its kinetics derived from extensive experimental [115-117,187-190], electronic 
structure [191-196], and reaction rate theory [117,190,194,197-201] studies. Building from their early density functional theory analyses [191-193], the most important stationary points on the PES were ultimately mapped with a high-level focal point analysis by Schaefer and coworkers [196]. Meanwhile, the pioneering kinetic study of Wagner et al., which illuminated many aspects of the kinetics through model RRKM calculations [190], was followed by extensive master equation analyses by Miller and coworkers [194,199,201]. Most recently, a joint experimental and theory analysis has explored the pressure dependence of the recombination process from 200 - $500 \mathrm{~K}$ [117].

There are still some notable limitations in prior theoretical kinetics studies of the $\mathrm{C}_{2} \mathrm{H}_{5}+\mathrm{O}_{2}$ reaction system. Treatments of the entrance channel kinetics have either been empirical in nature or have employed electronic structure methods that are not adequate for treating the radical-radical interactions in the TS region. Furthermore, the high-level stationary point predictions of Wilke et al. [196] have not yet been implemented in any kinetics analysis, and corresponding high accuracy ab initio data has not been obtained for a number of the kinetically relevant stationary points. The role of the QOOH species (i.e., $\mathrm{CH}_{2} \mathrm{CH}_{2} \mathrm{OOH}$ ), which might be significant at the high pressures of relevance to combustion, has also not been adequately explored.

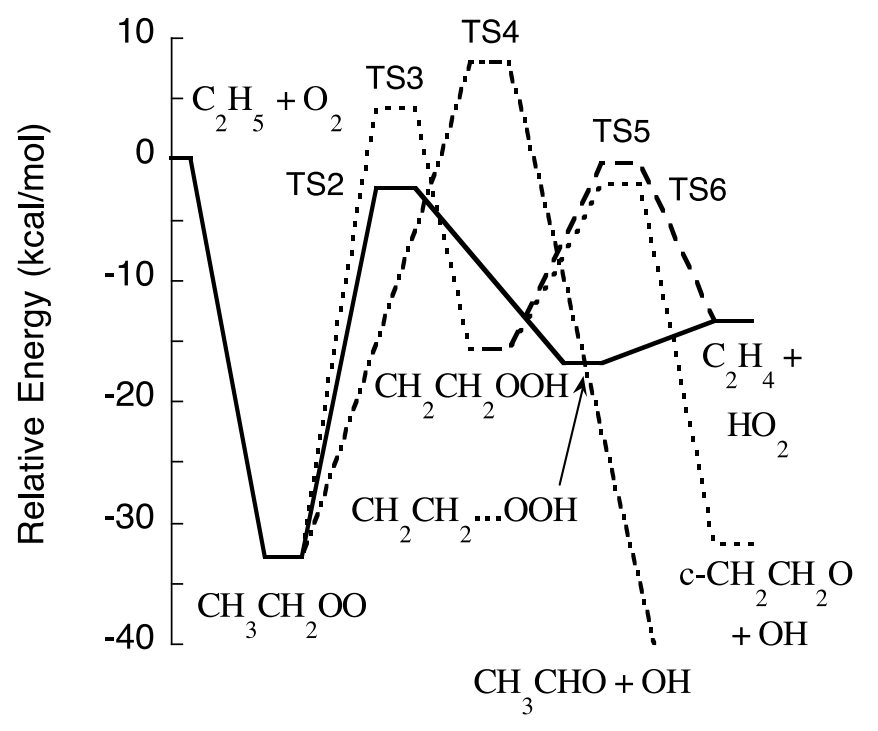

Figure 12: Schematic plot of the low energy stationary points on the PES for the $\mathrm{C}_{2} \mathrm{H}_{5}+\mathrm{O}_{2}$ system. 
A schematic plot of the $\mathrm{C}_{2} \mathrm{H}_{5}+\mathrm{O}_{2}$ PES calculated at the ANL0 level is provided in Fig. 12 and the corresponding energies are reported in Table 1 together with corresponding CBS-QB3, G4, and focal point energy differences. Prior master equation modeling suggested a $0.7 \mathrm{kcal} / \mathrm{mol}$ more strongly bound $\mathrm{RO}_{2}$ and a $0.8 \mathrm{kcal} / \mathrm{mol}$ lower TS2 [194]. It is unlikely that the ANL0 predictions are that much in error especially for the well depth, which suggests different problems in the theoretical modeling. Indeed, as shown below, the consistent use of the ANL0 properties yields quantitative agreement with the experimental observations.

Table 1: Stationary point energies for the $\mathrm{C}_{2} \mathrm{H}_{5}+\mathrm{O}_{2}$ system.

\begin{tabular}{|c|c|c|c|c|c|}
\hline \multirow[t]{2}{*}{ Stationary Point } & Label $^{b}$ & ANL0 & CBS-Q & G4 & \multirow{2}{*}{ FP } \\
\hline & \multicolumn{2}{|r|}{ Energy } & \multicolumn{2}{|c|}{ Error $^{\mathrm{c}}$} & \\
\hline $\mathrm{CH}_{3} \mathrm{CH}_{2}+\mathrm{O}_{2}$ & $\mathrm{R}$ & 0 & 0 & 0 & 0 \\
\hline $\mathrm{CH}_{3} \mathrm{CH}_{2} \mathrm{OO}$ & W1 & -32.77 & -1.4 & -0.7 & רד \\
\hline $\mathrm{CH}_{2} \mathrm{CH}_{2} \mathrm{OOH}$ & W2 & -15.74 & -1.5 & -1.0 & \\
\hline $\mathrm{CH}_{2} \mathrm{CH}_{2} \ldots \mathrm{HO}_{2}$ & W3 & -16.87 & -0.4 & -0.2 & \\
\hline $\mathrm{CH}_{3} \mathrm{CH}_{2} \mathrm{OO} \leftrightarrow \mathrm{CH}_{2} \mathrm{CH}_{2} \ldots \mathrm{HO}_{2}$ & TS2 & -2.21 & -0.7 & 0.5 & -0.77 \\
\hline $\mathrm{CH}_{3} \mathrm{CH}_{2} \mathrm{OO} \leftrightarrow \mathrm{CH}_{2} \mathrm{CH}_{2} \mathrm{OOH}$ & TS3 & 4.10 & -2.3 & -0.4 & \\
\hline $\mathrm{CH}_{3} \mathrm{CH}_{2} \mathrm{OO} \leftrightarrow \mathrm{CH}_{3} \mathrm{CHO}+\mathrm{OH}$ & TS4 & 9.32 & -2.3 & 0.5 & \\
\hline $\mathrm{CH}_{2} \mathrm{CH}_{2} \mathrm{OOH} \leftrightarrow \mathrm{CH}_{2} \mathrm{CH}_{2}+\mathrm{HO}_{2}$ & TS5 & -0.13 & -0.9 & 1.1 & \\
\hline $\mathrm{CH}_{2} \mathrm{CH}_{2} \mathrm{OOH} \leftrightarrow \mathrm{c}-\mathrm{CH}_{2} \mathrm{CH}_{2} \mathrm{O}+\mathrm{OH}$ & TS6 & -2.06 & -1.3 & 1.7 & \\
\hline $\mathrm{CH}_{2} \mathrm{CH}_{2}+\mathrm{HO}_{2}$ & & -13.38 & -0.2 & 0.2 & -036 \\
\hline $\mathrm{CH}_{3} \mathrm{CHO}+\mathrm{OH}$ & & -59.33 & -0.9 & -0.6 & 077 \\
\hline $\mathrm{c}-\mathrm{CH}_{2} \mathrm{CH}_{2} \mathrm{O}+\mathrm{OH}$ & & -31.87 & -1.3 & -0.8 & \\
\hline $\mathrm{CH}_{3} \mathrm{CH}_{2} \mathrm{O}+\mathrm{O}$ & & 28.15 & -1.0 & -0.9 & \\
\hline Mean Deviation & & & -1.2 & -0.1 & \\
\hline $2 \sigma$ & & & 2.7 & 1.7 & \\
\hline
\end{tabular}


${ }^{a}$ All energies include vibrational zero-point energy (ZPE) corrections and are in $\mathrm{kcal} / \mathrm{mol}$ relative to $\mathrm{C}_{2} \mathrm{H}_{5}+\mathrm{O}_{2}$.

${ }^{\mathrm{b}}$ Labels are as in [194].

${ }^{\mathrm{c}}$ Difference between CBS-QB3, G4, or focal point (FP) [196] values and ANL0 values.

There are two distinct pathways from $\mathrm{CH}_{3} \mathrm{CH}_{2} \mathrm{OO}$ leading to $\mathrm{HO}_{2}$ formation. A low energy path involves an attack by a departing $\mathrm{O}_{2}$ group on one of the $\mathrm{H}$ atoms to yield a $\mathrm{CH}_{2} \mathrm{CH}_{2} \ldots \mathrm{OOH}$ van der Waals complex, which then dissociates to $\mathrm{C}_{2} \mathrm{H}_{4}+\mathrm{HO}_{2}$. A higher energy path involves an internal $\mathrm{H}$ abstraction to form the QOOH species $\left(\mathrm{CH}_{2} \mathrm{CH}_{2} \mathrm{OOH}\right)$, which may dissociate to either $\mathrm{C}_{2} \mathrm{H}_{4}+\mathrm{HO}_{2}$ or a cyclic ether $+\mathrm{OH}$. These two pathways are representative of those for other larger alkyl radicals, although the relative barriers can be quite different and there are more channels, particularly more QOOH species, arising from alternative internal $\mathrm{H}$ abstractions. Especially important is the lowering of the barrier to QOOH formation for abstractions that involve 6 membered rings in the TS. For the $\mathrm{C}_{2} \mathrm{H}_{5}$ case, the $\mathrm{H}$ abstraction barrier is high enough that the QOOH species is of little import, although it does play a role in understanding the minor production of $\mathrm{OH}$ radicals.

To explore the kinetics further, we implemented the ANL0 stationary point properties and the dynamically corrected direct CASPT2 VRC-TST analysis (from Sec. 4) in one-dimensional master equation (1DME) calculations that incorporate all three wells. The average downwards energy transferred for $\mathrm{He},\left\langle\Delta \mathrm{E}_{\mathrm{d}}\right\rangle$, was set to $180(\mathrm{~T} / 300)^{0.95} \mathrm{~cm}^{-1}$. The room temperature value, which is fairly representative of values for systems this size (e.g., fitted values of 150 and $100 \mathrm{~cm}^{-1}$ were obtained for the slightly smaller $\mathrm{C}_{2} \mathrm{H}_{5} \mathrm{OH}$ [202] and $\mathrm{CH}_{3} \mathrm{OCH}_{3}$ [203] systems in $\mathrm{Kr}$ ), yields optimum agreement with experiment, while the temperature dependence is taken from classical trajectory calculations for $\mathrm{CH}_{4}$ in He [204]. Further details of these calculations are provided in the Supplementary Material. 


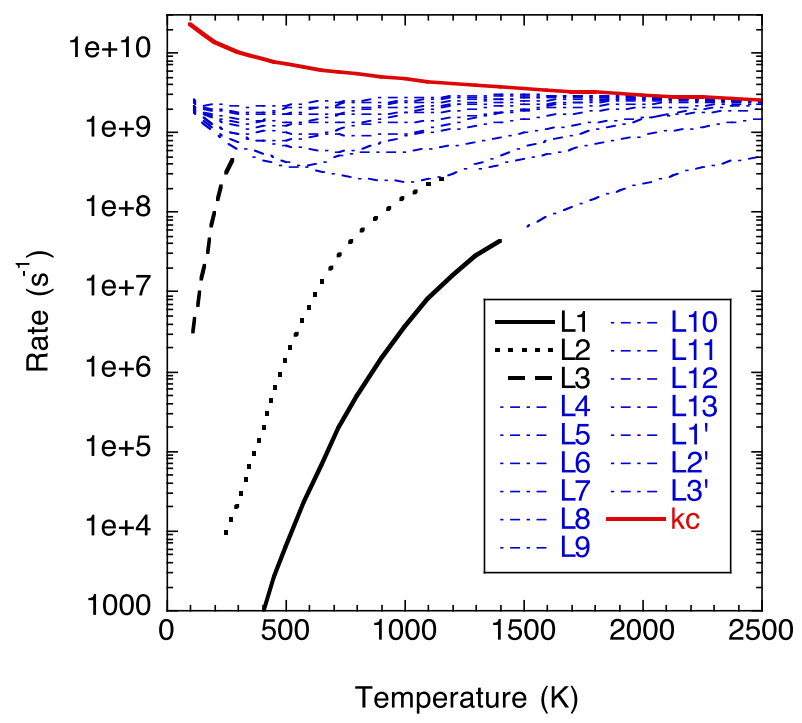

Figure 13: Temperature dependence of the eigenvalues for the $\mathrm{C}_{2} \mathrm{H}_{5}+\mathrm{O}_{2}$ system. The 3 chemically significant eigenvalues (CSEs) are denoted at low temperature as the black solid, dotted, and dashed lines. At higher temperatures these eigenvalues merge with the sea of internal energy relexation eigenvalues (IEREs) denoted as blue dashed dotted lines (the lowest 10 are shown here) and the distinction between CSE and IEREs is lost. The red line denotes the constant pressure collision rate.

The plot in Fig. 13 illustrates the temperature dependence of the CSEs together with the lowest 10 IEREs, and the collision rate, all calculated for a pressure of $1 \mathrm{~atm}$. Plots for other pressures are very similar in form and largely just shift the IERE eigenvalues up or down in proportion to the pressure. The third CSE, which describes the equilibration of the $\mathrm{CH}_{2} \mathrm{CH}_{2} \ldots \mathrm{HO}_{2}$ van der Waals well with products is seen to merge with the quasicontinuum of IEREs at about $300 \mathrm{~K}$. Above this temperature the van der Waals complex no longer exists as an isolatable chemical species. Due to the low temperature of this merging, such alkene... $\mathrm{HO}_{2}$ van der Waal's complexes are rarely considered in comprehensive chemical schemes. More problematic is the fact that the second CSE, which represents the QOOH species $\left(\mathrm{CH}_{2} \mathrm{CH}_{2} \mathrm{OOH}\right)$ equilibrating with products, merges with the quasicontinuum at about $900 \mathrm{~K}$. At even higher temperature even the lowest CSE approaches the IERE quasicontinuum. In this case, 
determination of a precise merging temperature is difficult, but detailed considerations suggest that this merging occurs at about $1400 \mathrm{~K}$, where this CSE curve becomes parallel to the lowest IERE curve.

For ethyl, the relatively high isomerization barriers imply that the oxidation kinetics is dominated by the reactions

$$
\begin{aligned}
& \mathrm{C}_{2} \mathrm{H}_{5}+\mathrm{O}_{2} \rightarrow \mathrm{C}_{2} \mathrm{H}_{5} \mathrm{O}_{2} \\
& \mathrm{C}_{2} \mathrm{H}_{5}+\mathrm{O}_{2} \rightarrow \mathrm{C}_{2} \mathrm{H}_{4}+\mathrm{HO}_{2} \\
& \mathrm{C}_{2} \mathrm{H}_{5} \mathrm{O}_{2} \rightarrow \mathrm{C}_{2} \mathrm{H}_{5}+\mathrm{O}_{2} \\
& \mathrm{C}_{2} \mathrm{H}_{5} \mathrm{O}_{2} \rightarrow \mathrm{C}_{2} \mathrm{H}_{4}+\mathrm{HO}_{2}
\end{aligned}
$$

For simplicity, we now focus our attention on a comparison with experimental observations for the first two processes. Work in progress will provide a more complete treatment, including the possible role of $\mathrm{CH}_{2} \mathrm{CH}_{2} \mathrm{OOH}$ stabilization at high pressures.

The 'predictions' for the pressure dependence of the $\mathrm{C}_{2} \mathrm{H}_{5}+\mathrm{O}_{2}$ rate constant and branching ratio at room temperature are compared with corresponding experimental observations in Figs. 14 and 15 , respectively. Descriptions of these two quantities near $800 \mathrm{~K}$ are a key component of high fidelity models for low temperature combustion, but experimental data for that region is generally limited. The present 'predictions', which are strongly dependent on the properties of TS2, the $\mathrm{C}_{2} \mathrm{H}_{5} \mathrm{O}_{2}$ well depth, and the energy transfer parameters, but to differing degrees, are seen to provide a satisfactory representation of the experimental data. The agreement illustrated in Figs. 8, 14, and 15 is obtained through adjustment of solely the room temperature energy transfer parameter, which suggests that other details of the theoretical model are largely accurate. Thus, one might expect this model to provide useful predictions for other conditions outside the experimentally accessible range, although the limitation to a 1DME with a simplified energy tranfser form may still lead to significant extrapolation errors. 


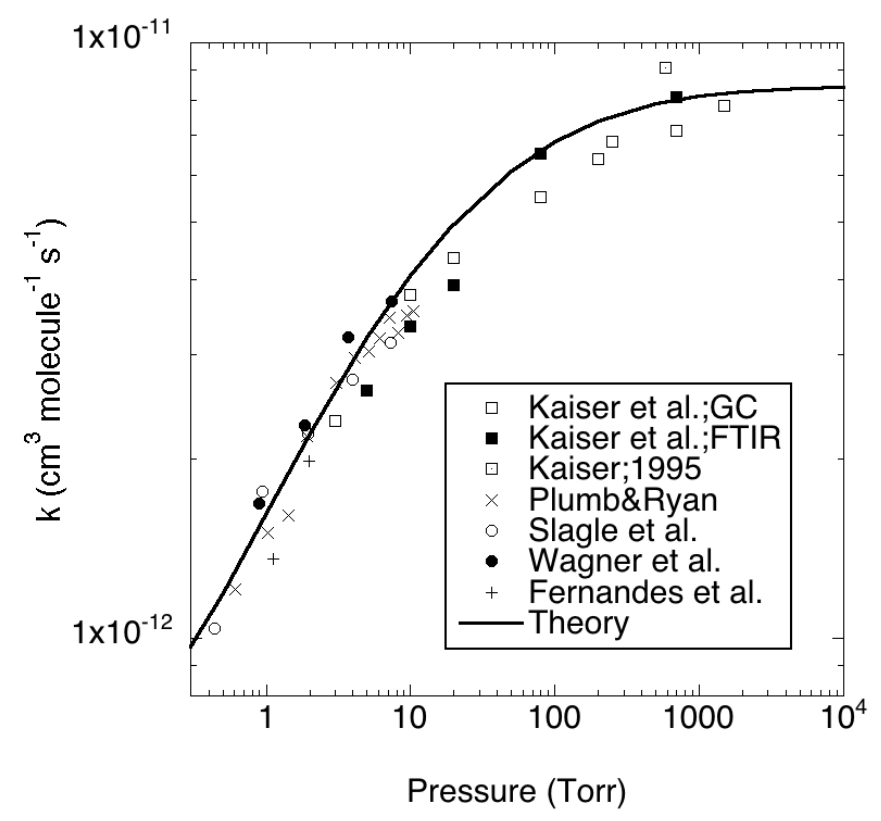

Figure 14: Plot of the pressure dependence of the room temperature rate constant for $\mathrm{C}_{2} \mathrm{H}_{5}+\mathrm{O}_{2} \rightarrow$ products with $\mathrm{He}$ as the bath gas. Symbols denote experimental values from [115,117,187-190].

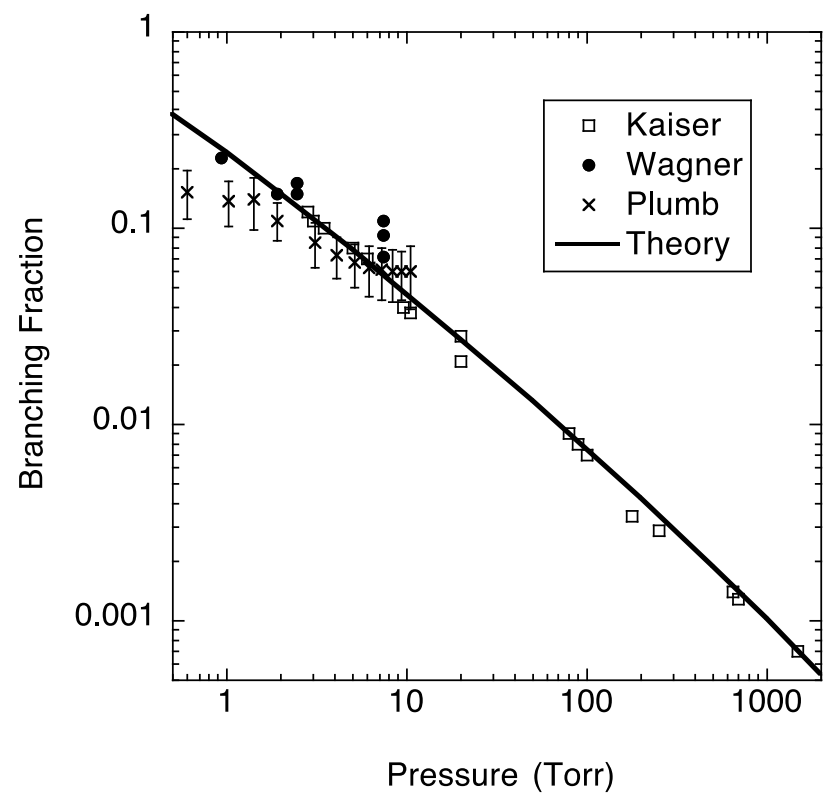

Figure 15: Plot of the pressure dependence of the branching to form $\mathrm{C}_{2} \mathrm{H}_{4}+\mathrm{HO}_{2}$ in the reaction of $\mathrm{C}_{2} \mathrm{H}_{5}$ with $\mathrm{O}_{2}$ at room temperature in $\mathrm{He}$ bath gas. Symbols denote experimental values from $[187,189,190]$.

\subsection{Propane Oxidation}


Propane, which exhibits classic negative temperature coefficient (NTC) behaviour, with an ignition delay that shows a minimum with respect to temperature variations near $750 \mathrm{~K}$ [205], provides an excellent prototype for understanding low temperature oxidation of larger fuel molecules [206]. Its small size allows for quantitative theoretical analyses. The PES for the interaction of $n$-propyl radical with $\mathrm{O}_{2}$ has the important property that the barrier for formation of $\mathrm{CH}_{2} \mathrm{CH}_{2} \mathrm{CH}_{2} \mathrm{OOH}$ (i.e, a classic QOOH) lies well below the n-propyl $+\mathrm{O}_{2}$ asymptote, i.e., at $-8.5 \mathrm{kcal} / \mathrm{mol}$. Thus, this QOOH is readily formed in $n$-propyl oxidation and its reaction with $\mathrm{O}_{2}$ leads to the chain branching that is central to NTC behavior in low temperature oxidation.

Initially, our theoretical effort for this system focused on the kinetics of the propyl $+\mathrm{O}_{2}$ reaction system, mapping out the PES and kinetics of stabilization, of $\mathrm{HO}_{2}$ formation, and of $\mathrm{OH}$ formation with master equation calculations [201,207-210]. This theoretically motivated description evolved in tandem with sophisticated flow reactor experiments in the Taatjes group. This collaboration was a central element of our early master equation efforts, motivating a number of methodological improvements. Our initial studies focused on achieving consistency between theory and experiment for the production of $\mathrm{HO}_{2}$ [207,208]. The direct observation of the time-resolved appearance for $\mathrm{HO}_{2}$ illuminated the importance of the competition between the formally direct (or well skipping) and sequential mechanisms for forming $\mathrm{HO}_{2}$. The former mechanism proceeds through the $\mathrm{RO}_{2}$ well, but is not stabilized in it, so that the phenomenological rate directly describes the $\mathrm{R}+\mathrm{O}_{2} \rightarrow$ alkene $+\mathrm{HO}_{2}$ process. Additional work explored models for $\mathrm{OH}$ formation [201] and for $\mathrm{DO}_{2}$ formation in fully deuterated propyl radicals [209]. This effort concluded with an improved description of $\mathrm{OH}$ formation based on a better understanding of $\mathrm{OH}$ concentrations [210]. Such iterative collaborations between theory and experiment are of great utility for obtaining detailed well-validated descriptions of the kinetics.

Subsequent theoretical work of Goldsmith et al. employed the QCISD(T)/CBS $\{$ T,Q\}//B3LYP/6$311++\mathrm{G}(\mathrm{d}, \mathrm{p})$ method to explore the PESs for $\mathrm{R}+\mathrm{O}_{2}$, for $\mathrm{QOOH}+\mathrm{O}_{2}$, and for the decomposition of the OQ'OOH ketohydroperoxide arising from the decomposition of the OOQOOH molecule [45]. Master 
equation calculations were also performed for each of these systems to obtain for the first time a more or less complete set of well-founded temperature and pressure dependent phenomenlogical rate coefficients for the classic low temperature branching process in a radical oxidation system. The work of Goldsmith concluded with a discussion of the role of the $\mathrm{QOOH}+\mathrm{O}_{2}$ reaction in chain branching, including some suggestions on how their propyl specific results would extrapolate to larger alkyl radicals.

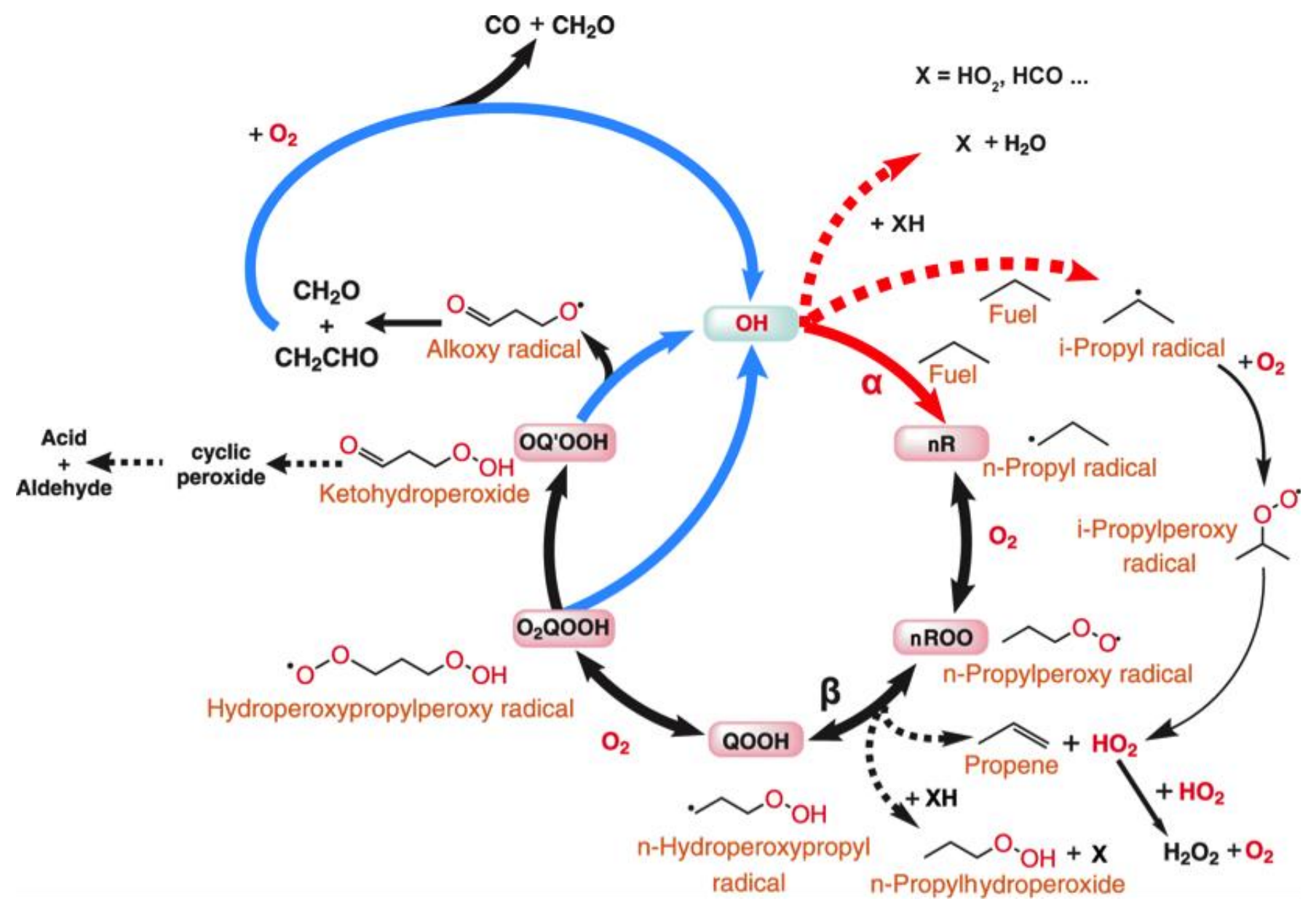

Figure 16: Schematic diagram of the key pathways involved in the first stage of propane ignition. The process begins at the top of the circle with $\mathrm{OH}$ radicals abstracting from the fuel, propane. Reactions shown in blue lead to formation of $\mathrm{OH}$ radicals, while those in red consume $\mathrm{OH}$. The reactions shown by dotted lines divert radicals away from the main chain branching pathway and delay the first-stage ignition. Reproduced with permission from [175]

The AI-TST-ME work of Goldmsith et al. [45] provided the basis for a detailed exploration of first-stage ignition behavior in propane by Green and coworkers [175]. This work also included the 
novel Korcek channel for decomposition of the ketohydroperoxide to an acid and a carbonyl [186], but which proved to be unimportant for temperatures where $\mathrm{QOOH}+\mathrm{O}_{2}$ chemistry is important. A schematic diagram of the key steps involved in the low temperature oxidation leading to first stage ignition is provided in Fig. 16.

The traditional first stage ignition can be broken into two stages: 1A and 1B. During stage-1A there is exponential growth of radicals until the concentration of $\mathrm{HO}_{2}$ is large enough for the $\mathrm{HO}_{2}+\mathrm{HO}_{2}$ chain terminating step to compete with other $\mathrm{HO}_{2}$ reactions. During stage-1B, the continued growth of radicals is marked by increasing temperature and growing side reactions (e.g., $\left.\mathrm{H}_{2} \mathrm{CO}+\mathrm{OH}\right)$ that reduce the positive feedback. This behavior ultimately leads to a maximum in the ketohydroperoxide concentration, which marks the end of stage-1B. This work derived analytic models for these two components of first stage ignition, and also considered the extension of the models to larger alkanes.

\subsection{Larger Radicals}

Recent theoretical studies have extended the detailed understanding of radical oxidation kinetics to much larger systems [176-184]. These studies have mostly focused on high pressure rate predictions for various aspects of the $\mathrm{R}+\mathrm{O}_{2}$ system [176-178,180,182,183]. Miyoshi also examined the pressure dependence for the $\mathrm{RO}_{2} / \mathrm{QOOH}$ system [181] and Villano et al. examined the pressure dependence for the $\mathrm{HO}_{2}+$ olefin channel [184]. In a pioneering study, Asatryan and Bozzelli explored the second $\mathrm{O}_{2}$ kinetics for 2-pentyl radical [179]. Sharma et al. also examined hydrogen migration reactions for $\mathrm{O}_{2} \mathrm{QOOH}[177]$.

Interestingly, some recent studies suggest a possible role for a third $\mathrm{O}_{2}$ addition $[211,212]$, which should be explored theoretically. A recent modeling study of n-butane by Battin-Leclerc and coworkers noted significant discrepancies in the kinetic predictions from calculations by various groups [213]. Typically, the ratio of the highest to lowest prediction was a factor of 5 to 10. These discrepancies largely arise from uncertainties in the barrier height predictions, and the hindered rotor and tunneling 
treatments. Given the importance of these studies to the development of rate rules that are used in all low temperature modeling studies, it seems worthwhile to reexplore many of these systems with higherlevel theoretical methods including a treatment of their pressure dependence.

\section{Uncertainty and Multi-Scale Modeling}

An improved understanding of the uncertainty in their predictions is an important frontier for chemical modeling. Thus, with theory playing an increasing role in chemical mechanisms, it becomes important to have realistic estimates for the uncertainty in theorietical kinetics predictions. Such estimates are also important in evaluating rate data and in deciding whether to prefer theoretical predictions or experimental measurements.

Historically, the uncertainties in theoretical predictions have been dominated by uncertainties in the barrier height predictions, but this is no longer the case. Uncertainties in the partition function evaluations are now often of comparable or even larger magnitude. For simple abstraction and highpressure addition reactions it is relatively straightforward to estimate the coupling of the barrier height

$\left(\sigma_{\mathrm{V}}{ }^{\#}\right)$, partition function $\left(\sigma_{\mathrm{Q}} \# / \mathrm{QR}\right)$, and tunneling $\left(\sigma_{\mathrm{K}}\right)$ uncertainties [64], as long as they are uncorrelated:

$$
\frac{\sigma_{k}^{2}}{k^{2}}=\frac{\sigma_{\kappa}^{2}}{\kappa^{2}}+\frac{\sigma_{Q^{ \pm} / Q_{R}}^{2}}{\left(Q^{ \pm} / Q_{R}\right)^{2}}+\frac{\sigma_{V^{ \pm}}^{2}}{\left(k_{B} T\right)^{2}}
$$

In an AI-TST calculation for an abstraction reaction, knowledge of the accuracy in predicted heats of formation can be used to assign an uncertainty to the Boltzmann factor in the barrier height. Similarly, knowledge of the accuracy in the predicted vibrational frequencies from separate comparisons with spectroscopic data can be used to assign uncertainties in the partition functions. However, barrier height and tunneling contributions are likely to be correlated, and partition function errors may be as well.

For complex forming reactions, such as those involved in radical oxidation, the coupling of energy transfer and microcanonical rates for different channels makes it considerably more difficult to 
estimate the uncertainties in the predictions. Goldsmith and coworkers employed global sensitivity methodologies to estimate the uncertainties in their kinetic predictions for the n-propyl $+\mathrm{O}_{2}$ system [63]. As illustrated in Fig. 17, the $2 \sigma$ uncertainties ranged from a factor of 2 to 5 , with most being near 3, and typically had significant contributions from numerous parameters including the energy transfer parameters, the TS energies, entrance channel flux predictions, and tunneling estimates. This level of uncertainty helps rationalize the size of the variations in the theoretical predictions observed by BattinLeclerc and coworkers [213] in their butane modeling study.

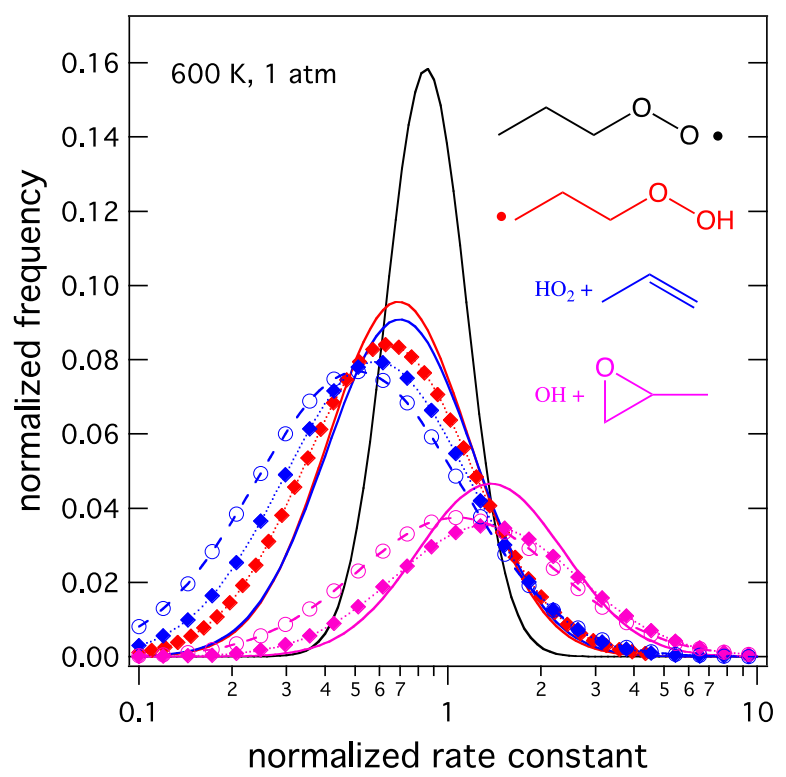

Figure 17: Normalized frequency distribution for the predicted rate constants at $600 \mathrm{~K}$ and $1 \mathrm{~atm}$. The line+symbol types denote different reactants (without symbols denotes $\mathrm{R}+\mathrm{O}_{2}$; with filled diamonds denotes $\mathrm{RO}_{2}$; with open circles denotes $\mathrm{QOOH}$ ) while the line colors denote different products (black denotes $\mathrm{RO}_{2}$; red denotes QOOH; blue denotes $\mathrm{HO}_{2}$ + propene; pink denotes cylic ether).

A global sensitivity study of $\mathrm{C}_{2} \mathrm{H}_{5} \mathrm{OH}$ dissociation showed an extraordinarily large uncertainty for decomposition to the higher energy channel, $\mathrm{CH}_{3}+\mathrm{CH}_{2} \mathrm{OH}$, at low pressures [214]. This high uncertainty arises from the need for collision induced transitions from below the first threshold to above the second threshold in order to produce the $\mathrm{CH}_{3}+\mathrm{CH}_{2} \mathrm{OH}$ products in the low-pressure limit. This required large-scale energy transition introduces an exceptionally strong dependence on the presumed 
energy transfer. Accurately predicting such energy transfer properties currently presents a signficant challenge for theory. Fortunately, the low probability of forming such channels generally implies that high accuracy predictions are not needed.

As noted by Burke in his multiscale informatics (MSI) approach [46,63], a detailed understanding of the uncertainties in the components of the theoretical analysis is of great value in obtaining kinetic representations that show the maximum consistency across all scales of theory and experiment. In this approach, Burke considers the uncertainties in theory, global property measurements, and elementary kinetics experiments on an even footing, and then optimizes the parameters in each to minimize the net discrepancy. Calculations based on the optimized theoretical model then yield the best possible rate representations for utilization in comprehensive chemical modeling.

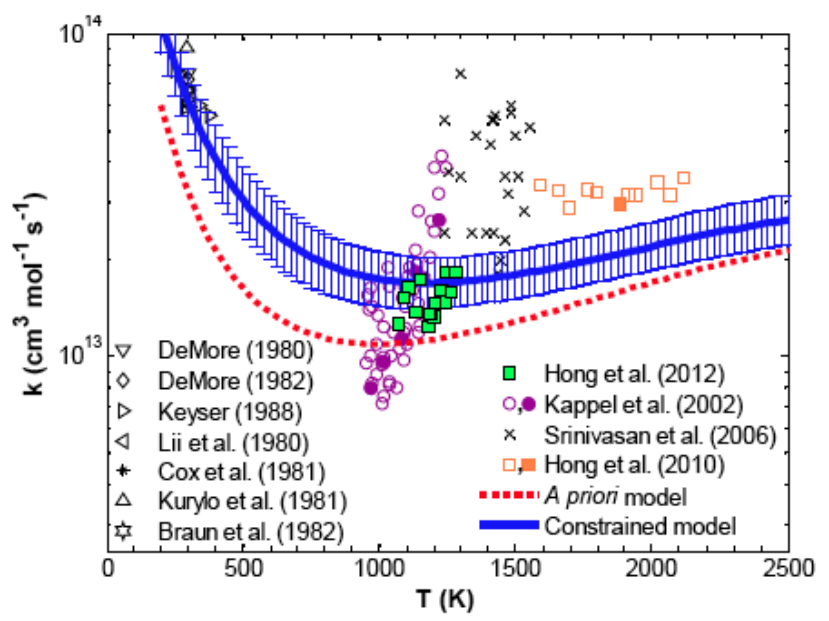

Figure 18: Selected rate constants for $\mathrm{OH}+\mathrm{HO}_{2} \rightarrow \mathrm{H}_{2} \mathrm{O}+\mathrm{O}_{2}$. The symbols denote various experimental results as noted in the original reference [65]. The lines denote a priori (red dashed) and multi-scale optimized (blue solid) theoretical predictions.

The plot in Fig. 18 illustrates the MSI predictions for $\mathrm{k}_{9}$

$$
\mathrm{OH}+\mathrm{HO}_{2} \rightarrow \mathrm{H}_{2} \mathrm{O}+\mathrm{O}_{2}
$$

as obtained by Burke and coworkers in their analysis of $\mathrm{H}_{2} \mathrm{O}_{2}$ decomposition. From this plot, it appears that many of the experimental data points are inconsistent with the model. The MSI modeling reveals that in fact the experimental data is largely consistent, and it is just the inherent uncertainties in 
extracting rate constants from the data that causes the apparent discrepancies. Notably, the green symbols, which denote experimental results obtained by Hong et al. [215] after the completion of the model, confirm the predictions of the optimized model. Furthermore, the optimization yields a reduction in the barrier height for the reaction

$$
\mathrm{OH}+\mathrm{OH} \rightarrow \mathrm{O}+\mathrm{H}_{2} \mathrm{O}
$$

from the nominal value of $2.8 \mathrm{kcal} / \mathrm{mol}$ to $1.2 \mathrm{kcal} / \mathrm{mol}$, whereas the ANL0 barrier of $0.6 \mathrm{kcal} / \mathrm{mol}$ goes even further; i.e., the optimization yields a physically correct reduction, but slightly underestimates its magnitude.

In a recent study, Burke applied his MSI approach to the much more complex low temperature propyl oxidation system [46]. The analysis focused on deriving a model that is consistent with the AITST-ME model of Goldsmith and coworkers [45] as well as with the time dependent species concentrations observed in a series of pulsed laser photolysis kinetics studies of Taatjes and coworkers, and various other experimental observations. Notably, as part of the theory-experiment collaboration [216] the prior observations of $\mathrm{OH}$ and $\mathrm{HO}_{2}$ species profiles were supplemented with time-resolved, multiplexed synchrotron photoionization mass-spectrometric observations for a large set of reactants, intermediates, and products. These observations deviated significantly from the predictions based on the AI-TST-ME based model of Huang et al. [210], where some of the barrier heights were optimized to yield agreement with the experimental data available at the time. These discrepancies are most dramatic for the $\mathrm{OH}$ co-products.

The MSI model was able to largely resolve these discrepancies, providing a consistent description for the vast majority of the observations. Perhaps more importantly, it indicates where the experiments are sensitive to the reactions of interest, and where other phenomena play a key role. At high temperature (e.g., $733 \mathrm{~K}$ ) the experimental observations are affected by secondary chemistry, while at low temperature (e.g., $300 \mathrm{~K}$ ) non-thermal effects may have a dominant effect on the production of $\mathrm{OH}$. Interestingly, the MSI analysis indicated that at some low and intermediate temperatures the $\mathrm{OH}$ 
observations are strongly affected by the $\mathrm{QOOH}+\mathrm{O}_{2}$ reaction, which had previously been ignored in the modeling (cf. Fig. 19). These same conditions also highlighted the important role of $\mathrm{C}_{3} \mathrm{H}_{7}+\mathrm{HO}_{2}$ kinetics. The MSI indications can be a valuable aid in design of experiments, and indeed were instrumental to the success of the companion experiments, with the MSI model helping resolve various difficulties with early versions of the experimental effort.

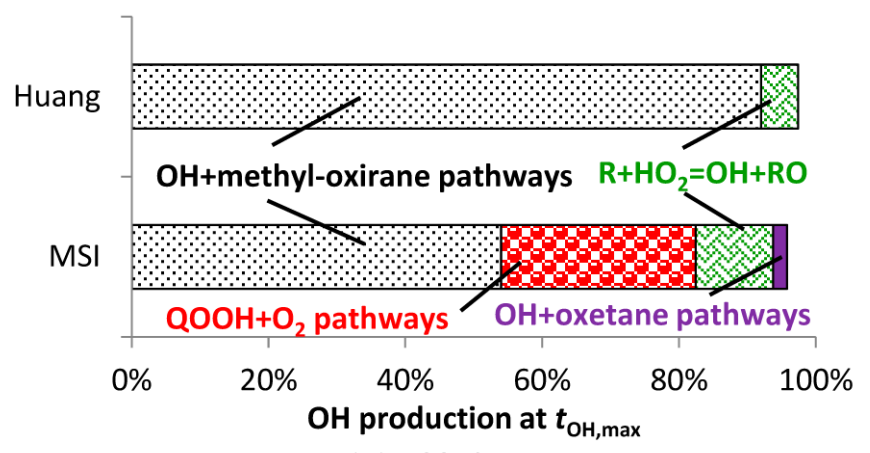

(a) $426 \mathrm{~K}$

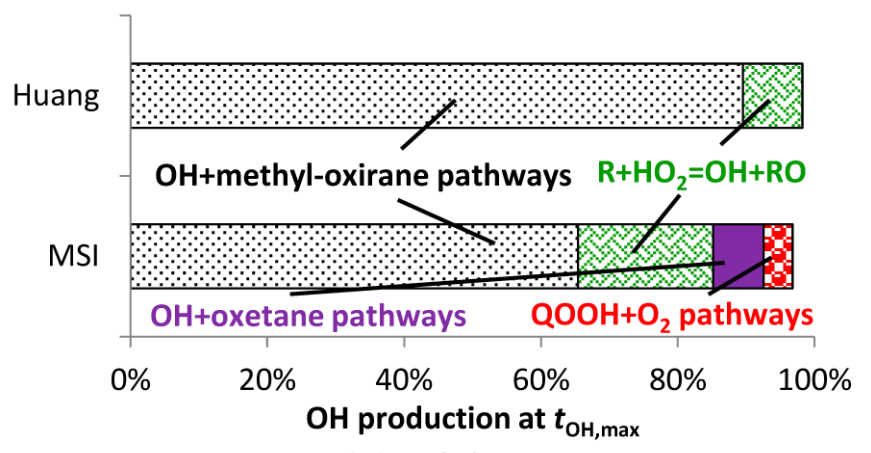

(b) $594 \mathrm{~K}$

Figure 19: Sources of $\mathrm{OH}$ production in pulsed photolysis experiments probing the propyl oxidation system using rate constants from either Huang et al. [210] or the multiscale informed model [46]. Reprinted with permission from [46]. Copyright 2015 American Chemical Society.

\section{Non-Thermal Effects in Combustion}

An assumption of complete thermalization prior to reaction is one of the cornerstones of chemical modeling. This assumption allows for the treatment of the chemical conversion from fuel to combustion products as a sequence of bimolecular and unimolecular reactions. Recent detailed theoretical analyses have indicated that the failure of this assumption can significantly affect the combustion process $[39,217-220]$.

\subsection{Prompt Dissociation}

The chemical conversion of the fuel occurs through a multitude of mostly exothermic steps, with many of these steps involving the formation of weakly-bound radicals. The presumption of 
thermalization is most problematic for such weakly-bound radicals. Consider, for example, the abstraction of an $\mathrm{H}$ atom from $\mathrm{H}_{2} \mathrm{CO}$ by an $\mathrm{OH}$ radical to produce $\mathrm{HCO}+\mathrm{H}_{2} \mathrm{O}$, which is $31 \mathrm{kcal} / \mathrm{mol}$ exothermic (cf. Fig. 20). For HCO, the barrier to dissociation is only $19 \mathrm{kcal} / \mathrm{mol}$, and, due to its small size, the microcanonical dissociation rate rapidly becomes very large as the energy is increased above the dissociation threshold. As a result, any of the incipient HCO that has an internal energy of about 19 $\mathrm{kcal} / \mathrm{mol}$ or more has a high probability of dissociating prior to suffering any collisions with the bath gas.

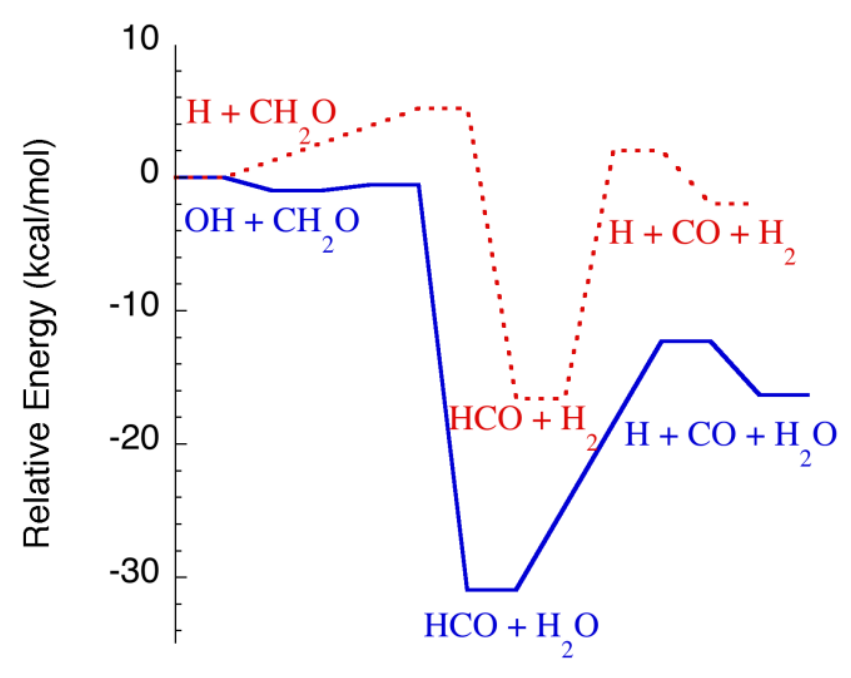

Figure 20: Schematic plot of the potential energy surfaces for the $\mathrm{H}_{2} \mathrm{CO}+\mathrm{OH}$ and $\mathrm{H}_{2} \mathrm{CO}+\mathrm{H}$ reactions together with the subsequent dissociation to produce H + CO. Modified from [39].

Direct trajectory simulations [221-223] of the dynamics from the TS on to products provide a means for predicting the distribution of energy in the products, i.e., between $\mathrm{HCO}, \mathrm{H}_{2} \mathrm{O}$, and relative translation in our $\mathrm{H}_{2} \mathrm{CO}+\mathrm{OH}$ example. Master equation calculations for $\mathrm{HCO} \rightarrow \mathrm{H}+\mathrm{CO}$ provide the prompt dissociation probability for a given HCO energy. Temperature and pressure dependent prompt dissociation probabilities [39], $P_{\text {prompt }}(T, P)$, are then readily obtained through Boltzmann averaging and energy convolution. Direct trajectory based $P_{\text {prompt }}(T, P)$ are illustrated in Fig. 21 for $\mathrm{OH}$ and $\mathrm{H}$ abstractions from $\mathrm{H}_{2} \mathrm{CO}$. The prompt dissociation process is seen to become significant at about $800 \mathrm{~K}$ for $\mathrm{H}$ as an abstractor and $1200 \mathrm{~K}$ for $\mathrm{OH}$ as an abstractor. 


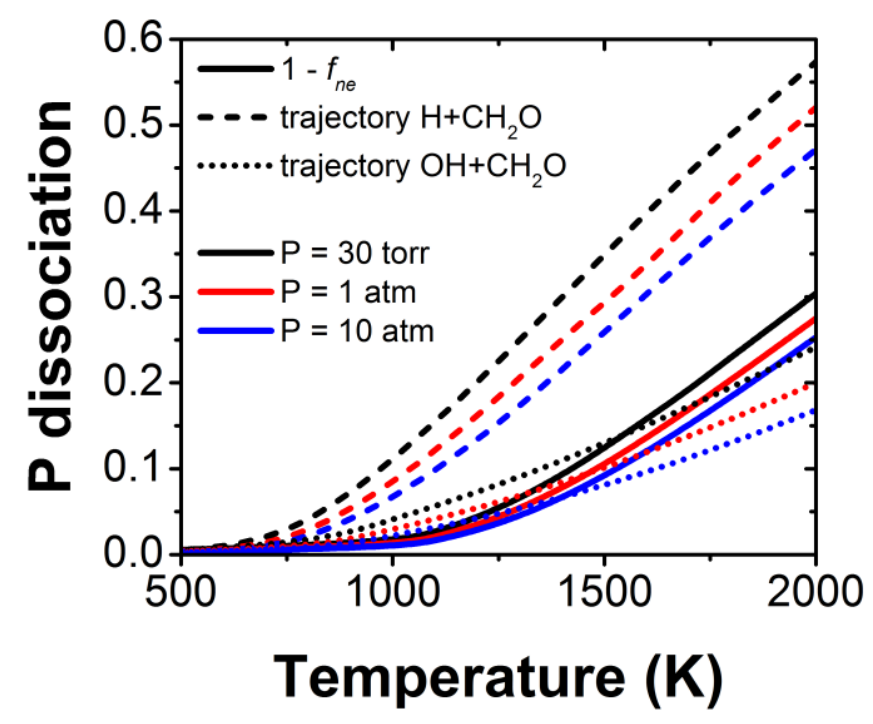

Figure 21: Probabilities for prompt dissociation of $\mathrm{HCO}$ as calculated with direct M06-2X/6$311++\mathrm{G}(\mathrm{d}, \mathrm{p})$ trajectories for the $\mathrm{H}_{2} \mathrm{CO}+\mathrm{OH}$ and $\mathrm{H}_{2} \mathrm{CO}+\mathrm{H}$ reactions and for a thermal incipient distribution of HCO. Reprinted with permission from [39]. Copyright 2016 American Chemical Society.

Importantly, at high enough temperature, even the Boltzmann distribution, which typically (but not always) provides a lower bound to the incipient energy distribution arising from any reaction, may have a significant component that dissociates promptly, prior to thermalization. For a single channel reaction, $P_{\text {prompt }}(T, P)$ for a Boltzmann initial distribution turns out to be just $1-f_{\text {ne, }}$ where the

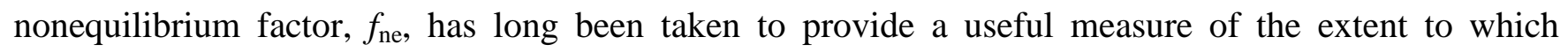
dissociation interferes with the collisional relaxation process [35,42]. Interestingly, for $\mathrm{HCO}$ such Boltzmann prompt dissociations are similar in magnitude to those for $\mathrm{OH}$ as an abstractor from $\mathrm{H}_{2} \mathrm{CO}$ (cf. Fig. 21).

The effects of such prompt dissociations are readily incorporated in chemical models. One simply (i) reduces the rate constants for all reactions that produce HCO by the factor $1-P_{\text {prompt }}$ and (ii) introduces a corresponding reaction producing $\mathrm{H}+\mathrm{CO}$ with a rate that is $P_{\text {prompt }}$ times the original rate constant. As illustrated in Fig. 22, such revisions to AramcoMech1.3 [29] and USCMech II [32] yield an increase in trioxane (a surrogate for $\mathrm{H}_{2} \mathrm{CO}$ ) flame speeds by up to $16 \%$. From a fundamental perspective, the increased discrepancy with experiment implies a significant shortcoming in some other aspect of the 
models. Noting, and subsequently resolving such discrepancies is an important component of the gradual march towards a model that faithfully reproduces chemical behavior. Recent calculations of flame speeds, ignition delays, and speciation profiles, indicate similarly significant prompt dissociation effects for a variety of fuels [217].

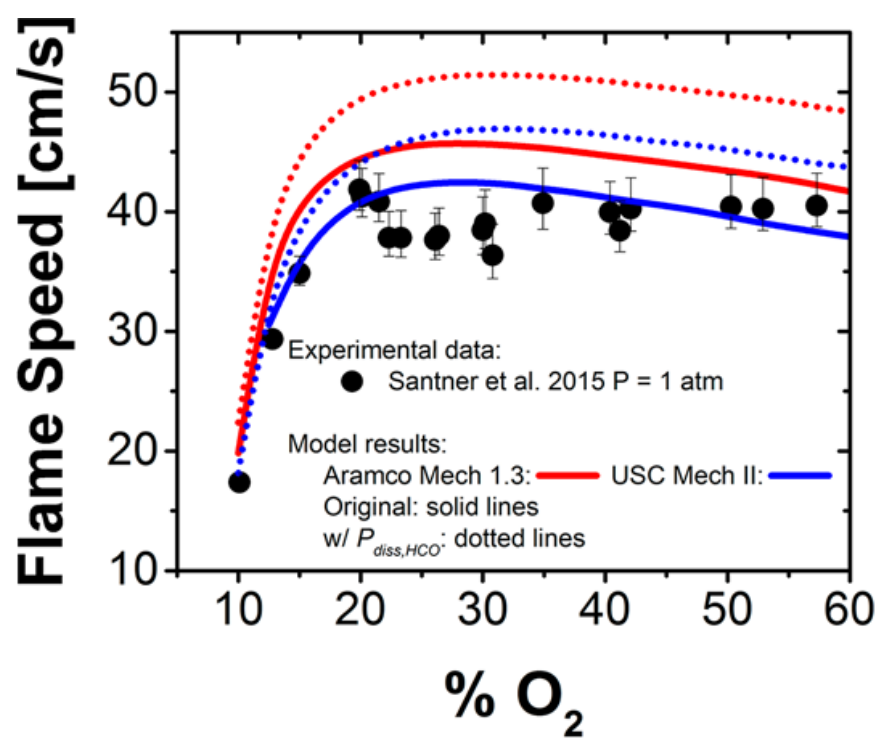

Figure 22: Laminar flame speeds for 5\% 1,3,5-trioxane in $\mathrm{O}_{2} / \mathrm{N}_{2}$ at $\mathrm{T}_{\mathrm{i}}=373 \mathrm{~K}$ and $\mathrm{P}=1$ atm. Solid lines are the unaltered model results, while the dotted lines represent the new models incorporating the $\mathrm{H} / \mathrm{OH}+\mathrm{CH}_{2} \mathrm{O}$ trajectory-based $P_{\text {diss }}$ and $f_{n e}$-based $P_{\text {diss }}$ for all other reactions involving HCO. Reproduced with permission from [39]. Copyright 2016 American Chemical Society.

Many oxidation reactions that convert $\mathrm{OO}$ bonds to $\mathrm{CO}$ bonds (or that generate $\mathrm{CO}$ bonds from $\mathrm{O}$ atoms or $\mathrm{OH}$ radicals) are very exothermic. For example, the reaction of $\mathrm{C}_{2} \mathrm{H}_{3}+\mathrm{O}_{2}$ to produce $\mathrm{CH}_{2} \mathrm{O}$ $+\mathrm{HCO}$, the reaction of $\mathrm{HCCO}+\mathrm{O}_{2}$ to produce $\mathrm{HCO}+\mathrm{CO}_{2}$, and the reaction of $\mathrm{CH}_{3}+\mathrm{O}$ to produce $\mathrm{HCO}+\mathrm{H}_{2}$ are exothermic by 87,126 , and $85 \mathrm{kcal} / \mathrm{mol}$, respectively. For such reactions, the $\mathrm{HCO}$ prompt dissociation probabilities are expected to be large (e.g., > 0.5) regardless of the temperature $[113,224,225]$

\subsection{Bimolecular Reactions of Chemically Activated Species}


Another interesting type of non-thermal effect arises when secondary reactions of chemically activated species are rapid enough to compete with stabilization. For example, in some combustion environments $\mathrm{H}$ atoms and other radicals can have mole fractions of a few percent. Generally, radicals react with other radicals at rates that are within about a factor of ten of the collision limit. In contrast, weak collider stabilization efficiencies are a few percent or less. Thus, radicals may act as particularly effective third bodies in determining the outcome of the chemically activated complexes. Apparently, such effects have not been explored previously for the combustion environment. In collaboration with Burke we recently explored the effect of $\mathrm{H}, \mathrm{O}$, and $\mathrm{OH}$ acting as third body colliders in the $\mathrm{H}+\mathrm{O}_{2}$ reaction [226]. For the $\mathrm{H}$ radical as a third body, either $\mathrm{H}_{2}+\mathrm{O}_{2}$ or two $\mathrm{OH}$ radicals are produced instead of stabilization to $\mathrm{HO}_{2}$. The effective conversion of two $\mathrm{H}$ atoms to an $\mathrm{H}_{2}$ molecule significantly decreases the flame speed, as illustrated in Fig. 23. There are many interesting alternative perspectives on such transient-molecule induced radical reactivities as discussed at length in [226]. Such effects will generally be important for the reaction of radicals that have high mole fractions (so that the reaction competes with stabilization) with transient chemically activated species.

Another such example involves the low temperature oxidation sequence corresponding to the addition of $\mathrm{OH}$ to an alkene or alkyne followed by the addition of $\mathrm{O}_{2}$ to the adduct, which has been shown to have important non-thermal effects under atmospheric conditions [227-230]. For example, for $\mathrm{C}_{2} \mathrm{H}_{2}$, allowing the chemically activated $\mathrm{C}_{2} \mathrm{H}_{2} \mathrm{OH}$ complex to react with $\mathrm{O}_{2}$ while it cools yields good agreement between predicted and observed $[\mathrm{OH}]$ [228]. At combustion temperatures, such alkene/alkyne $\mathrm{OH}$ adducts may or may not be stable $[231,232]$, but the reaction of $\mathrm{O}_{2}$ with an ephemeral complex may still provide an important pathway, in much the same way that the $\mathrm{H}+\mathrm{O}_{2}+\mathrm{H}$ reaction is significant in certain flame environments. 


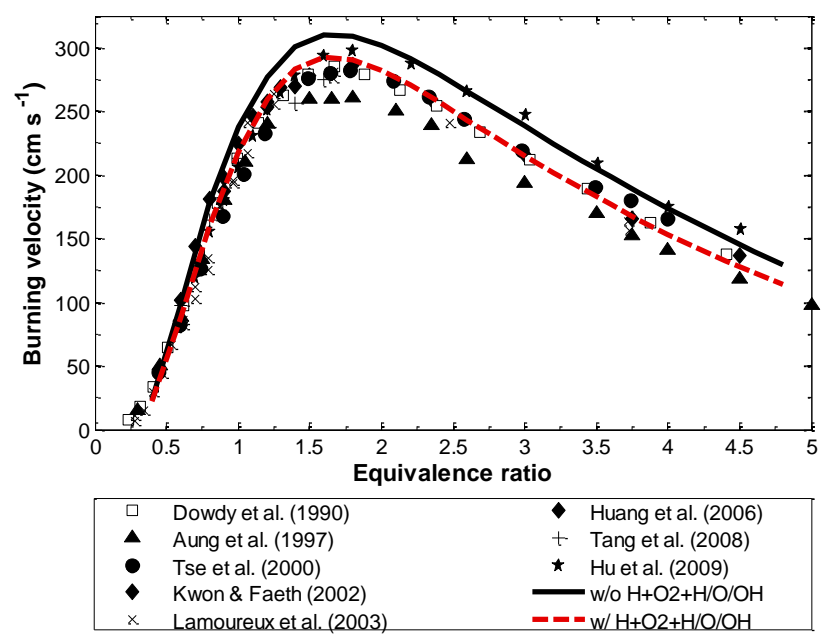

Figure 23: Laminar flame speeds at $1 \mathrm{~atm}$ and $298 \mathrm{~K}$ for $\mathrm{H}_{2} /$ air. Symbols represent experimental data [233-240]; solid black line represents model predictions using an early version of our work-in-progress C0-C3 checmical model [241]; dashed red line represents model predictions using the same C0-C3 model but with $\mathrm{H}+\mathrm{O}_{2}+\mathrm{H} / \mathrm{O} / \mathrm{OH}$ reactions included.

\subsection{Low Temperature Radical Oxidation}

Low temperature chain branching provides a more complex case that combines possible effects from both prompt dissociation and from bimolecular reaction of chemically activated species. Our intial work on this subject for the oxidation of propane [218,219] laid the groundwork for our related exploration of the effects summarized above. For propane, chain branching occurs through the sequence of reactions [175]

$$
\begin{aligned}
& \mathrm{C}_{3} \mathrm{H}_{8}+\mathrm{OH} \rightarrow \mathrm{C}_{3} \mathrm{H}_{7}+\mathrm{H}_{2} \mathrm{O} \\
& \mathrm{C}_{3} \mathrm{H}_{7}+\mathrm{O}_{2} \rightarrow \mathrm{C}_{3} \mathrm{H}_{7} \mathrm{O}_{2} \leftrightarrow \mathrm{C}_{3} \mathrm{H}_{6} \mathrm{OOH} \\
& \mathrm{C}_{3} \mathrm{H}_{6} \mathrm{OOH}+\mathrm{O}_{2} \rightarrow \mathrm{OOC}_{3} \mathrm{H}_{6} \mathrm{OOH} \rightarrow \mathrm{OH}+\mathrm{OC}_{3} \mathrm{H}_{5} \mathrm{OOH} \\
& \mathrm{OC}_{3} \mathrm{H}_{5} \mathrm{OOH} \rightarrow \mathrm{OH}+\mathrm{OC}_{3} \mathrm{H}_{5} \mathrm{O}
\end{aligned}
$$

The $\mathrm{C}_{3} \mathrm{H}_{7}$ radical may be formed hot enough for it to dissociate promptly to either $\mathrm{H}+\mathrm{C}_{3} \mathrm{H}_{6}$ or $\mathrm{CH}_{3}+$ $\mathrm{C}_{2} \mathrm{H}_{4}$, just as discussed above for prompt dissociations of $\mathrm{HCO}$. The relative amounts of $\mathrm{C}_{3} \mathrm{H}_{7} \mathrm{O}_{2}$ and 
$\mathrm{C}_{3} \mathrm{H}_{6} \mathrm{OOH}$ formed in (R12) varies as the energy of chemical activation is collisionally quenched. If the $\mathrm{C}_{3} \mathrm{H}_{6} \mathrm{OOH}+\mathrm{O}_{2}$ reaction is rapid enough, then $\mathrm{C}_{3} \mathrm{H}_{6} \mathrm{OOH}$ may react during this quenching process, implying a deviation from complete thermalization. This deviation affects not only the population of $\mathrm{C}_{3} \mathrm{H}_{6} \mathrm{OOH}$ available for reaction, but also the energy of the $\mathrm{OOC}_{3} \mathrm{H}_{6} \mathrm{OOH}$ adduct. Some of this energy may be conserved in the dissociative step to produce $\mathrm{OC}_{3} \mathrm{H}_{5} \mathrm{OOH}$, which may be hot enough to promptly dissociate.

A combination of master equation and direct dynamics calculations were used to explore the role of non-thermal effects for steps (R12)-(R14) in the oxidation of propyl radical. This analysis concluded that, for combustion conditions, such non-thermal effects are generally quite small $[218,219]$. However, near room temperature the effects are predicted to be significant, and must be accounted for when interpreting low temperature experimental observations [46] such as the experiments of Taatjes and coworkers [207-209].

It is difficult to predict how general such conclusions are because different fuel molecules will have different exothermicities, their different molecular sizes will strongly affect the pressure dependence, and additional complexities arise. For example, for dimethyl ether, the net exothermicity in the sequence from fuel to chain branching is much larger than for propane ( 83.8 versus $55.0 \mathrm{kcal} / \mathrm{mol}$ ), and we predict much more significant non-thermal effects [220]. For larger fuel molecules, the sequence of coupled reactions is even more complex, as there is branching between beta-bond scission and radical oxidation for each of the radicals produced during the breakdown. Furthermore, the addition of a third $\mathrm{O}_{2}$ molecule may contribute to the kinetics [211,212].

\section{Nitrogen Chemistry}

Theory played a key role in Miller and Bowman's landmark examination of nitrogen chemistry [25], with a number of the key steps validated by BAC-MP4 calculations of Melius. This strong theoretical basis allowed for its effective use in numerous developments of NOx removal strategies. One 
aspect of their work involved an enumeration of the key role for $\mathrm{NNH}$ radical in $\mathrm{NO}$ formation and control. The thermal DeNOx process is strongly dependent on the branching $\alpha_{\mathrm{NNH}}=\mathrm{k}_{16} /\left(\mathrm{k}_{15}+\mathrm{k}_{16}\right)$ between the $\mathrm{NNH}+\mathrm{OH}$ and $\mathrm{N}_{2}+\mathrm{H}_{2} \mathrm{O}$ channels in the reaction of $\mathrm{NH}_{2}$ with $\mathrm{NO}$ :

$$
\begin{aligned}
& \mathrm{NH}_{2}+\mathrm{NO} \rightarrow \mathrm{N}_{2}+\mathrm{H}_{2} \mathrm{O} \\
& \mathrm{NH}_{2}+\mathrm{NO} \rightarrow \mathrm{NNH}+\mathrm{OH}
\end{aligned}
$$

Theoretical studies played an important role in validating the $\mathrm{NH}_{2}+\mathrm{NO}$ mechanism, which involves a sequence of steps that ultimately break each of the bonds in the reactants, and in developing quantitative models for the branching [242-245]. For many years, there was considerable debate regarding the lifetime of $\mathrm{NNH}$, with modeling efforts requiring longer lifetimes than appeared feasible theoretically. A recent joint theory and modeling effort finally provided a fully consistent description of the role of $\mathrm{NNH}$ in the thermal DeNOx process [18]. This study also explored the role of the reaction of NNH with O as a high temperature pathway for NO formation.

The accurate determination of branching ratios is one of the more challenging kinetic problems both experimentally and theoretically. Prior theory based models for $\alpha_{\mathrm{NNH}}$ have obtained satisfactory agreement with experimental measurements, but have required significant adjustments in some of the PES parameters (e.g., $4 \mathrm{kcal} / \mathrm{mol}$ for some stationary points) [244,245]. We have reexamined these stationary point energies with our high level ab initio thermochemistry methods (both ANL0 and an even higher-level method termed ANL1 [137]) to explore the consistency of these PES adjustments. The results tabulated in Table 2 show broad consistency with the corresponding modeling adjusted values (cf. Fig. S4 for a schematic diagram illustrating the PES).

\begin{tabular}{|c|c|c|c|c|c|c|c|c|}
\hline $\begin{array}{l}\text { Stationary } \\
\text { Point }\end{array}$ & Label & $\begin{array}{l}\text { BAC- } \\
\text { MP4 }^{\text {b }}\end{array}$ & $\mathrm{G}^{2} \mathrm{M}^{\mathrm{c}}$ & $\begin{array}{l}\operatorname{CCSD}_{(\mathrm{T}) /} \\
\operatorname{aVTZ}^{\mathrm{d}}\end{array}$ & ANLO & ANL1 & Model $^{\mathrm{e}}$ & Model $^{\mathrm{d}}$ \\
\hline $\mathrm{NH}_{2}+\mathrm{NO}$ & $\mathrm{R}$ & 0.0 & 0.0 & 0.0 & 0.0 & 0.0 & & 0.0 \\
\hline $\mathrm{NH}_{2} \mathrm{NO}$ & W1 & -48.1 & -46.7 & & -46.04 & & & \\
\hline
\end{tabular}

Table 2: Stationary point energies for the $\mathrm{NH}_{2}+\mathrm{NO}$ reaction system. ${ }^{\text {a }}$ 


\begin{tabular}{|c|c|c|c|c|c|c|c|c|}
\hline HNNOH;tc & W2a & -47.5 & -46.6 & & -46.04 & & & \\
\hline HNNOH;tt & W2b & -45.5 & -46.0 & & -45.23 & & & \\
\hline HNNOH;cc & W3a & -41.1 & -40.2 & & -45.74 & & & \\
\hline HNNOH;ct & W3b & -39.4 & -46.3 & & -39.73 & & & \\
\hline $\begin{array}{l}\mathrm{NH}_{2} \mathrm{NO}= \\
\mathrm{HNNOH} ; \mathrm{tc}\end{array}$ & $\mathrm{TS} 2$ & -19.7 & -14.8 & -12.1 & -15.45 & -15.55 & -16.0 & -14.1 \\
\hline $\begin{array}{l}\text { HNNOH;tc = } \\
\text { HNNOH;cc }\end{array}$ & TS3 & & -8.1 & -4.4 & -7.91 & -8.04 & -8.8 & -8.4 \\
\hline $\begin{array}{l}\mathrm{HNNOH} ; \mathrm{tt}= \\
\mathrm{HNNOH} ; \mathrm{ct}\end{array}$ & TS4 & -7.0 & -10.9 & -7.8 & -10.71 & -10.75 & -11.8 & -11.8 \\
\hline $\begin{array}{l}\mathrm{HNNOH} ; \mathrm{ct}= \\
\mathrm{N}_{2}+\mathrm{H}_{2} \mathrm{O}\end{array}$ & TS5 & -25.2 & -24.9 & -22.1 & -24.56 & -24.91 & -23.4 & -22.1 \\
\hline $\begin{array}{l}\mathrm{HNNOH} ; \mathrm{ct}= \\
\mathrm{N}_{2} \mathrm{O}+\mathrm{H}_{2}\end{array}$ & TS6 & & 2.6 & & 2.57 & & 2.6 & \\
\hline $\mathrm{N}_{2}+\mathrm{H}_{2} \mathrm{O}$ & $\mathrm{P} 1$ & -124.0 & -124.3 & -121.4 & & & & \\
\hline $\mathrm{NNH}+\mathrm{OH}$ & $\mathrm{P} 2$ & 2.4 & 3.6 & 2.5 & 2.18 & $2.12^{\mathrm{f}}$ & -0.6 & 0.9 \\
\hline
\end{tabular}

\footnotetext{
${ }^{\text {a }}$ All energies include corresponding ZPE corrections.

${ }^{\mathrm{b}}$ From [242].

${ }^{\mathrm{c}}$ From [243].

${ }^{\mathrm{d}} \mathrm{CCSD}(\mathrm{T}) / \mathrm{aug}-\mathrm{cc}-\mathrm{pVTZ} / / \mathrm{CCSD}(\mathrm{T}) / \mathrm{cc}-\mathrm{pVTZ}$ and model from [245].

${ }^{\mathrm{e}}$ From [244].

${ }^{\mathrm{f}}$ This reaction enthalpy can be converted to an NNH $0 \mathrm{~K}$ enthalpy of formation of $60.11 \mathrm{kcal} / \mathrm{mol}$ through the ATcT values for the enthalpy of formation of $\mathrm{NH}_{2}, \mathrm{NO}$, and $\mathrm{OH}$. This value is in reasonable agreement with the value of $60.4 \mathrm{kcal} / \mathrm{mol}$ employed in our prior modeling effort [18].
}

To further explore the adequacy of these predictions we have used them to generate new fully a priori rate predictions for the $\mathrm{NH}_{2}+\mathrm{NO}$ reaction. These studies employ the ANL1 stationary point properties, improved VRC-TST predictions for the barrierless radical-radical channels, and new variational TST treatments with Eckart tunneling for the other channels, as detailed in the supplementary material. There is again some ambiguity in the optimal MEP for the $\mathrm{NNH}+\mathrm{OH}$ exit channel, particularly at short separations (cf. Fig. S5), which affects high temperature rate predictions. Here, we report calculations based on both a CASPT2 MEP and an MRCI+Q MEP.

Notably, as illustrated in Fig. 24, the two theoretical predictions provide what might be considered as two separate near optimal interpolations of the somewhat scattered experimental data [246-261] from $500 \mathrm{~K}$ and higher. The MRCI+Q based predictions lie somewhat higher than the optimal line from our prior modeling study [18], but do stay well within the range of the experimental data. 
Meanwhile, the CASPT2 based predictions more closely follow the modeling based line, but fall below the average experimental result. It would be interesting to repeat the modeling work of [18] to explore the consistency of these two predictions with regard to global observations. For now we note that the success of that effort hinged on the use of a relatively low value for $\alpha_{N N H}$. Thus, the MRCI+Q predictions would likely be problematic, while the CASPT2 results should be fine.

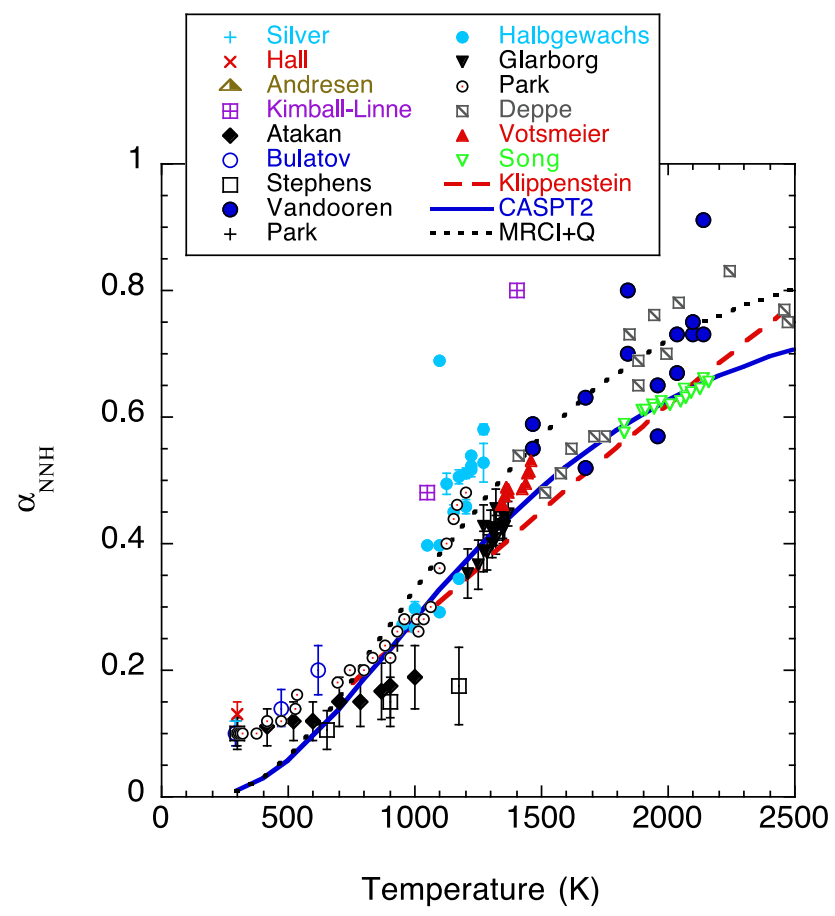

Figure 24: Plot of the temperature dependence of the branching to $\mathrm{NNH}+\mathrm{OH}$ in the $\mathrm{NH}_{2}+\mathrm{NO}$ reaction. The symbols denote various experimental results [246-261], while the solid, dotted, and dashed lines denote the present a priori theoretical predictions for the CASPT2 or MRCI+Q MEPs and the past optimized model values from [18], respectively.

The discrepancy at low temperature suggests that the enthalpy of reaction for (R16) remains problematic. Unless the predicted endothermicity is lower by at least $1 \mathrm{kcal} / \mathrm{mol}$, which is extremely unlikely given the error distribution reported in Fig. 9, the predicted room temperature branching is simply too low. Thus, the discrepancy must imply some experimental artifact such as insufficient 
cooling of reactant radicals prior to reaction, or some novel phenomenon, or some unexpected theoretical shortcoming.

Quantitative theoretical models such as this provide a means for exploring the possibility of pressure dependence in the kinetics for pressures that are inaccessible for experimental study. The deep wells on the PES (> $45 \mathrm{kcal} / \mathrm{mol}$ ) may allow for some stabilization of some of the intermediates, but the low energies of the intermediate saddle points and the small molecular size hamper this stabilization. Our calculations suggest that for $1100 \mathrm{~K}$ (i.e., a key temperature for thermal DeNOx), this stabilization begins to be significant at about 30 atm, with about 5-10\% stabilization. By 100 atm this stabilization has increased to $\sim 25 \%$. This stabilization also increases $\alpha_{N N H}$, because the lower energies, which contribute more to the $\mathrm{N}_{2}+\mathrm{H}_{2} \mathrm{O}$ flux, are preferentially stabilized. But this increase is mild; i.e., an increase from 0.38 to 0.40 on increasing the pressure from 1 to 100 atm at $1100 \mathrm{~K}$.

\section{Nonadiabaticity}

Nonadiabatic reactions, where, for example, the electronic spin of the products is different from that of the reactants, are occasionally of importance in combustion. For example, the $\mathrm{O}\left({ }^{3} \mathrm{P}\right)$ atom, whose reactions are particularly important under lean conditions, commonly reacts with unsaturated hydrocarbons, at least in part, through intersystem crossing to a singlet state [262]. Statistical theories may be generalized to treat such nonadiabatic processes [263,264], taking a form similar to RRKM theory, but with the state count evaluated as a phase space average over an approximate crossing seam (where the two electronic states are degenerate) instead of the TS dividing surface. The integrand in this phase space average is modified by a factor corresponding to the nonadiabatic transition probability, which is typically evaluated with a Landau-Zener weak spin-orbit coupling model.

One of the first applications of such a nonadiabatic statistical treatment in combustion was to the reaction of $\mathrm{CH}$ with $\mathrm{N}_{2}$ [264]. This reaction, which is a central reaction in the Fenimore mechanism for prompt NO formation [25], was long presumed to occur through intersystem crossing from the doublet 
to a quartet state [12] to produce $\mathrm{N}\left({ }^{4} \mathrm{~S}\right)+\mathrm{HCN}$. However, the analysis of Cui et al. clearly demonstrated that, due to a slow intersystem crossing rate, the reaction to produce $\mathrm{HCN}+\mathrm{N}$ was much slower than had been presumed and thus could not explain the observed prompt NO formation [264]. Subsequently, Moskaleva and Lin suggested a role for the spin-conserving NCN $+\mathrm{H}$ channel $[265,266]$, but modeling studies incorporating their rate predictions underpredicted the amount of prompt NO by a factor of 6 [267]. This discordancy was resolved by Harding and coworkers, who used high-level multireference electronic structure methods to obtain more quantitative predictions for the rate to produce $\mathrm{NCN}+\mathrm{H}$ [268]. Their a priori TST predictions, which were about an order of magnitude higher than those of Moskaleva and Lin, accurately reproduced high temperature experimental rate data [269], extending it down to temperatures of relevance to prompt NO, and also yielding markedly improved descriptions of prompt NO formation in subsequent modeling studies [26,27].

In recent work, Jasper has explored the kinetics of the reaction of $\mathrm{O}\left({ }^{3} \mathrm{P}\right)$ with $\mathrm{CO}$ to produce $\mathrm{CO}_{2}$ [270,271]. These analyses extended the statistical approach with considerations of multidimensional couplings of the nuclear motions and the spin-crossing dynamics, and with the implementation of surface-hopping trajectory-based schemes. Their predicted high pressure limit is about an order of magnitude larger than the early theoretical estimate of Troe [272], which is commonly employed in modeling studies.

The reaction of $\mathrm{O}\left({ }^{3} \mathrm{P}\right)$ with $\mathrm{C}_{2} \mathrm{H}_{4}$, which is representative of the reaction of $\mathrm{O}\left({ }^{3} \mathrm{P}\right)$ with unsaturated hydrocarbons, commonly shows up in sensitivity analyses under lean conditions, and is particular important in the oxidation of ethylene [273]. Nguyen et al. provided an extensive theoretical analysis of this reaction based on a detailed mapping of both the triplet and singlet PESs [274]. Due to the difficulty of accurately predicting the intersystem crossing rate, Nguyen et al. assumed a constant (independent of energy and temperature) branching from the triplet to the singlet state, with this branching normalized to agree with room temperature experimental observations. In a submission to this symposium, Jasper and coworkers reanalyzed this kinetics utilizing nonadiabatic TST to predict the 
intersystem crossing rates [275]. This analysis also employs direct trajectory simulations to predict the incipient products of the intersystem crossing and analogues of the ANL0 thermochemistry approach [137] in a reevaluation of the PES. This analysis predicts $\mathrm{CH}_{2} \mathrm{CHO}+\mathrm{H}$ and ${ }^{3} \mathrm{CH}_{2}+\mathrm{CH}_{2} \mathrm{O}$ as the primary products at high temperature (> $1500 \mathrm{~K}$ ), with little contribution from $\mathrm{CH}_{3}+\mathrm{HCO}$ in contrast with the predictions of Nguyen et al [274]. Notably, these changes lead to a factor of 2-3 reduction in the predicted ignition delay for $\mathrm{C}_{2} \mathrm{H}_{4}$ with our work-in-progress chemical model [241] for $\mathrm{C} 0$ - $\mathrm{C} 3$ fuels, as illustrated in Fig. 25.

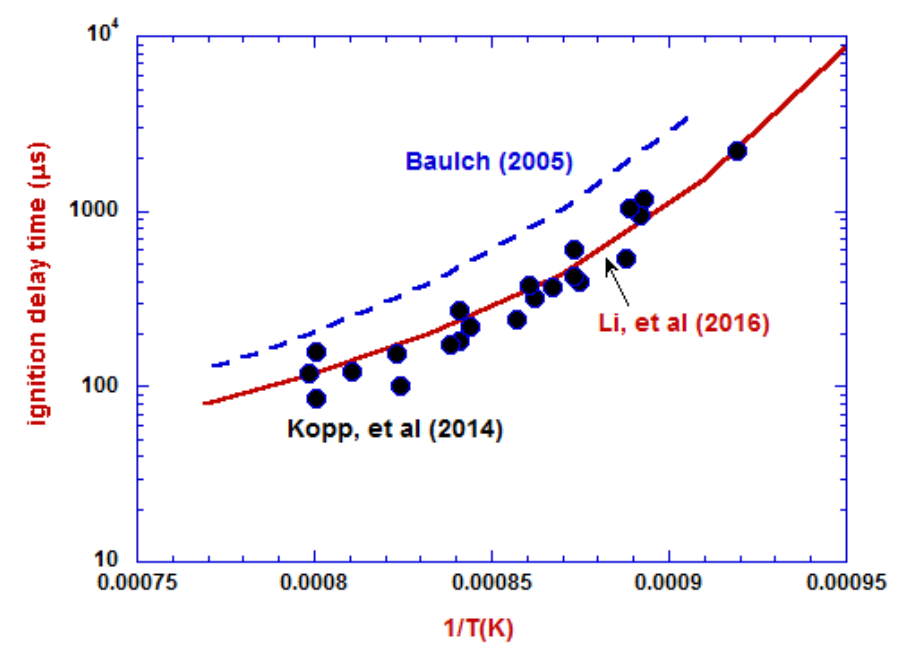

Figure 25: Predicted ignition delay for the fuel lean experimental conditions of Kopp et al. [273] ( $p=$ $1.1 \mathrm{~atm}, \phi=0.5$ ) employing either the Baulch et al. [276] recommendations for the $\mathrm{C}_{2} \mathrm{H}_{4}+\mathrm{O}$ rate and branching or the predictions from the work of Li et al. [275].

\section{PAH Growth and Decay: HACA Mechanism}

The growth of PAHs from small linear hydrocarbons to large multi-ring aromatics is a complex process that involves a bewildering array of possible pathways. These pathways generally involve a sequence of reactions that occur over complicated potential energy surfaces with multiple wells and multiple bimolecular products. For many of these reactions there is little experimental information available, with that data generally being far from sufficient to map out the details of the chemical transformations that occur. Thus, electronic structure theory has played an extremely important role in 
enumerating the properties of the stationary points for specific proposed reactions. Our AI-TST-ME study of the $\mathrm{C}_{3} \mathrm{H}_{3}+\mathrm{C}_{3} \mathrm{H}_{3}$ reaction, which provides the most important pathway to the formation of the first aromatic ring, illustrates the complexity of the underlying "potential energy surfaces", with 12 wells, 3 bimolecular products, and 21 TSs required in order to incorporate all kinetically relevant pathways [277]. Many other PAH related PES are even more complex, as can be seen, for example, in numerous studies from Mebel and from Cavallotti.

Although most PAH growth reactions exhibit a strong pressure dependence at combustion temperatures, their kinetics has commonly been modeled with high-pressure limits. The desire to obtain proper pressure dependent predictions for the $\mathrm{C}_{3} \mathrm{H}_{3}+\mathrm{C}_{3} \mathrm{H}_{3}$ reaction was the driving force behind our development of the CSE based master equation analysis, with initial attempts to explore the kinetics with traditional exponential decay considerations stymied by the complexities of multiple overlapping decays. The implementation of the CSE approach for this reaction yielded pressure dependent predictions that were in good agrement with a wide variety of experimental data [277].

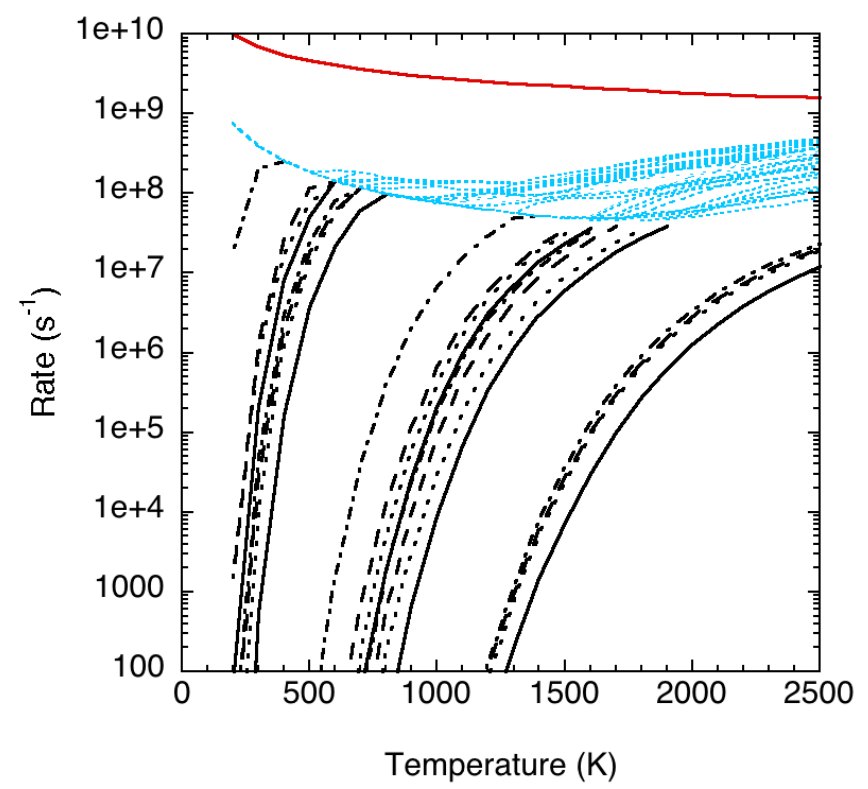

Figure 26: Temperature dependence of the eigenvalues of the master equation for the xylyl system at a pressure of $1 \mathrm{~atm}$. The black lines denote the lowest 20 eigenvalues, which correspond to the CSEs at low temperature. At higher temperatures these eigenvalues merge with the sea of IEREs, the lowest ten 
of which are depicted with blue dotted lines. The red line denotes the constant pressure collision rate, which serves as an effective upper bound for the IEREs.

The complexity of the eigenvalue spectrum for an AI-TST-ME study of xylyl decomposition, which has 20 wells, 7 products, and 36 TSs is illustrated in Fig. 26 [278]. Notably, many of the eigenvalues merge with the quasicontinuum in exactly the temperature range of relevance to $\mathrm{PAH}$ growth kinetics in the combustion environment (i.e., near $1500 \mathrm{~K}$ ). Our recently developed master equation code (MESS), with its automatic analysis of the merging phenomenon, provides a major step forward in our ability to predict the kinetics for such complex reactions. Nevertheless, the merging phenomenon still creates some discontinuities in the phenomenological rate constants, due to the changing definition of what a given species is. We are currently exploring means to automatically produce meaningful analytic continuations of all relevant rate coefficents beyond the merging temperatures, in order to obtain a self-consistent description of the kinetics for utility in comprehensive modeling studies. In the meantime, reasonable kinetics models can often be obtained through consideration of the kinetics for a select set of key intermediates. For example, in the xylyl decomposition, consideration of only the 4 deepest wells (o-, m-, p-xylyl, and a five-membered ring species) provides a complete set of kinetic data that is valid from $1500 \mathrm{~K}$ to about $2500 \mathrm{~K}$, which is precisely the range of temperatures of interest to soot modeling.

The HACA mechanism for ring expansion is a central component of all PAH/soot formation models. Remarkably, current models for this process generally employ the early AM1/RRKM calculations of Wang and Frenklach [279] in representing the pressure dependence of this kinetics, apparently due to the absence of any higher-level calculations. In a submission to this symposium, we collaborated with Mebel in predicting the pressure dependence of the kinetics for the key steps in various HACA related mechanisms for converting phenyl to naphthalene [47]. These AI-TST-ME calculations employed G3(MP2,CC) electronic structure properties.

A sample comparison of the predicted pressure dependences for reaction (R17) 


$$
\text { c- }\left(\mathrm{C}_{6} \mathrm{H}_{4}\right) \mathrm{CCH}+\mathrm{C}_{2} \mathrm{H}_{2} \rightarrow \text { naphthyne }+\mathrm{H}
$$

is provided in Fig. 27. Similar order-of-magnitude sorts of discrepancies exist for many other channels, which is not too surprising given the level of electronic structure theory that had to be relied upon in their pioneering work, and the limitations of modified strong-collider assumptions in treating the pressure dependent kinetics of complex systems. We are continuing this effort in further collaborations with Mebel and Cavallotti, in an attempt to provide more reliable AI-TST-ME temperature and pressure dependent rate coefficients for all reactions of relevance to the growth from the first to the second aromatic ring. Such studies also serve as prototypes for the continued growth to larger PAHs.

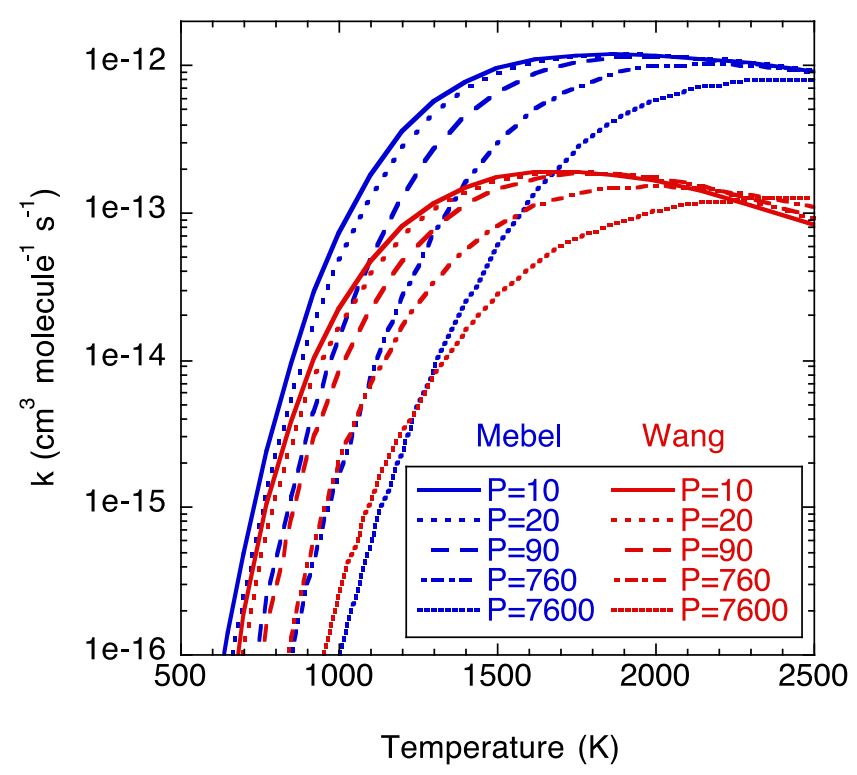

Figure 27: Comparison of the predicted temperature and pressure dependence of the rate coefficient for c- $\left(\mathrm{C}_{6} \mathrm{H}_{4}\right) \mathrm{CCH}+\mathrm{C}_{2} \mathrm{H}_{2} \rightarrow$ naphthyne $+\mathrm{H}$ from the calculations of Mebel et al. [47] with the earlier calculations of Wang and Frenklach [279].

\section{Transport}

Transport properties such as diffusion coefficients, viscosities, and thermal conductivities are also an integral part of combustion mechanisms. The informative review of Brown and coworkers [280] 
noted the utility of transport property calculations and emphasized the need for improved mixture rules, additional data for radicals, and general updating of the databases. In response to this need, we have recently employed $\operatorname{CCSD}(\mathrm{T}) /$ aug-cc-pVTZ calculations to predict the dipole moments and polarizabilities for a large set of core combustion species [281]. Recent studies from Jasper et al. [282, 283] and Dagdigian et al. [284,285] illustrate the high degree of accuracy that can now be obtained in first principles evaluations of transport properties. Earlier work by Middha et al. [286] demonstrated the importance of employing accurate representations for the diffusion coefficients, particularly for key properties such as those involving the interaction of $\mathrm{H}$ atoms with bath gas molecules. These studies again lead to the conclusion that shortcomings in the allowed representations are hampering the accuracy of the modeling. For example, presumed mixture rules do not allow for a quantitative reproduction of high accuracy calculations of binary diffusion coefficients.

\section{Software}

We have recently released a software package termed PAPR that provides access to many of the master equation, statistical theory, and dynamical methods utilized in this work. The master equation system solver (MESS) [43] converts ab initio and RRKM data into thermal rates. The VaReCoF code [287] couples with electronic structure codes such as MOLPRO and GAUSSIAN to produce high accuracy rate constants for barrierless reactions. The DiNT code [288] provides dynamical routines for evaluating quantities such as the energy transfer rates and nonadiabatic dynamics. NST provides the means for implementing nonadiabatic statistical theory. OneDMin is a code for calculating LennardJones parameters. TB+exp/6 provides a PES subroutine for $\mathrm{C}_{\mathrm{x}} \mathrm{H}_{\mathrm{y}}+\mathrm{M}$ collisions. A heavily modifed version of the older VariFlex master equation code [289] was utilized in the 2DME calculations discussed here. All of these codes, except the 2DME version of VariFlex, have been made available as freeware [290]. 


\section{Conclusions}

It is interesting to review the progression in perspectives of the role of theory in combustion over the last twenty years. In his 1996 plenary review [12], Jim Miller took the perspective that "The power of theoretical chemistry and mathematical modeling is only beginning to be felt in combustion. The first 10 years or so of the next century should see an explosion of knowledge and predictive power that most of us never dreamed would occur.” In his 2002 plenary review [13], Al Wagner reviewed a number of examples of this growing role of theoretical chemical kinetics, concluding with a perspective on the continued need for "a close interaction between theory and experiment. This interaction should intensify in the future as faster computers and more efficient theoretical methods allow more realistic calculations." Most recently, in 2005, Miller, Pilling, and Troe again reviewed a number of important contributions from theory [14], but still had the perspective that "one has still a long way to go before rate coefficients and branching ratios as a function of temperature, pressure, and bath gas can be quantitatively characterized. At this stage, modern quantum chemistry and reaction dynamics will play a crucial role in the detailed understanding, although a fine-tuning of input parameters by fitting to experimental observations for long will still be required." They did, however, note that "the situation from the side of theory improves visibly." In 2011 as part of my review at the US Combustion meeting, I suggested that "in the near future, with a concerted effort, it will likely be possible to make a priori predictions of the kinetics for many reactions to within about 20-30\%."

In this review, I have tried to demonstrate that this long sought for a priori prediction of rate constants with accuracies that rival those of high quality experimental studies is now feasible for many important classes of combustion reactions. This transformation from an empirical to a predictive science is a result of methodological advances in electronic structure, dynamics, and kinetics theories, each of which take advantage of ever expanding computational capabilities. Such high-accuracy predictions (with $2 \sigma$ uncertainties of a factor of 1.5 or better) require careful attention to the details of the calculations and are generally limited to relatively small molecules, (e.g., ones that contain 6 or fewer 
heavy atoms), but still cover prototypes for the key reactions in combustion. In some instances, such as simple barrierless association reactions, single-channel addition/dissociation reactions, and simple abstractions, the uncertainties do appear to be as low as 20-30\%.

The future holds prospects for making similar quality predictions for much larger and more complex systems through thoughtful extensions of the very detailed studies for prototypical reactions. Currently, high accuracy predictions for such systems continue to be constrained primarily by the difficulty of applying high accuracy electronic structure methods to larger systems. The results obtained for the smaller protypical systems should be of great value in tuning simplified electronic structure methods to obtain effective treatments of larger systems. The need to consider numerous torsional degrees of freedom also presents some difficulties. Fortunately, since most of the torsional modes are effectively spectator modes that are not directly involved in the chemistry, it should be feasible to develop appropriate approximate treatments from these prototypical results [291-293]. Monte Carlo sampling and the free energy methods employed in the biochemical literature are likely to play a role in these extensions.

The ability to make high accuracy theoretical predictions presents various opportunities and challenges for combustion modelers. Large scale automation of theoretical calculations, which is clearly on the horizon [294-298], would remove much of the ambiguity and arbitrariness involved in modeling optimization/fitting. However, limitations in some of the basic tenets of chemical modeling, which are essentially unchanged from the 1970s, have been shown to have significant effects on the predicted global chemistry. Thus, a model that implements data from fully accurate phenomenological rate laws might not reproduce global observables. Most simply, in many instances, the methods for representing the data are more limited in accuracy than the predictions. More importantly, the energy distributions are not always well equilibrated prior to reaction. At high temperatures, chemical species merge together and cannot really be thought of as distinct species. At pressures near 100 atm and beyond, the standard model of isolated binary collisions gradually becomes inapplicable. Each of these challenges has 
important ramifications for mechanism optimization work, which implicitly assumes that the shortcomings are in the parameters being optimized and not in the representations and assumptions. The next decade should see important progress in moving beyond these foundational assumptions of kinetic modeling, and theory will play an important role in this progress.

Expanding on Jim Miller's 1996 statement, I would conclude that the power of theoretical chemical kinetics is just beginning to be utilized in combustion. Over the next 5-10 years the development of chemical mechanisms for combustion is likely to transform into primarily an exercise in applied theoretical chemical kinetics. As Al Wagner concluded, a coupling "with advances in computational fluid mechanics will [then] usher in the kind of powerful and realistic simulations of practical combustion devices that are needed to help meet the pollution and efficiency requirements of the future."

\section{Acknowledgements}

This material is based upon work supported by the U.S. Department of Energy, Office of Science, Office of Basic Energy Sciences, Division of Chemical Sciences, Geosciences, and Biosciences under Contract No. DE-AC02-06CH11357. This support largely arose from our core Gas Phase Chemical Physics grant, with software development supported by the AITSTME project as part of the Predictive Theory and Modeling component of the Materials Genome Initiative, other collaborations with Sandia supported through the Argonne-Sandia Consortium on High Pressure Combustion Chemistry, and support for the propane ignition modeling through the Energy Frontier Research Center for Combustion Science, all within DOE-BES. I also gratefully acknowledge numerous fruitful and enjoyable discussions with my colleagues, postdocs, and visiting faculty and students. Most notably, Jim Miller and Larry Harding have taught me all that I know about combustion chemistry and electronic structure theory, respectively. Jim has also been a partner in crime in our master equation developments, while Larry has joined with me in coupling ab initio electronic structure theory with dynamical theories. Ahren Jasper, whose work on 
nonadiabatic reactions and transport properties is reviewed here, was also the driving force behind our work on the two-dimensional master equation plus dynamics approach, and has generally contributed to the intellectual foundations of this work. Yuri Georgievskii has contributed through his deep knowledge of chemical physics and his high-level programming skills. The insight of these four scientists pervades this review. Mike Burke, Franklin Goldsmith, Nicole Labbe, Alexander Landera, and Marco Verdicchio have amply demonstrated Mike's facetious truism - postdocs are not students because they don't learn from their advisor, rather the advisor learns from them. Among other things, Mike and Franklin initiated our work on non-thermal effects in combustion, Mike developed his multiscale informatics approach, Nicole led the exploration of the effects of prompt dissociations, Franklin was largely responsible for our propyl oxidation and direct dynamics studies, Alex contributed to our knowledge of the chemistry in nitrogen containing systems, while Marco further developed and applied the two-dimensional master equation approach. The present research has also benefitted immensely from long-term interactions with Craig Taatjes, Joe Michael, Robert Tranter, and Nils Hansen whose experiments have repeatedly pushed forward the frontiers of our theoretical analyses. Finally, Raghu Sivaramakrishnan, Peter Glarborg, and Bill Green have led the way in a number of the modeling efforts summarized here, Alison Tomlin and Mike Davis have introduced me to the importance of understanding uncertainties, while Branko Ruscic has shown me the beauty and value of high accuracy thermochemistry, and interactions with Alex Mebel and Carlo Cavallotti are advancing my understanding of PAH chemistry. 


\section{References}

[1] J.E. Dec, Proc. Comb. Inst. 32 (2009) 2727-2742.

[2] R.D. Reitz, G. Duraisamy, Prog. Energy Comb. Sci. 46 (2015) 12-71.

[3] F.L. Dryer, Proc. Comb. Inst. 35 (2015) 117-144.

[4] M.B. Toftegaard, J. Brix, P.A. Jensen, P. Glarborg, A.D. Jensen, Prog. Energy Comb. Sci. 36 (2010) 581-625.

[5] A. Cavaliere, M. de Joannon, Prog. Energy Comb. Sci. 30 (2004) 329-366.

[6] M. Chaos, F.L. Dryer, Comb. Flame 152 (2008) 293-299.

[7] P. Pal, A.B. Mansfield, P.G. Arias, M.S. Wooldridge, H.G. Im, Comb. Theory Modelling 19 (2015) 587-601.

[8] K. Anand, R.D. Reitz, E. Kurtz, W. Willems, Energy Fuels 27 (2013) 7827-7842.

[9] S. Som, D.E. Longman, Z.Y. Luo, M. Plomer, T.F. Lu, P.K. Senecal, E. Pomraning, J. Energy Res. Tech. - Trans ASME, 134, (2012) 032204.

[10] R.D. Reitz, Comb. Flame 160 (2013) 1-8.

[11] Virtual Engine Research Institute and Fuels Initiative. http://verifi.anl.gov.

[12] J.A. Miller, Proc. Comb. Inst. 26 (1996) 461-480.

[13] A.F. Wagner, Proc. Comb. Inst. 29 (2002) 1173-1200.

[14] J.A. Miller, M.J. Pilling, J. Troe, Proc. Comb. Inst. 30 (2005) 43-88.

[15] Y. Sakai, A. Miyoshi, M. Koshi, W.J. Pitz, Proc. Comb. Inst. 32 (2009) 411-418.

[16] S. Sharma, M.R. Harper, W.H. Green, Comb. Flame 157 (2010) 1331-1345.

[17] A. Matsugi, A. Miyoshi, Proc. Comb. Inst. 34 (2013) 269-277.

[18] S.J. Klippenstein, L.B. Harding, P. Glarborg, J.A. Miller, Comb. Flame 158 (2011) 774-789.

[19] S.S. Merchant, E.F. Zanoelo, R.L. Speth, M.R. Harper, K.M. Van Geem, W.H. Green, Comb. Flame 160 (2013) 1907 1929.

[20] J.W. Allen, A.M. Scheer, C.W. Gao, S.S. Merchant, S.S. Vasu, O. Welz, J.D. Savee, D.L. Osborn, C. Lee, S. Vranckx, Z. Wang, F. Qi, R.X. Fernandes, W.H. Green, M.Z. Hadi, C.A. Taatjes, Comb. Flame 161 (2014) 711-724.

[21] C.W. Gao, A.G. Vandeputte, N.W. Yee, W.H. Green, R.E. Bonomi, G.R. Magoon, H.-W. Wong, O.O. Oluwole, D.K. Lewis, N.M. Vandwiele, K.M. Van Geem, Comb. Flame, 162 (2015) 3115-3129.

[22] L.-S. Tran, R. De Bruycker, H.-H. Carstensen, P.-A. Glaude, F. Monge, M.U. Alzueta, R.C. Martin, F. Battin-Leclerc, K.M. Van Geem, G.B. Marin, Comb. Flame 162 (2015) 4283-4303.

[23] H. Hashemi, J. M. Christensen, S. Gersen, H. Levinsky, S.J. Klippenstein, P. Glarborg, Comb. Flame, in press (2016).

[24] C.K. Westbrook, F.L. Dryer, Prog. Energy Comb. Sci. 10 (1984) 1-57.

[25] J.A. Miller, C.T. Bowman, Prog. Energy Comb. Sci. 15 (1989) 287-338.

[26] J.A. Sutton, J.W. Fleming, Comb. Flame 154 (2008) 630-636.

[27] A.A. Konnov, Comb. Flame 156 (2009) 2093-2105.

[28] M.P. Burke, Int. J. Chem. Kin. 48 (2016) 212-235.

[29] W.K. Metcalfe, S.M. Burke, S.S. Ahmed, H.J. Curran, Int. J. Chem. Kinet. 45 (2013) 638-675.

[30] S.M. Burke, W. Metcalfe, O. Herbinet, F. Battin-Leclerc, F. M. Haas, J. Santner, F. L. Dryer, H. J. Curran, Comb. Flame 161 (2014) 2765-2784.

[31] N. Donohoe, A. Heufer, W.K. Metcalfe, H.J. Curran, M.L. Davis, O. Mathieu, D. Plichta, A. Morones, E.L. Petersen, F. Guthe, Comb. Flame 161 (2014) 1432-1443.

[32] H. Wang, X. You, A.V. Joshi, S.G. Davis, A. Laskin, F. Egolfopoulos, C.K. Law, USC Mech Version II. HighTemperature Combustion Reaction Model of H2/CO/C1-C4 Compounds. http://ignis.usc.edu/USC_Mech_II.htm, May 2007.

[33] J.A. Miller, S.J. Klippenstein, S.H. Robertson, M.J. Pilling, R. Shannon, J. Zador, A.W. Jasper, C.F. Goldsmith, M.P. Burke, J. Phys. Chem. A 120 (2016) 306-312.

[34] The rate constant for an irreversible dissociation is a good approximation to that for the reversible dissociation system as shown in J.A. Miller, S.J. Klippenstein, J. Phys. Chem. A 108 (2004) 8296-8306.

[35] R.G. Gilbert, S.C. Smith, Theory of Unimolecular and Recombination Reactions, Blackwell, Oxford, 1990.

[36] K.A. Holbrook, M.J. Pilling, S.H. Robertson, Unimolecular Reactions, $2^{\text {nd }}$ Ed., John Wiley, Chichester, 1996.

[37] W. Tsang, V. Bedanov, M.R. Zachariah, J. Phys. Chem. 100 (1996) 4011-4018.

[38] W. Tsang, V. Bedanov, M.R. Zachariah, Ber. Bunsenges. Phys. Chem. 101 (1997) 491-499.

[39] N.J. Labbe, R. Sivaramakrishnan, C.F. Goldsmith, Y. Georgievskii, J.A. Miller, S.J. Klippenstein J. Phys. Chem. Lett. 7 (2016) 85-89.

[40] This prescription is actually forced on us by the definition of phenomenological reactions, which extends through internal energy relaxation of the products.

[41] S.J. Klippenstein, J.A. Miller, J. Phys. Chem. A 106 (2002) 9267-9277.

[42] J.A. Miller, S.J. Klippenstein, J. Phys. Chem. A 110 (2006) 10528-10544.

[43] Y. Georgievskii, J.A. Miller, M.P. Burke, S.J. Klippenstein, J. Phys. Chem. A 117 (2013) 12146-12154.

[44] J.A. Miller, S.J. Klippenstein, Phys. Chem. Chem. Phys. 15 (2013) 4744-4753.

[45] C.F. Goldsmith, W.H. Green, S.J. Klippenstein, J. Phys. Chem. A 116 (2012) 3325-3346. 
[46] M.P. Burke, C.F. Goldsmith, S.J. Klippenstein, O. Welz, H. Huang, I.O. Antonov, J.D. Savee, D.L. Osborn, J. Zador, C.A. Taatjes, and L. Sheps, J. Phys. Chem. A 119 (2015) 7095-7115

[47] A.M. Mebel, Y. Georgiesvkii, A.W. Jasper, S.J. Klippenstein, Temperature- and Pressure-Dependent Rate Coefficients for the HACA Pathways from Benzene to Naphthalene. Proc. Comb. Inst. 36, submitted (2016).

[48] D.G. Truhlar, B.C. Garrett, S.J. Klippenstein, J. Phys. Chem. 100 (1996) 12771-12800.

[49] L.B. Harding, S.J. Klippenstein, A.W. Jasper, Phys. Chem. Chem. Phys. 9 (2007) 4055-4070.

[50] J.D. Watts, J. Gauss, R.J. Bartlett, J. Chem. Phys. 98 (1993) 8718-8733.

[51] R.G. Parr, W. Yang, Density-Functional Theory of Atoms and Molecules, Oxford, 1989.

[52] Y. Zhao, D.G. Truhlar, Theor. Chem. Acc. 120 (2008) 215-241.

[53] S. Grimme, J. Chem. Phys. 124 (2006) 034108.

[54] S. Grimme, J. Antony, S. Ehrlich, H. Krieg, J. Chem. Phys. 132 (2010) 154104.

[55] S.J. Klippenstein, J. Chem. Phys. 96 (1992) 367-371.

[56] M.A. Hanning-Lee, N.J.B. Green, M.J. Pilling, S.H. Robertson, J. Phys. Chem. 97 (1993) 860-870.

[57] Y. Feng, J.T. Niiranen, A. Bencsura, V.D. Knyazev, D. Gutman, W. Tsang, J. Phys. Chem. 87 (1993) 871-880.

[58] J.A. Miller, S.J. Klippenstein, C. Raffy, J. Phys. Chem. A 106 (2002) 4904-4913.

[59] J.A. Miller, S.J. Klippenstein, Phys. Chem. Chem. Phys. 6 (2004) 1192-1202.

[60] A.W. Jasper, J.A. Miller, J. Phys. Chem. A, 113 (2009) 5612-5619.

[61] A.W. Jasper, C.M. Oana, J.A. Miller, Proc. Comb. Inst. 35 (2015) 197-204.

[62] B. Ruscic, R.E. Pinzon, M.L. Morton, G. von Laszevski, S.J. Bittner, S.G. Nijsure, K.A. Amin, M. Minkoff, A.F. Wagner, J. Phys. Chem. A 108 (2004) 9979-9997.

[63] C.F. Goldsmith, A.S. Tomlin, S.J. Klippenstein, Proc. Comb. Inst. 34 (2013) 177-185.

[64] A.W. Jasper, N. Hansen, Proc. Comb. Inst. 34 (2013) 279-287.

[65] M.P. Burke, S.J. Klippenstein, L.B. Harding, Proc. Comb. Inst., 34 (2013) 547-555.

[66] M.P. Burke, F.L. Dryer, Y. Ju, Proc. Combust. Inst. 33 (2011) 905-912.

[67] G.A. Pang, D.F. Davidson, R.K. Hanson, Proc. Combust. Inst. 32 (2009) 181-188.

[68] G. Mittal, C.-J. Sung, R.A. Yetter, Int. J. Chem. Kinet. 38 (2006) 516-529.

[69] G.H. Abd-Alla, Energy Conv. Manag. 43 (2002) 1027-1042.

[70] M. Zheng, G.T. Reader, J.G. Hawley, Energy Conv. Manag. 45 (2004) 883-900.

[71] M.P. Burke, M. Chaos, Y.G. Ju, F.L. Dryer, S.J. Klippenstein, Int. J. Chem. Kinet. 7 (2012) 444-474.

[72] A.W. Jasper, K.M. Pelzer, J.A. Miller, E. Kamarchik, L.B. Harding, S.J. Klippenstein, Science 346 (2014) 1212-1215.

[73] A.W. Jasper, J.A. Miller, J. Phys. Chem. A 115 (2011) 6438-6455.

[74] S.J. Klippenstein, Y. Georgievskii, L.B. Harding, Proc. Comb. Inst. 29 (2002) 1229-1236.

[75] M. Verdicchio, A.W. Jasper, M.P. Burke, K.M. Pelzer, J.A. Miller, S.J. Klippenstein, A Priori Pressure-Dependent Kinetics for the $\mathrm{H}+\mathrm{O}_{2}(+\mathrm{M}) \rightarrow \mathrm{HO} 2(+\mathrm{M})$ Reaction, manuscript in preparation (2016).

[76] L.B. Harding, S.J. Klippenstein, H. Lischka, R. Shepard, Theor. Chem. Acc. 133 (2013) 1429-1435.

[77] J. Troe, V. G. Ushakov, Chem. Phys. 346 (2008) 186-192.

[78] J. Troe, V. G. Ushakov, Chem. Phys. 346 (2008) 193-197.

[79] M.J. Kurylo, J. Phys. Chem. 76 (1972) 3518-3526.

[80] W. Wong, D.D. Davis, Int. J. Chem. Kinet. 6 (1974) 401-416.

[81] C.J. Cobos, H. Hippler, J. Troe, J. Phys. Chem. 89 (1985) 342-349.

[82] K.L. Carleton, W.J. Kessler, W.J. Marinelli, J. Phys. Chem. 97 (1993) 6412-6417.

[83] J.V. Michael, M. Su, J.W. Sutherland, J.J. Carroll, A.F. Wagner, J. Phys. Chem. A 106 (2002) 5297-5313.

[84] R.X. Fernandes, K. Luther, J. Troe, V.G. Ushakov, Phys. Chem. Chem. Phys. 10 (2008) 4313-4321.

[85] S.R. Sellevag, Y. Georgievskii, J.A. Miller, J. Phys. Chem. A 112 (2008) 5085-5095.

[86] R. W. Getzinger, L. S. Blair, Combust. Flame 13, (1969) 271.

[87] D.F. Davidson, E.L. Petersen, M. Roehrig, R.K. Hanson, C.T. Bowman Proc. Comb. Inst. (1996) 481-488.

[88] P.J. Ashman, B.S. Haynes, Proc. Comb. Inst. 27 (1998) 185-191.

[89] R. Bates, D.M. Golden, R.K. Hanson, C. T. Bowman, Phys. Chem. Chem. Phys. 106 (2002) 5297-5313.

[90] CHEMKIN and CHEMKIN-PRO, Reaction Design: San Diego, 2013; notably, at least partially in response to the comments in this manuscript, ANSYS is addressing these issues in a CHEMKIN release targeted for August.

[91] J. Troe, J. Phys. Chem. 83 (1979) 114-126.

[92] J. Troe, V.G. Ushakov, J. Chem. Phys. 135 (2011) 054304.

[93] J.A. Miller, S.J. Klippenstein, J. Phys. Chem. A 117 (2013) 2718-2727.

[94] M. P. Burke, R. Song, Proc. Comb. Inst. 36, submitted (2016).

[95] N.J. Labbe, R. Sivaramakrishnan, S.J. Klippenstein, Proc. Comb. Inst. 35 (2015) 447-455.

[96] P. Celani, H.-J. Werner, J. Chem. Phys. 112 (2000) 5546-5547.

[97] S.J. Klippenstein, Y. Georgievskii, L.B. Harding, Phys. Chem. Chem. Phys. 8 (2006) 1133-1147.

[98] Y. Georgievskii, S.J. Klippenstein, J. Chem. Phys. 122 (2005) 1941013. 
[99] L.B. Harding, Y. Georgievskii, S.J. Klippenstein, J. Phys. Chem. A 109 (2005) 4646-4656.

[100] A.W. Jasper, S.J. Klippenstein, L.B. Harding, B. Ruscic, J. Phys. Chem. A 111 (2007) 3932-3950.

[101] S.J. Klippenstein, L.B. Harding, B. Ruscic, R. Sivaramakrishnan, N.K. Srinivasan, M.C. Su, J.V. Michael, J. Phys. Chem. A 113 (2009) 10241-10259.

[102] L.B. Harding, S.J. Klippenstein, Y. Georgievskii, J. Phys. Chem. A 111 (2007) 3789-3801.

[103] A.W. Jasper, S.J. Klippenstein, L.B. Harding, J. Phys. Chem. A 114 (2010) 5759-5768.

[104] D. Polino, S.J. Klippenstein, L.B. Harding, Y. Georgievskii, J. Phys. Chem. A 117 (2013) 12677-12692.

[105] M. Sangwan, C. Yan, E.N. Chesnokov, L. Krasnoperov, J. Phys. Chem. A 119 (2015) 7847-7857.

[106] M.A. Blitz, N.J.B. Green, R.J. Shannon, M.J. Pilling, P.W. Seakins, C.M. Western, S.H. Robertson, J. Phys. Chem. A 119 (2015) 7668-7682.

[107] C.F. Goldsmith, S.J. Klippenstein, W.H. Green, Proc. Comb. Inst. 33 (2011) 273-282.

[108] C.-W. Zhou, S.J. Klippenstein, J.M. Simmie, H.J. Curran, Proc. Comb. Inst. 34, (2013) 501-509.

[109] S.J. Klippenstein, L.B. Harding, P. Glarborg, Y. Gao, H. Hu, P. Marshall, J. Phys. Chem. A 117 (2013) 9011-9022.

[110] L. Ye, Y. Georgievskii, S.J. Klippenstein, Proc. Comb. Inst. 35 (2015) 223-230.

[111] H.-J. Werner, P. J. Knowles, J. Chem. Phys. 89 (1988) 5803-5814.

[112] P. J. Knowles, H.-J. Werner. Chem. Phys. Lett. 145 (1988) 514-522.

[113] C.F. Goldsmith, L.B. Harding, Y. Georgievskii, J.A. Miller, S.J. Klippenstein, J. Phys. Chem. A 119 (2015) 77667779.

[114] J. Munk, P. Pagsberg, E. Ratajczak, A. Sillesen. J. Phys. Chem. 90 (1986) 2752-2757.

[115] E.W. Kaiser, J. Phys. Chem. 99 (1995) 707-711.

[116] H. Dilger, M. Schwager, P.L.W. Tregenna-Piggot, E. Roduner, I.D. Reid, D.J. Arsenau, J.J. Pan, M. Senba, M. Shelley, D.G. Fleming, J. Phys. Chem. 100 (1996) 6561-6571, 16445.

[117] R.X. Fernandes, K. Luther, G. Marowsky, M.P. Rissanen, R. Timonen, J. Troe, J. Phys. Chem. A 119 (2015) 72637269.

[118] K.J. Hughes, J.F. Griffiths, M. Fairweather, A.S. Tomlin, Phys. Chem. Chem. Phys. 8 (2006) 3197-3210.

[119] H. Wang, Proc. Comb. Inst. 33 (2011) 41-67.

[120] J.A. Montgomery, M.J. Frisch, J.W. Ochterski, G.A. Petersson, J. Chem. Phys. 110 (1999) 2822-2827.

[121] L.A. Curtiss, P.C. Redfern, K. Raghavachari, J. Chem. Phys. 126 (2007) 084108.

[122] A.M. Mebel, K. Morokuma, M.C. Lin, J. Chem. Phys. 103 (1995) 7414-7421.

[123] B. Ruscic, Int. J. Quan. Chem. 114 (2014) 1097-1101.

[124] L.A. Curtiss, P.C. Redfern, K. Raghavachari, Chem. Phys. Lett. 499 (2010) 168-172.

[125] D. Feller, K.A. Peterson, J.G. Hill, J. Chem. Phys. 135 (2011) 044102.

[126] A. Karton, J.M.L. Martin, J. Chem. Phys. 136 (2012) 124114.

[127] D. Feller, K.A. Peterson, J. Chem. Phys. 139 (2013) 084110.

[128] C.F. Goldsmith, G.R. Magoon, W.H. Green, J. Phys. Chem. A 116 (2012) 9033-9057.

[129] C.F. Melius, J.S. Binkley, Proc. Comb. Inst. 21 (1986) 1953-1963.

[130] A.D. Becke, J. Chem. Phys. 98 (1993) 5648-5652.

[131] G. daSilva, Chem. Phys. Lett. 558 (2013) 109-113.

[132] A. Karton, S. Daon, J.M.L. Martin, Chem. Phys. Lett. 510 (2011) 165-178.

[133] M.E. Harding, J. Vazquez, B. Ruscic, A.K. Wilson, J. Gauss, J.F. Stanton, J. Chem. Phys. 128 (2008) 114111.

[134] H.M. Jaeger, H.F. Schaefer, J. Demaison, A.G. Császár, W.D. Allen, J. Chem. Theory Comp. 6 (2010) 3066-3078.

[135] K.A. Peterson, D. Feller, D.A. Dixon, Theor. Chem. Acc. 131 (2012) 1079-1099.

[136] T.H. Dunning, J. Chem. Phys. 90 (1989) 1007-1023.

[137] S.J. Klippenstein, L.B. Harding, B. Ruscic, Ab Initio Computations and Active Thermochemical Tables Hand in Hand:

Heats of Formation of Core Combustion Species, J. Phys. Chem. A, manuscript in preparation (2016).

[138] http://www.energy.gov/eere/bioenergy/co-optimization-fuels-and-engines

[139] N.J. Labbe, B. Ruscic, A.W. Jasper, S.J. Klippenstein, R. Sivaramakrishnan, work in progress (2016).

[140] T. Ziehn, K.J. Hughes, J.F. Griffiths, R. Porter, A.S. Tomlin, Comb. Theory Modelling 13 (2009) 589-605.

[141] S.J. Klippenstein, L.B. Harding, M.J. Davis, A.S. Tomlin, Proc. Comb. Inst. 33 (2011) 351-357.

[142] D.D.Y. Zhou, M.J. Davis, R.T. Skodje, J. Phys. Chem. A 117 (2013) 3569-3584.

[143] W. Liu, R. Sivaramakrishnan, M.J. Davis, S. Som, D.E. Longman, T.F. Lu, Proc. Comb. Inst. 34 (2013) 401-409.

[144] M.K. Sabbe, K.M. Van Gem, M.-F. Reyniers, G. B. Marin, AIChE 57 (2011) 482-496.

[145] L.L. Ye, Y. Georgievskii, S.J. Klippenstein, Complexities in Abstraction Reactions: A Case Study of $\mathrm{CH}_{3} \mathrm{OH}+\mathrm{OH}$. J. Phys. Chem. A, manuscript in preparation (2016).

[146] J.J. Zheng, D.G. Truhlar, Faraday Disc. 157 (2012) 59-88.

[147] E. Al. Tings, D.C. Kyritsis, D.A. Goussis, Comb. Flame 162 (2015) 3263-3276.

[148] U. Burke, K.P. Somers, P. O’Tooel, C.M. Zinner, N. Marquet, G. Bourque, E.L. Petersen, W.K. Metcalfe, Z. Serinyel, H.J. Curran, Comb. Flame 162 (2015) 315-330. 
[149] G. Bansal, A. Mascarenhas, J. H. Chen, Comb. Flame 162 (2015) 688-702.

[150] Z. Wang, X. Zhang, L. Xing, L. Zhang, F. Herrmann, K. Moshammer, F. Qi, K. Kohse-Hoinghaus, Comb. Flame 162 (2015) 1113-1125.

[151] S. Popp, F. Hunger, S. Hartl, D. Messig, B. Coriton, J.H. Frank, F. Fuest, C. Hasse, Comb. Flame 162 (2015) 30163029.

[152] S. Deng, P. Zhao, M.E. Mueller, C.K. Law, Comb. Flame 162 (2015) 3437-3445.

[153] Y. Ju, C.B. Reuter, S.H. Won, Comb. Flame 162 (2015) 3580-3588.

[154] J.C. Prince, F.A. Williams, Comb. Flame 162 (2015) 3589-3595.

[155] S. Deng, P. Zhao, M.E. Mueller, C.K. Law, Comb. Flame 162 (2015) 4471-4478.

[156] R.A. Perry, R. Atkinson, J.N. Pitts, J. Chem. Phys. 67 (1977) 611-614.

[157] T.J. Wallington, R. Liu, P. Dagaut, M.J. Kurylo, Int. J. Chem. Kinet. 20 (1988) 41-49.

[158] A. Mellouki, S. Teton, G. Le Bras, Int. J. Chem. Kinet. 27 (1995) 791-805.

[159] M. Arif, B. Dellinger, P.H. Taylor, J. Phys. Chem. A 101 (1997) 2436-2441.

[160] W.B. DeMore, K.D. Bayes, J. Phys. Chem. A 103 (1999) 2649-2654.

[161] R.S. Tranter, R.W. Walker, Phys. Chem. Chem. Phys. 3 (2001) 4722-4732.

[162] A. Bonard, V. Daele, J.-L. Delfau, C. Vovelle, J. Phys. Chem. A 106 (2002) 4384-4389.

[163] R.D. Cook, D.F. Davidson, R.K. Hanson, J. Phys. Chem. A 113 (2009) 9974-9980.

[164] R.J. Shannon, S. Taylor, A. Goddard, M.A. Blitz, D.E. Heard 12 (2010) 13511-13514.

[165] C. Bansch, J. Kiecherer, M. Szori, M. Olzmann, J. Phys. Chem. A 117 (2013) 8343-8351.

[166] S.A. Carr, T.J. Still, M.A. Blitz, A.J. Eskola, M.J. Pilling, P.W. Seakins, R.J. Shannon, B. Wang, S.H. Robertson, J.

Phys. Chem. A 117 (2013) 11142-11154.

[167] J. Prager, H.N. Najm, J. Zador, Proc. Comb. Inst. 34 (2013) 583-590.

[168] C.-W. Zhou, J.M. Simmie, H.J. Curran, Phys. Chem. Chem. Phys. 12 (2010) 7221-7233.

[169] T. Yu, J. Zheng, D.G. Truhlar, Chem. Sci, 2 (2011) 2199-2123.

[170] J. Zheng, D.G. Truhlar, Faraday Disc. 157 (2012) 59-88.

[171] T. Nagy, E. Valko, I. Sedyo, I. G. Zsely, M.J. Pilling, T. Turanyi, Comb. Flame, 162 (2015) 2059-2076.

[172] G. Mittal, C.J. Sung, M. Fairweather, A.S. Tomlin, J.F. Griffiths, K.J. Hughes, Proc. Comb. Inst. 31 (2007) 419-427.

[173] R. Sivaramakrishnan, A. Comandini, R.S. Tranter, K. Brezinsky, S.G. Davis, H. Wang, Proc. Comb. Inst. 31 (2007) 429-437.

[174] X. You; H. Wang, E. Goos, C.-J. Sung, S.J. Klippenstein, J. Phys. Chem. A 111 (2007) 4031-4042.

[175] S.S. Merchant, C.F. Goldsmith, A.G. Vandeputte, M.P. Burke, S.J. Klippenstein, W.H. Green, Comb. Flame 162 (2015) 3658-3673.

[176] C.D. Wijaya, R. Sumathi, W.H. Green, J. Phys. Chem. A 107 (2003) 4908-4920.

[177] S. Sharma, S. Raman, W.H. Green, J. Phys. Chem. A 114 (2010) 5689-5701.

[178] L. Zhu, J.W. Bozzelli, L.M. Kardos, J. Phys. Chem. A 111 (2007) 6361-6377.

[179] R. Asatryan, J.W. Bozzelli, J. Phys. Chem. A 114 (2010) 7693-7708.

[180] A. Miyoshi, J. Phys. Chem. A 115 (2011) 3301-3325.

[181] A. Miyoshi, Int. J. Chem. Kinet. 44 (2012) 59-74.

[182] S.M. Villano, L.K. Huynh, H.-H. Carstensen, A.M. Dean, J. Phys. Chem. A 115 (2011) 13425-13442.

[183] S.M. Villano, L.K. Huynh, H.-H. Carstensen, A.M. Dean, J. Phys. Chem. A 116 (2012) 5068-5089.

[184] S.M. Villano, H.-H. Carstensen, A.M. Dean, J. Phys. Chem. A 117 (2013) 6458-6473.

[185] O. Welz, S.J. Klippenstein, L.B. Harding, C.A. Taatjes, J. Zador, J. Phys. Chem. Lett. 4 (2013) 350-354.

[186] A. Jalan, I.M. Alecu, R. Meana-Paneda, J. Aguilera-Iparraguire, K.R. Yang, S.S. Merchant, D.G. Truhlar, W.H. Green, J. Am. Chem. Soc. 135 (2013) 11100-11114.

[187] I.C. Plumb, K.R. Ryan. Int. J. Chem. Kinet. 13 (1981) 1011-1028.

[188] I.R. Slagle, Q. Feng, D. Gutman, J. Phys. Chem. 88 (1984) 3648-3653.

[189] E.W. Kaiser, T.J. Wallington, J.M. Andino, Chem. Phys. Lett. 168 (1990) 309-313.

[190] A.F. Wagner, I.R. Slagle, D. Sarzynski, D. Gutman, J. Phys. Chem. 94 (1990) 1853-1868.

[191] G.E. Quelch, M.M. Gallo, H.F. Schaefer, J. Am. Chem. Soc. 114 (1992) 8239-8247.

[192] G.E. Quelch, M.M. Gallo, M.Z. Shen, Y.M. Xie, H.F. Schaefer, D. Moncrieff, J. Am. Chem. Soc. 116 (1994) 49534962.

[193] I.S. Ignatyev, Y.M. Xie, W.D. Allen, H.F. Schaefer, J. Chem. Phys. 107 (1997) 141-155.

[194] J.A. Miller, S.J. Klippenstein, S.H. Robertson, Proc. Comb. Inst. 28 (2000) 1479-1486.

[195] J.C. Rienstra-Kiracofe, W.D. Allen, H.F. Schaefer, J. Phys. Chem. A 104 (2000) 9823-9840.

[196] J.J. Wilke, W.D. Allen, H.F. Schaefer, J. Chem. Phys. 128 (2008) 074308.

[197] J.W. Bozzelli, A.M. Dean, J. Phys. Chem. 94 (1990) 3313-3317.

[198] P.K. Venkatesh, A.M. Dean, M.H. Cohen, R.W. Carr, J. Chem. Phys. 111 (1999) 8313-8329.

[199] J.A. Miller, S.J. Klippenstein, Int. J. Chem. Kinet. 33 (2001) 654-668. 
[200] C.Y. Sheng, J.W. Bozzelli, A.M. Dean, A.Y. Chang, J. Phys. Chem. A 106 (2002) 7276-7293.

[201] J.D. Desain, S.J. Klippenstein, J.A. Miller, C.A. Taatjes, J. Phys. Chem. A 107 (2003) 4415-4427.

[202] R. Sivaramakrishnan, M.-C. Su, J.V. Michael, S.J. Klippenstein, L.B. Harding, B. Ruscic, J. Phys. Chem. A 114 (2010) 9425-9439.

[203] R. Sivaramakrishnan, J.V. Michael, A.F. Wagner, R. Dawes, A.W. Jasper, L.B. Harding, Y. Georgievskii, S. J. Klippenstein, Comb. Flame 158 (2011) 618-632.

[204] A.W. Jasper, J.A. Miller, J. Phys. Chem. A 115 (2011) 6438-6455.

[205] S.M. Gallagher, H.J. Curran, W.K. Metcalfe, D. Healy, J.M. Simmie, G.A. Bourque, Comb. Flame 153 (2008) 316333.

[206] There is however one key distinction for larger molecules: the formation of the QOOH species is enhanced through the presence and increased accessibility of additional isomers, which will have some quantitative effect on the details of the behaviour. Nevertheless, propyl radical exhibits the key properties of relevance to NTC and cool-flames.

[207] J.D. DeSain, C.A. Taatjes, J.A. Miller, S.J. Klippenstein, D.K. Hahn, Faraday Disc. 119 (2001) 101-120.

[208] E.G. Estupinan, S.J. Klippenstein, C.A. Taatjes, J. Phys. Chem. B 109 (2005) 8374-8387.

[209] E.G. Estupinan, J.D. Smith, A. Tezaki, S.J. Klippenstein, C.A. Taatjes, J. Phys. Chem. A 111 (2007) 4015-4030.

[210] H.F. Huang, D.J. Merthe, J. Zador, L.E. Jusinski, C.A. Taatjes, Proc. Comb. Inst. 33 (2011) 293-299.

[211] Z. Wang, L. Zhang, K. Moshammer, D.M. Popolan-Vaida, V.S. Bhavani Shankar, A. Lucassen, K. Khose-Hoinghaus, N. Hansen, P. Dagaut, S.M. Sarathy, Comb. Flame 164 (2016) 386-396.

[212] Z. Wang, S.M. Sarathy, Third $\mathrm{O}_{2}$ Addition Reactions Promote the Low-Temperature Auto-Ignition of n-Alkanes. Comb. Flame, in press (2016).

[213] M. Cord, B. Sirjean, R. Fournet, A. Tomlin, M. Ruiz-Lopez, F. Battin-Leclerc, J. Phys. Chem. A 116 (2012) 61426158.

[214] L.L. Xing, S. Li, Z.H. Wang, B. Yang, S.J. Klippenstein, F. Zhang, Comb. Flame 162 (2015) 3427-3436.

[215] Z.K. Hong, K.Y. Lam, R. Sur, S.K. Wang, D.F. Davidson, R.K. Hanson, Proc. Comb. Inst. 34 (2013) 565-571.

[216] O. Welz, M.P. Burke, I.O. Antanov, C.F. Goldsmith, J.D. Savee, D.L. Osborn, C.A. Taatjes, S.J. Klippenstein, L. Sheps, J. Phys. Chem. A 119 (2015) 7116-7129.

[217] N.J. Labbe, R. Sivaramakrishnan, C.F. Goldsmith, Y. Georgievskii, J.A. Miller, S.J. Klippenstein, Ramifications of Including Non-Equlibrium Effects for HCO in Flame Chemistry. Proc. Comb. Inst. 36, submitted (2016).

[218] M.P. Burke, C.F. Goldsmith, Y. Georgievskii, S.J. Klippenstein. Proc. Comb. Inst. 35 (2015) 205-213.

[219] C.F. Goldsmith, M.P. Burke, Y. Georgievskii, S.J. Klippenstein, Proc. Comb. Inst. 35, (2015) 283-290.

[220] M. Dontgen, K. Leonhard, H. Pitsch, S.J. Klippenstein, Effects of Non-Thermal Product Energy Distributions on Dimethyl Ether Low-Temperature Oxidation Chemistry, in preparation (2016).

[221] T. Helgaker, E. Uggerud, H.J.A. Jensen, Chem. Phys. Lett. 173 (1990) 145-150.

[222] W. Chen, W.L. Hase, H.B. Schlegel, Chem. Phys. Lett. 228, (1994) 436-442.

[223] J.M. Millam, V. Bakken, W. Chen, W.L. Hase, H.B. Schlegel, J. Chem. Phys. 111, 3800-3805 (1999).

[224] S.J. Klippenstein, J.A. Miller, L.B. Harding, Proc. Comb. Inst. 29 (2002) 1209-1217.

[225] T.P. Marcy, R.R. Diaz, D. Heard, S.R. Leone, L.B. Harding, S.J. Klippenstein, J. Phys. Chem. A 105 (2001) 8361 8369.

[226] M.P. Burke, S.J. Klippenstein, Chemical Transformations Induced by Ephemeral Collision Complexes Affect Global Chemistry, manuscript in preparation (2016).

[227] A. Maranzana, J.R. Barker, G. Tonachini, J. Phys. Chem. A 112 (2008) 3666-3675.

[228] D.R. Glowacki, J. Lockhart, M.A. Blitz, S.J. Klippenstein, M.J. Pilling, S.H. Robertson, P.W. Seakins, Science 337 (2012) 1066-1069.

[229] G. da Silva, J. Phys. Chem. A 116 (2012) 5317-5324.

[230] M. Pfeifle, M. Olzmann, Int. J. Chem. Kin. 46 (2014) 231-244.

[231] J.P. Senosiain, S.J. Klippenstein, J.A. Miller, J. Phys. Chem. A 109 (2005) 6045-6055.

[232] J.P. Senosiain, S.J. Klippenstein, J.A. Miller, J. Phys. Chem. A 110 (2006) 6960-6970.

[233] D.R. Dowdy, D.B. Smith, S.C. Taylor, Proc. Comb. Inst. 23 (1990) 325-332.

[234] K.T. Aung, M.I. Hassan, G.M. Faeth, Combust. Flame 109 (1997) 1-24.

[235] S.D. Tse, D.L. Zhu, C.K. Law, Proc. Combust. Inst. 28 (2000) 1793-1800.

[236] O.C. Kwon, G.M. Faeth, Combust. Flame 124 (2001) 590-610.

[237] N. Lamoureux, N. Djebaïli-Chaumeix, C.-E. Paillard, Exp Thermal Fluid Sci. 27 (2003) 385-393.

[238] Z. Huang, Y. Zhang, K. Zenga, B. Liu, Q. Wang, D. Jiang, Combust. Flame 146, (2006) 302-311.

[239] C. Tang, Z. Huang, C. Jin, J. He, J. Wang, X. Wang, H. Miao, Int. J. Hydrogen Energy 33 (2008) 4906-4914.

[240] E. Hu, Z. Huang, J. He, C. Jin, J. Zheng, Int. J. Hydrogen Energy 34, (2009) 4876-4888.

[241] J.A. Miller, S.J. Klippenstein, R. Sivaramakrishnan, M.P. Burke, C.F. Goldsmith, A.W. Jasper, J. Zador, P. Glarborg, N. Hansen, N.J. Labbe, B. Ruscic, Y. Georgievskii, L.B. Harding, ANL-Sandia HPCC Model, Version 8.0 (Unpublished), August 2015. 
[242] C.F. Melius, J.S. Binkley, Proc. Comb. Inst. 20 (1984) 575-583.

[243] E.W.G. Diau, S.C. Smith, J. Chem. Phys. 106 (1997) 9236-9251.

[244] J.A. Miller, S.J. Klippenstein, J. Phys. Chem. A 104 (2000) 2061-2069.

[245] D.C. Fang, L.B. Harding, S.J. Klippenstein, Faraday Disc. 119 (2001) 207-222.

[246] J.A. Silver, C.E. Kolb, J. Phys. Chem. 91 (1987) 3713-3714.

[247] M.A. Kimball-Linne, R.K. Hanson, Comb. Flame 64 (1986) 337-351.

[248] P. Andresen, A. Jacobs, C. Kleinermanns, J. Wolfrum, Proc. Comb.Inst. 19 (1982) 11-22.

[249] J.L. Hall, D. Zeitz, J.W. Stephens, J.V.V. Kasper, G.P. Glass, R.F. Curl, F.K. Tittel, J. Phys. Chem. 90 (1986) 25012505.

[250] B. Atakan, A. Jacobs, M. Wahl, R. Weller, J. Wolfrum, Chem. Phys. Lett. 155 (1989) 609-613.

[251] V.P. Bulatov, A.A. Ioffe, V.A. Lozovsky, O.M. Sarkisov, Chem. Phys. Lett. 161 (1989) 141-146

[252] J.W. Stephens, C.L. Morter, S.K. Farhat, G.P. Glass, R. F. Curl, J. Phys. Chem., 97 (1993) 8944-8951.

[253] J. Vandooren, J. Bian, P.J. van Tiggelen, Comb. Flame 98 (1994) 402-410.

[254] J. Park, M.C. Lin, J. Phys. Chem. 100 (1996) 3317-3319.

[255] M.J. Halbgewachs, E.W.-G. Diau, A.M. Mebel, M.C. Lin, C.F. Melius, Proc. Comb. Inst. 26 (1996) 2109.

[256] P. Glarborg, P. Kristensen, K. Dam-Johansen, J.A. Miller, J. Phys. Chem. A 101 (1997) 3741-3745.

[257] J. Park, M.C. Lin, J. Phys. Chem. A 101 (1997) 5-13.

[258] J. Deppe, G. Friedrichs, H.-J. Römming, H. Gg. Wagner, Phys. Chem. Chem. Phys. 1 (1999) 427-435.

[259] M. Votsmeier, S. Song, R.K. Hanson, C.T. Bowman, J. Phys. Chem. 103 (1999) 1566-1571.

[260] J.A. Miller and P. Glarborg, Int. J. Chem. Kinet. 31 (1999) 757.

[261] S. Song, R.K. Hanson, C.T. Bowman, Proc. Comb. Inst. 28 (2000) 2403-2409.

[262] R.J. Cvetanovic, J. Phys. Chem. Ref. Data 16 (1987) 261-326.

[263] J.N. Harvey, M. Aschi, Phys. Chem. Chem. Phys. 1 (1999) 5555-5563.

[264] Q. Cui, K. Morokuma, J.M. Bowman, S.J. Klippenstein J. Chem. Phys. 110 (1999) 9469-9482.

[265] L.V. Moskeleva, M.C. Lin, Proc. Comb. Inst. 28 (2000) 2393-2401.

[266] L.V. Moskaleva, W.S. Xia, M.C. Lin Chem. Phys. Lett. 331 (2000) 269-277.

[267] A. El Bakali, L. Pillier, P. Desgroux, B. Lefort, L. Gasnot, J.F. Pauwels, i. da Costa, Fuel 85 (2006) 896-909.

[268] L.B. Harding, S.J. Klippenstein, J.A. Miller, J. Phys. Chem. A 112 (2008) 522-532.

[269] V. Vasudevan, R.K. Hanson, C.T. Bowman, D.M. Golden, D.F. Davidson, J. Phys. Chem. A 111 (2007) 11818-11830.

[270] A.W. Jasper, R. Dawes, J. Chem. Phys. 139 (2013) 154313.

[271] A.W. Jasper, J. Phys. Chem. A 119 (2015) 7339-7351.

[272] J. Troe, Proc. Comb. Inst. 15 (1975) 667-680.

[273] M.M. Kopp, E.L. Petersen, W.K. Metcalfe, S.M. Burke, H.J. Curran, J. Prop. Power 30 (2014) 799-811.

[274] T.L. Nguyen, L. Vereecken, X.J. Hou, M.T. Nguyen, J. Peeters, J. Phys. Chem A 109 (2005) 7489-7499.

[275] X. Li, A.W. Jasper, J. Zador, J.A. Miller, S.J. Klippenstein, Proc. Comb. Inst. 36 (2017) in press.

[276] D.L. Baulch, C.T. Bowman, C.J. Cobos, R.A. Cox, T. Just, J.A. Kerr, M.J. Pilling, D. Stocker, J. Troe, W. Tsang, R.W. Walker, J. Warnatz, J. Phys. Chem. Ref. Data 34 (2005) 757-1397.

[277] J.A. Miller, S.J. Klippenstein, J. Phys. Chem. A 107 (2003) 7783-7799.

[278] R. Sivaramakrishnan, S.J. Klippenstein, J.V. Michael, D. Polino, C. Cavalotti, in preparation (2016).

[279] H. Wang, M. Frenklach, J. Phys. Chem. 98 (1994) 11465-11489.

[280] N.J. Brown, L.A.J. Bastien, P.N. Price, Prog. Energy Comb. Sci. 37 (2011) 565-582.

[281] S.J. Klippenstein, unpublished work.

[282] A.W. Jasper, E. Kamarchik, J.A. Miller, S.J. Klippenstein, J. Chem. Phys. 141 (2014) 124313.

[283] A.W. Jasper, J.A. Miller, Comb. Flame 161 (2014) 101-110.

[284] P.J. Dagdigian, J. Chem. Phys. 143 (2015) 054303; erratum, J. Chem. Phys. 143 (2015) 159902.

[285] P.J. Dagdigian, M.H. Alexander, J. Phys. Chem. A 118 (2014) 11935-11942.

[286] P. Middha, B.H. Yang, H. Wang, Proc. Comb. Inst. 29 (2002) 1361-1369.

[287] Y. Georgievskii, L.B. Harding, S.J. Klippenstein, VaReCoF, Argonne National Laboratory, (2011).

[288] A.W. Jasper, C.M. Oana, D.G. Truhlar, DiNT is a Direct Molecular Dynamics Program for Adiabatic and Nonadiabatic Chemistry. Sandia National Laboratory (2013).

[289] S.J. Klippenstein, A.F. Wagner, R.C. Dunbar, D.M. Wardlaw, S.H. Roberston, J.A. Miller, VariFlex: Version 2.04m, Argonne National Laboratory, Argonne, IL. (2011).

[290] tcg.cse.anl.gov/papr.

[291] T.N. Truong, J. Chem. Phys. 113 (2000) 4957-4964.

[292] T.N. Truong, T.T.T. Truong, Chem. Phys. Lett. 314 (1999) 529-533.

[293] L.D. Zhang, P. Zhang, Phys. Chem. Chem. Phys. 17 (2015) 200-208.

[294] P.M. Zimmerman, Mol. Sim. 41 (2015) 43-54.

[295] P.L. Bhoorasingh, R.H. West, Phys. Chem. Chem. Phys. 17 (2015) 32173-32182. 
[296] Y.V. Suleimanov, W.H. Green, J. Chem. Theory Comput. 11 (2015) 4248-4259.

[297] M.N. Ryazantsev, A. Jamal, S. Maeda, K. Morokuma, Phys. Chem. Chem. Phys. 17 (2015) 27789-27805.

[298] J. Zador, J.A. Miller, Proc. Comb. Inst. 35 (2015) 181-188. 